Florida International University

FIU Digital Commons

$9-27-2018$

\title{
Sensitivity of Marine Cynobacteria and Green Microlage to Nano and Bulk Zinc Oxides
}

Jennifer Gil-Acevedo 3664585

jgila003@fiu.edu

Follow this and additional works at: https://digitalcommons.fiu.edu/etd

Part of the Agriculture Commons, Environmental Microbiology and Microbial Ecology Commons, and the Marine Biology Commons

\section{Recommended Citation}

Gil-Acevedo, Jennifer 3664585, "Sensitivity of Marine Cynobacteria and Green Microlage to Nano and Bulk Zinc Oxides" (2018). FIU Electronic Theses and Dissertations. 3845.

https://digitalcommons.fiu.edu/etd/3845

This work is brought to you for free and open access by the University Graduate School at FIU Digital Commons. It has been accepted for inclusion in FIU Electronic Theses and Dissertations by an authorized administrator of FIU Digital Commons. For more information, please contact dcc@fiu.edu. 


\section{FLORIDA INTERNATIONAL UNIVERSITY \\ Miami, Florida}

\section{SENSITIVITY OF MARINE CYNOBACTERIA AND GREEN MICROALAGE TO NANO AND BULK ZINC OXIDES}

A thesis submitted in partial fulfillment of the requirements for the degree of MASTER OF SCIENCE

in

ENVIRONMENTAL STUDIES

by

Jennifer Gil 
To: Dean Michael R. Heithaus

College of Arts, Sciences and Education

This thesis, written by Jennifer Gil and entitled Sensitivity of Marine Cyanobacteria and Green Microalgae to Nano and Bulk Zinc Oxides, having been approved in respect to style and intellectual content, is referred to you for judgment.

We have read this thesis and recommend that it be approved.

Miroslav Gantar

Krishnaswamy Jayachandran

Kateel G. Shetty, Major Professor

Date of Defense: September 27,2018

The thesis of Jennifer Gil is approved.

Dean Michael R. Heithaus College of Arts, Sciences and Education

Andrés G. Gil Vice President for Research and Economic Development and Dean of the University Graduate School

Florida International University, 2018 
(C) Copyright 2018 by Jennifer Gil

All rights reserved. 


\section{DEDICATION}

I dedicate this thesis to microalgae because without them we would not have this planet and I will not have a thesis topic. I always say I did not find microalgae, microalgae found me when I was at my lowest. My thesis topic had to change because I became sick and then one day I just looked it up in one of my books and the word microalgae was there. I was able to study microalgae without getting sick and started even taking microalgae-based supplements for my sickness. Microalgae have taken me places I could only dream of. Thanks to them I will be able to write for my favorite magazine, National Geographic, and I will be collecting them throughout the Panama Canal area. I want to thank God for creating the microalgae and bringing them to my attention. By the grace of God and microalgae my sickness got better, and I was able to continue to keep loving life and having hope. Finally, I dedicate my thesis to Dr. Eve Hershberger and my mentors (Dr. Kateel G. Shetty, Dr. Krishnaswamy Jayachandran, and Miroslav Gantar) for believing in me, helping me, and listening to me when I felt hopeless. 


\section{ACKNOWLEDGMENTS}

The support that I have had during my master's program is more than I can put into words. I want to thank my mentor Dr. Kateel G. Shetty, Dr. Krishnaswamy Jayachandran, and Miroslav Gantar for their constant support and for believing in me even when I did not. I want to thank them for not giving up on me and seeing my potential. Especially Dr. Shetty for his great guidance and encoring words. Also, I want to thank everyone from FIU's Agroecology Department: Eric, Ariel, Mary, Shagufta, Ganesh, Meghan, Jessica, Claudia, Nick, Daphne, Cristina, Jazmin, Emily and Will. I would also like to thank the undergraduate lab assistant, Myles, for helping and repeating some of my experiments. The students, Maria Jose, for editing my microscope videos. I would like to thank my undergraduate student Ana for helping me in the lab especially for collecting samples with me and giving me inspiration. Special thanks to Dr. Gantar, David Berthold, and Javier Broche for sharing their algal cultures and their lab facilities. I would also like to acknowledge FIU's Student Health Center for taking care of my health and encouraging me to keep working on my master's. I would like to acknowledge FIU's Writing Center for helping correct my proposal especially Corey, Tricia, and Dr. Glenn and the staff members from the Department Earth and Environment especially Gail. Also, I will like to thank my friend Dominic Lomando for his willingness to help me with my writing. My boyfriend Osvaldo for not letting me give up achieving my goals. My family specially mom, dad and my brother for always keeping me on track and encourage me too keep perusing my dream. 


\title{
ABSTRACT OF THE THESIS \\ SENSITIVITY OF MARINE CYNOBACTERIA AND GREEN MICROALAGE TO NANO AND BULK ZINC OXIDES
}

\author{
by
}

Jennifer Gil

Florida International University, 2018

Miami, Florida

\section{Professor Kateel G. Shetty, Major Professor}

Nanoparticles are particles with sizes between 1 and 100 nanometers (nm). Owing to their unique chemical, electrical, mechanical, optical, and piezoelectric properties, zinc oxide nanoparticles ( $\mathrm{ZnO}-\mathrm{NPs})$ are finding widespread use in numerous applications with yearly production over 550 tons per year. Increasing use of ZnO NPs, and NPs in wastewater discharges from domestic and industrial sources will have significant potential for adverse impacts on aquatic phototrophic organisms. Comparative studies on microalgae species response to $\mathrm{ZnO}$ NPs and variation in tolerance among species is still mostly unexplored. The proposed research aims to evaluate interspecies' variation in tolerance to $\mathrm{ZnO}$ NPs among marine and freshwater microalgae. Multi-well culture plate and flask culture screening methods were utilized for assessing microalgae species’ tolerance to various levels of $\mathrm{ZnO}$ NPs. Microalgae cell morphology changes in response to nano $\mathrm{ZnO}$ exposure were explored using both the Optical Coherence Microscope (OCM) and SEM. Availability of Nano $\mathrm{ZnO}$ tolerant microalgae species may provide an impetus for future studies to understand the mechanism of tolerance and potential applications in NPs bioremediation in aquatic systems. 


\section{TABLE OF CONTENTS}

SECTION

PAGE

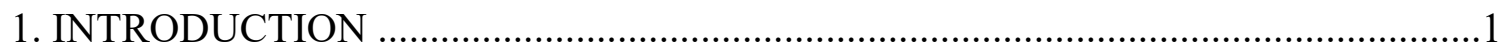

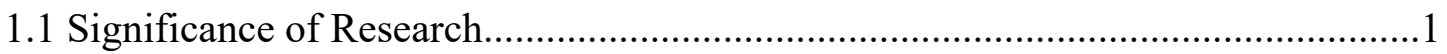

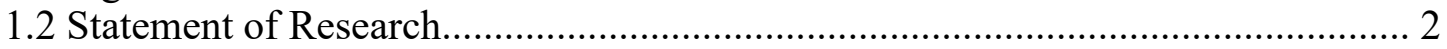

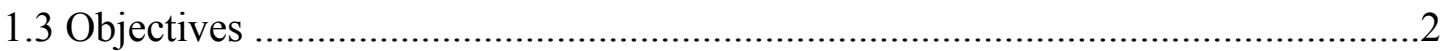

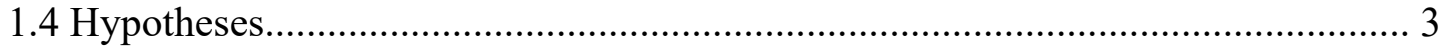

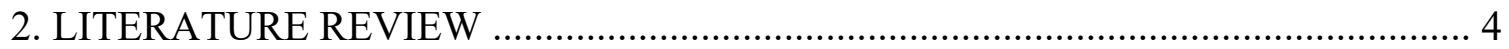

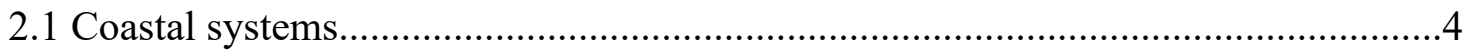

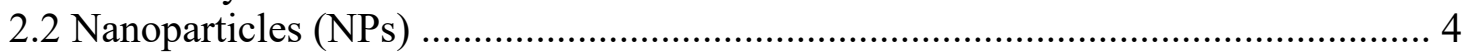

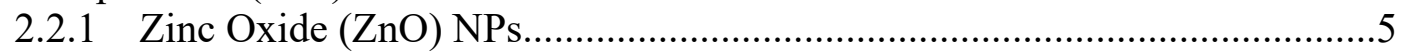

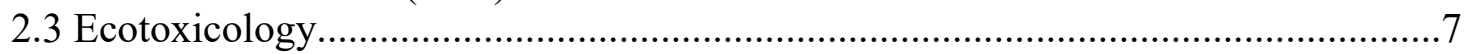

2.4 Marine Photosynthetic Microorganism ………….......................................... 10

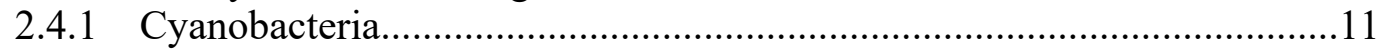

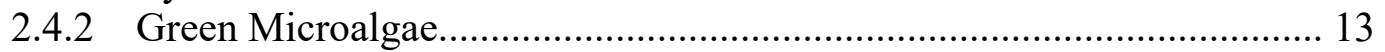

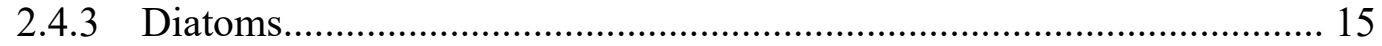

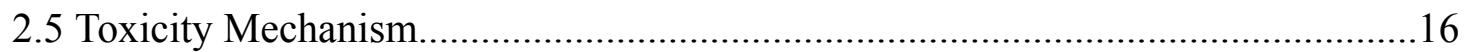

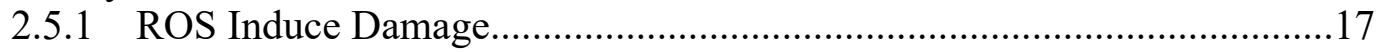

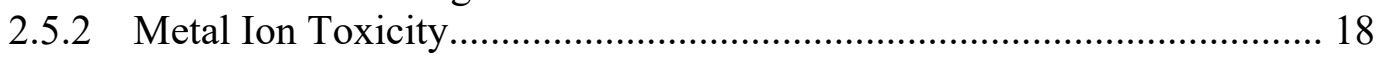

2.5.3 NPs accumulation on membrane surface................................................. 18

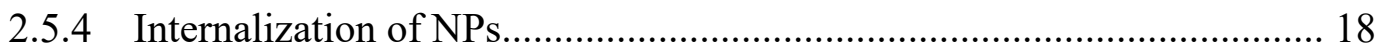

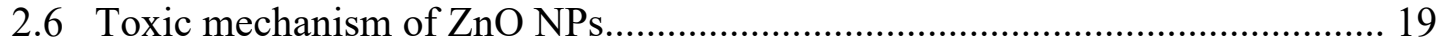

2.6.1 Toxic mechanism of $\mathrm{ZnO}$ NPs on microalgae........................................ 19

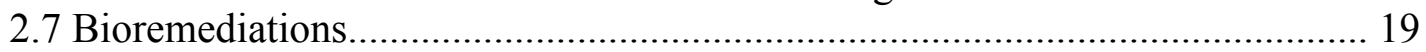

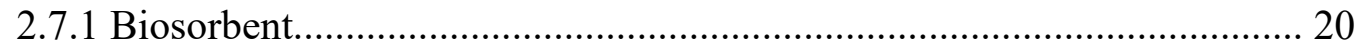

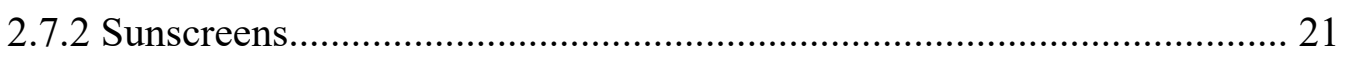

2.7.3 Microalgae Synthesis NPs..................................................................... 21

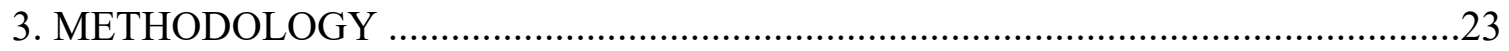

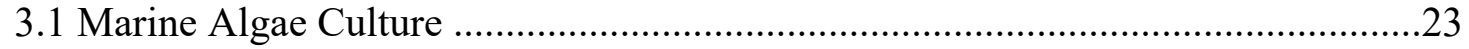

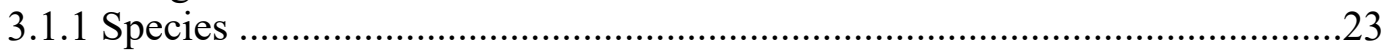

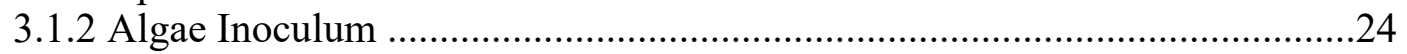

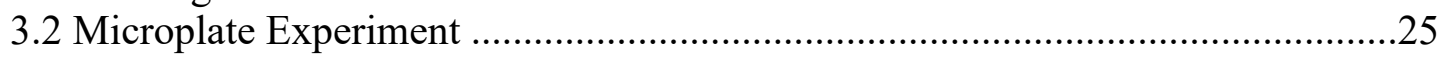

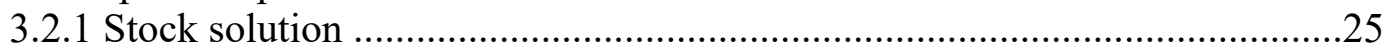

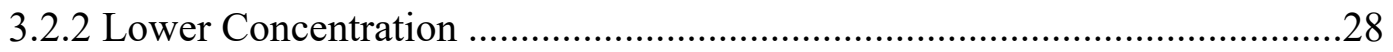

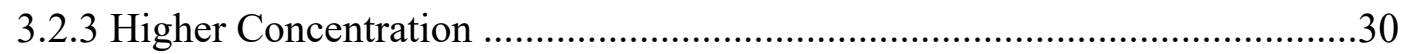

3.2.4 Higher Zinc Concentration ...................................................................

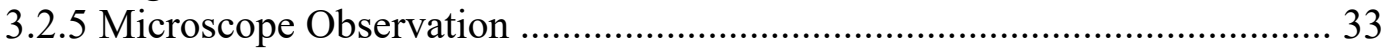

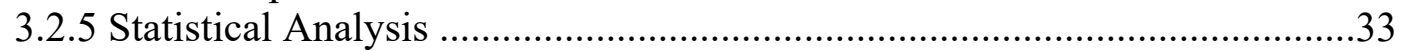

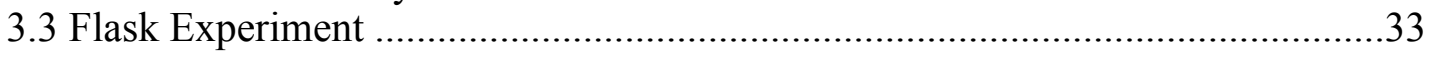

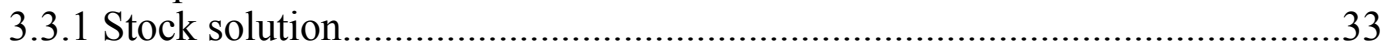

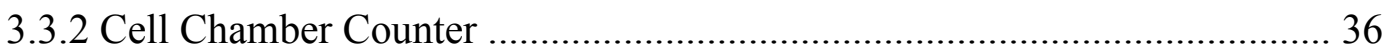

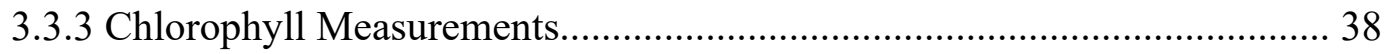

3.3.4 Absorbance Measurements...................................................................... 38 


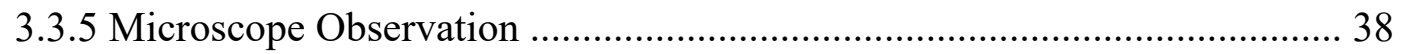

3.3.6 Scanning Electron Microscope (SEM) ………...........................................

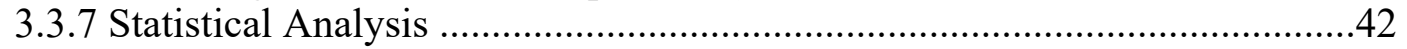

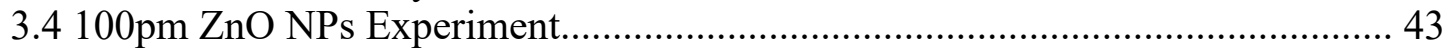

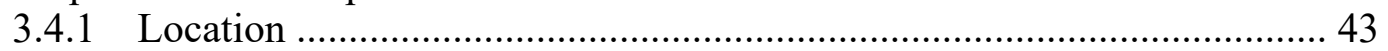

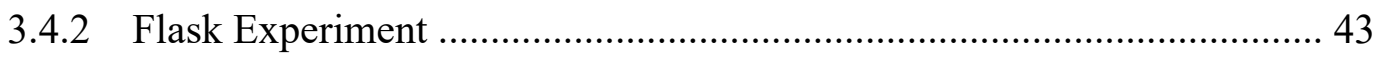

3.4.3 Microscope Observation ...................................................................... 43

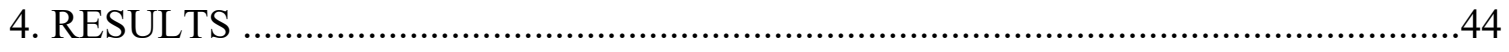

4.1 Cyanobacteria (Lower Concentration) ……………......................................... 44

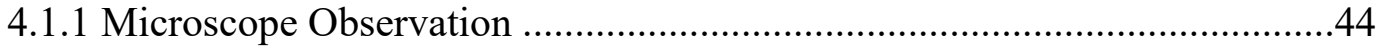

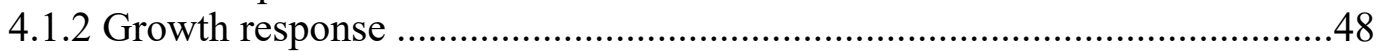

4.2 Cyanobacteria (Additional Zn Source) .............................................................60

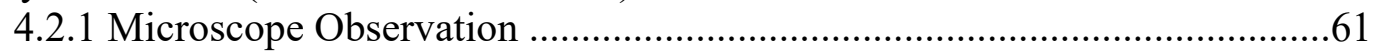

4.2.2 Statistical Analysis ..............................................................................63

4.3 Green Microalgae (Lower Concentration) ………………....................................70

4.3.1 Microscope Observation ......................................................................

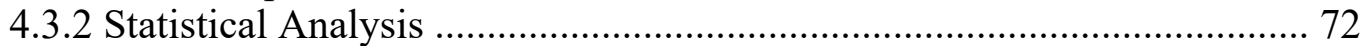

4.4 Green Microalgae (Higher Concentration) ………….........................................78

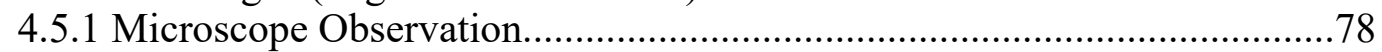

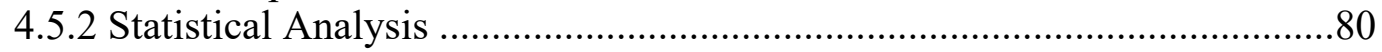

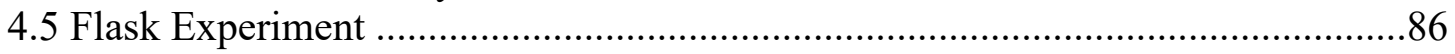

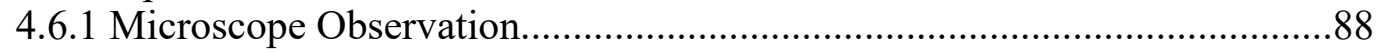

4.6.2 Cell Chamber Counter .......................................................................99

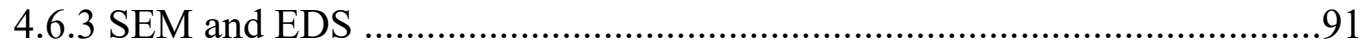

4.6.4 Statistical Analysis ...........................................................................94

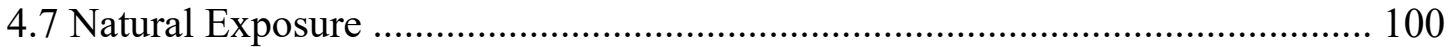

4.6.1 Microscope Observation ......................................................................100

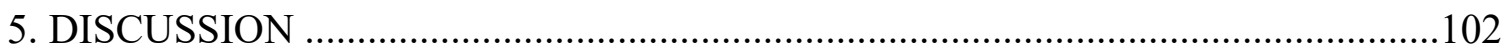

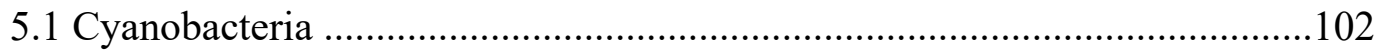

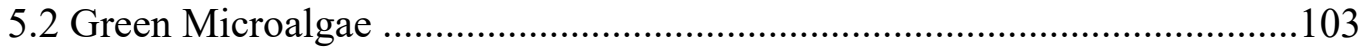

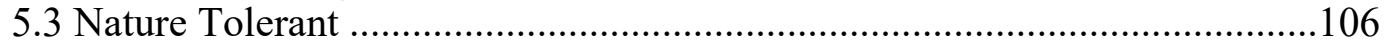

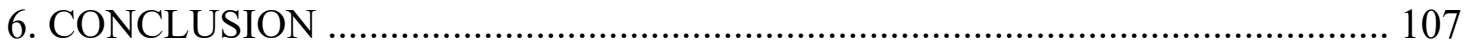

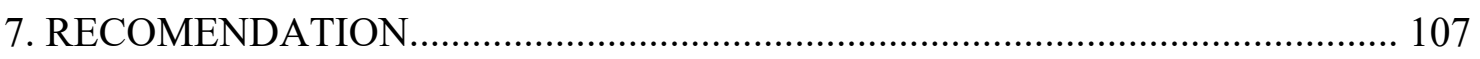

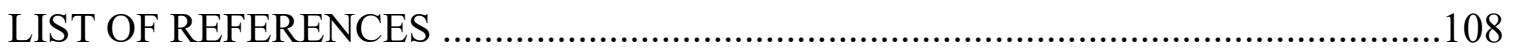




\section{LIST OF TABLES}

TABLE

PAGE

1. Compares the toxicity of NPs and salts to organisms........................ 10

2. $\mathrm{NPs} \mathrm{ZnO}$ effects upon microalgae.................................... 14

3. NPs $\mathrm{ZnO}$ effects upon microalgae..................................... 14

4. Potential Tolerance and Sensitivity of the Microalgae.........................78 


\section{LIST OF FIGURES}

FIGURE

PAGE

1. Compress the regular micro $\mathrm{ZnO}$ sunblock to $\mathrm{ZnO}$ NPs sunblock...............5

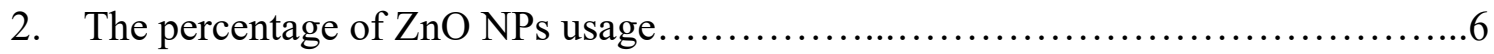

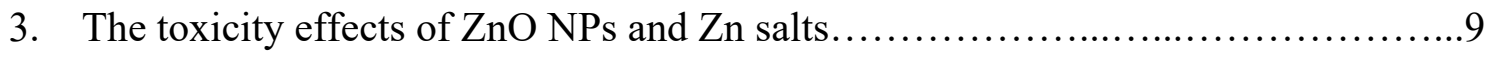

4. Show the results of Nano $\mathrm{ZnO}$ and Micro $\mathrm{ZnO} 50 \mathrm{ppm} \ldots \ldots \ldots \ldots \ldots \ldots \ldots \ldots \ldots \ldots \ldots \ldots$

5. E. paludosa grown in (control) or in the presence of $20 \mu \mathrm{M} \mathrm{Zn} \ldots \ldots \ldots \ldots \ldots \ldots \ldots$

6. A. coffeaeformis grown in (control) or in the presence of $20 \mu \mathrm{M} \mathrm{Zn...............15}$

7. Possible toxicity mechanisms against bacteria cells..........................

8. Green Microalgae strains used in this research: a) 146-2-6 Chlorococcum sp. b) 146-2-10 Chlamydomonas sp. and c)146-2-16 Chlorella sp. 100X magnification,

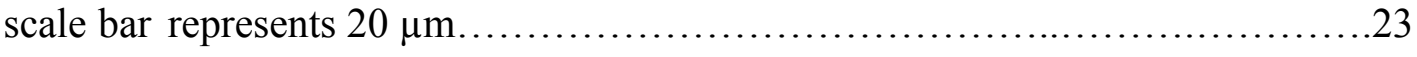

9. Cyanobacteria strains used in this research: d) Limnothrix sp., e) Leptolyngbya sp., f) Lyngbya 1 sp. , g) Lyngbya 2 sp. , h) Porphoridium sp. , i) Roseofilum sp. j) Nannochloris sp. 100X magnification, scale bar represents $20 \mu \mathrm{m} . \ldots \ldots \ldots \ldots . .24$

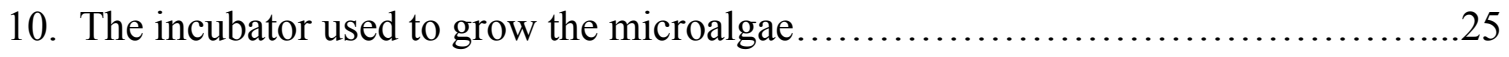

11. The microplate reader...................................................... 29

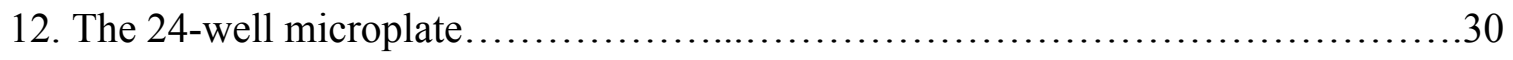

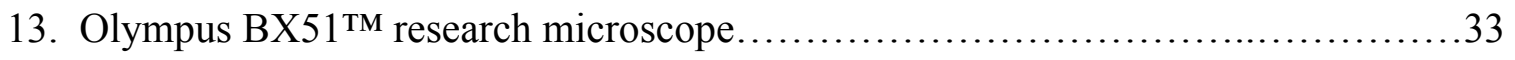

14. Bulk stock solution.................................................... 35

15. Nano stock solution.................................................. 36

16. Hemocytometer....................................................... 38

17. Preparation of the algae sample.......................................... 39 
18. Limnothrix sp. in $\mathrm{BG} 11$ media with a) standard $\mathrm{ZnSO}_{4}$ b) Bulk $\mathrm{ZnO} 1 \mathrm{ppm}$ c)

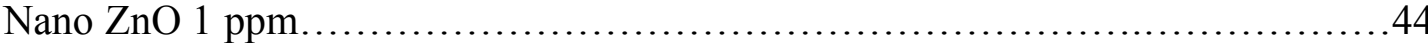

19. Leptolyngbya sp. in $\mathrm{BG} 11$ media with a) standard $\mathrm{ZnSO}_{4}$ b) Bulk $\mathrm{ZnO} 1 \mathrm{ppm}$ c)

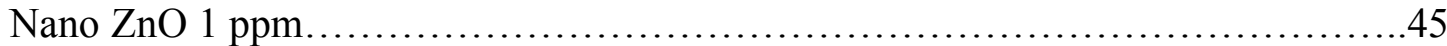

20. Lyngbya $1 s p$. in $\mathrm{BG} 11$ media with a) standard $\mathrm{ZnSO}_{4}$ b) Bulk $\mathrm{ZnO} 1 \mathrm{ppm} \mathrm{c)}$

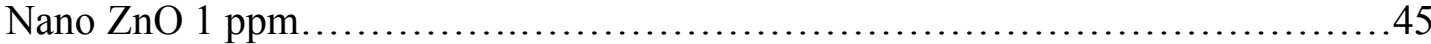

21. Lyngbya 2 sp. in $\mathrm{BG} 11$ media with a) standard $\mathrm{ZnSO}_{4}$ b) Bulk $\mathrm{ZnO} 1 \mathrm{ppm}$ c) Nano

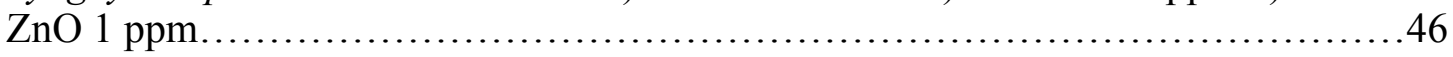

22. Porphoridium sp. in BG 11 media with a) standard $\mathrm{ZnSO}_{4}$ b) Bulk $\mathrm{ZnO} 1 \mathrm{ppm}$ c) Nano ZnO 1 ppm

23. Roseofilum sp. in $\mathrm{BG} 11$ media with a) standard $\mathrm{ZnSO}_{4}$ b) Bulk $\mathrm{ZnO} 1 \mathrm{ppm}$ c) Nano

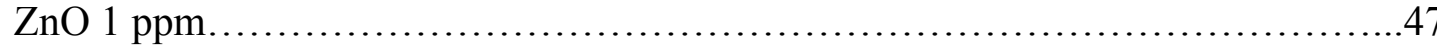

24. Apistonema sp. in $\mathrm{BG} 11$ media with a) standard $\mathrm{ZnSO}_{4}$ b) Bulk $\mathrm{ZnO} 1 \mathrm{ppm}$ c) Nano ZnO 1 ppm........................................................ 47

25. Box's plot's shows the effects of ZnO Nano and bulk particles on Limnothrix sp.,

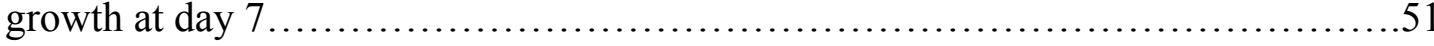

26. The effects of $\mathrm{ZnO}$ Nano and bulk particles on Limnothrix sp., growth...............52

27. Box's plot's shows the effects of ZnO Nano and bulk particles on Leptolyngbya

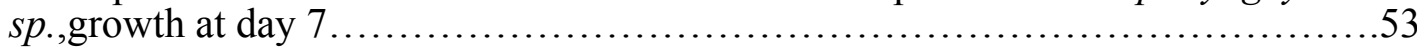

28. The effects of ZnO Nano and bulk particles on Leptolyngbya sp., growth...........53

29. Box's plot's shows the effects of $\mathrm{ZnO}$ Nano and bulk particles on Lyngbya 1

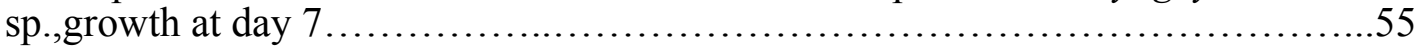

30. The effects of $\mathrm{ZnO}$ Nano and bulk particles on Lyngbya 1 sp., growth..............55 
31. Box's plot's shows the effects of ZnO Nano and bulk particles on Lyngbya 2 sp.,

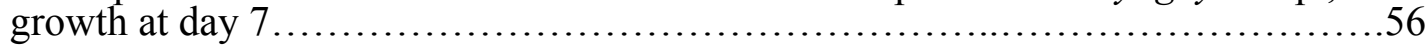

32. The effects of ZnO Nano and bulk particles on Lyngbya 2 sp., growth ..............57

33. Box's plot's shows the effects of ZnO Nano and bulk particles on Porphoridium

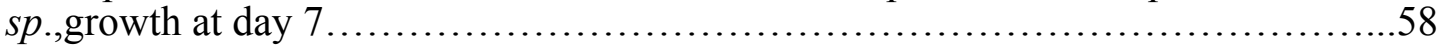

34. The effects of $\mathrm{ZnO}$ Nano and bulk particles on Porphoridium sp..................58

35. Box's plot's shows the effects of ZnO Nano and bulk particles on Roseofilum sp.

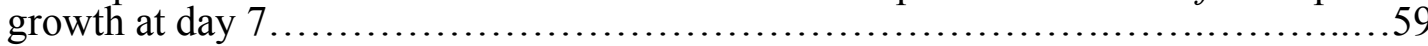

36. The effects of $\mathrm{ZnO}$ Nano and bulk particles on Roseofilum sp. growth.............60

37. 24 well plates of cyanobacteria with different concentration of nano $\mathrm{ZnO}$...........60

38. Limnothrix sp. in $\mathrm{BG} 11$ media with a) standard $\mathrm{ZnSO}_{4}$ b) High concentration of $\mathrm{ZnSO}_{4}$

39. Leptolyngbya sp. in $\mathrm{BG} 11$ media with a) standard $\mathrm{ZnSO}_{4}$ b) High concentration of $\mathrm{ZnSO}_{4}$

40. Lyngbya 1 sp. in BG 11 media with a) standard $\mathrm{ZnSO}_{4}$ b) High concentration of $\mathrm{ZnSO}_{4}$

41. Lyngbya 2 sp. in BG 11 media with a) standard $\mathrm{ZnSO}_{4}$ b) High concentration of $\mathrm{ZnSO}_{4}$

42. Box's plot's shows the effects of ZnO Nano, bulk particles and extra zinc on Limnothrix sp., growth at day 7 ....

43. The effects of ZnO Nano, bulk particles and extra zinc on Limnothrix sp. growth at day 7

44. Box's plot's shows the effects of ZnO Nano, bulk particles and extra zinc on Leptolyngbya sp., growth at day 7 ... 
45. The effects of $\mathrm{ZnO}$ Nano, bulk particles and extra zinc on Leptolyngbya sp. growth

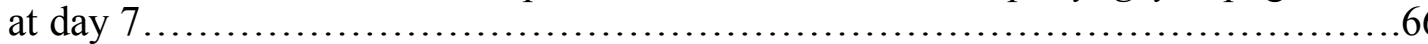

46. Box's plot's shows the effects of ZnO Nano, bulk particles and extra zinc on Lyngbya 1 sp., growth at day 7

47. The effects of $\mathrm{ZnO}$ Nano, bulk particles and extra zinc on Lyngbya $1 \mathrm{sp}$. growth at

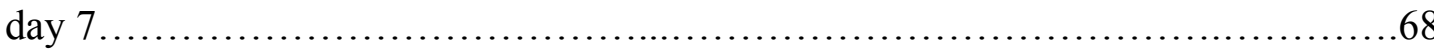

48. Box's plot's shows the effects of $\mathrm{ZnO}$ Nano, bulk particles and extra zinc on Lyngbya 2 sp., growth at day 7 .

49. The effects of $\mathrm{ZnO}$ Nano, bulk particles and extra zinc on Lyngbya $2 \mathrm{sp}$. growth at day 7

50. Chlorococcum sp., in $\mathrm{BG} 11$ media with a) standard $\mathrm{ZnSO}_{4}$ b) Bulk $\mathrm{ZnO} 1$ ppm c) Nano $\mathrm{ZnO} 1 \mathrm{ppm}$.

51. Chlamydomonas sp. in $\mathrm{BG} 11$ media with a) standard $\mathrm{ZnSO}_{4}$ b) Bulk $\mathrm{ZnO} 1$ ppm c) Nano $\mathrm{ZnO} 1 \mathrm{ppm}$.

52. Chlorella sp. in BG 11 media with a) standard $\mathrm{ZnSO}_{4}$ b) Bulk $\mathrm{ZnO} 1$ ppm c) Nano $\mathrm{ZnO} 1 \mathrm{ppm}$

53. Box's plot's shows the effects of ZnO Nano and bulk particles on Chlorococcum sp.,growth at day 7

54. The effects of $\mathrm{ZnO}$ Nano and bulk particles on Chlorococcum sp., growth. 75

55. Box's plot's shows the effects of ZnO Nano and bulk particles on Chlamydomonas

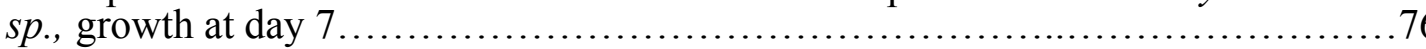

56. The effects of $\mathrm{ZnO}$ Nano and bulk particles on Chlamydomonas sp. ,growth......76

57. Box's plot's shows the effects of $\mathrm{ZnO}$ Nano and bulk particles on Chlorella sp., growth at day 7 
58. The effects of ZnO Nano and bulk particles on Chlorella sp., growth .78

59. Chlorococcum sp. in $\mathrm{BG} 11$ media with a) standard $\mathrm{ZnSO}_{4}$ b) Bulk $\mathrm{ZnO} 20$ ppm c) Nano ZnO 20 ppm.

60. Chlamydomonas sp. in $\mathrm{BG} 11$ media with a) standard $\mathrm{ZnSO}_{4}$ b) Bulk $\mathrm{ZnO} 20$ ppm

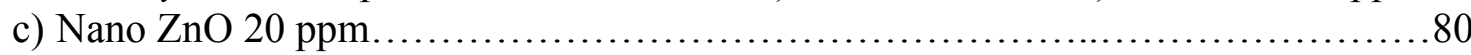

61. Chlorella sp. in $\mathrm{BG} 11$ media with a) standard $\mathrm{ZnSO}_{4}$ b) Bulk $\mathrm{ZnO} 20$ ppm c) Nano $\mathrm{ZnO} 20 \mathrm{ppm}$.

62. Box's plot's shows the effects of ZnO Nano and bulk particles on Chlorococcum

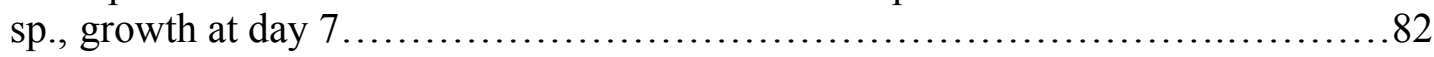

63. The effects of $\mathrm{ZnO}$ Nano and bulk particles on Chlorococcum sp., growth

64. Box's plot's shows the effects of $\mathrm{ZnO}$ Nano and bulk particles on Chlamydomonas

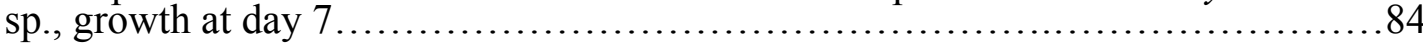

65. The effects of $\mathrm{ZnO}$ Nano and bulk particles on Chlamydomonas sp., growth ......84

66. Box's plot's shows the effects of $\mathrm{ZnO}$ Nano and bulk particles on Chlorella sp.,

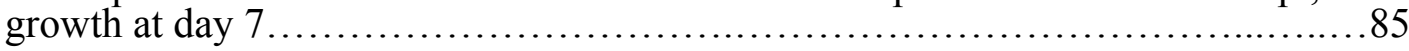

67. The effects of $\mathrm{ZnO}$ Nano and bulk particles on Chlorella sp., growth ..............86

68. Chlorococcum sp. in flask in $\mathrm{BG} 11$ media with a) standard $\mathrm{ZnSO}_{4}$ b) Bulk $\mathrm{ZnO} 20$ ppm c) Nano ZnO 20 ppm............................................... 87

69. Chlamydomona sp. in flask in $\mathrm{BG} 11$ media with a) standard $\mathrm{ZnSO}_{4}$ b) Bulk $\mathrm{ZnO} 20$ ppm c) Nano ZnO 20 ppm................................................... 87

70. Chlorella sp. in flask in $\mathrm{BG} 11$ media with a) standard $\mathrm{ZnSO}_{4}$ b) Bulk $\mathrm{ZnO} 20$ ppm

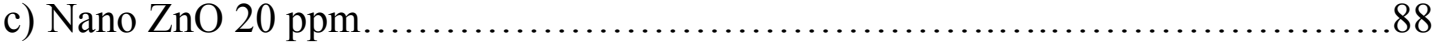

71. Chlorococcum sp. in $\mathrm{BG} 11$ media with a) standard $\mathrm{ZnSO}_{4}$ b) Bulk $\mathrm{ZnO} 20$ ppm c) Nano ZnO 20 ppm. 
72. Chlamydomonas sp. in $\mathrm{BG} 11$ media with a) standard $\mathrm{ZnSO}_{4}$ b) Bulk $\mathrm{ZnO} 20$ ppm

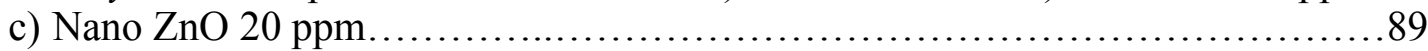

73. Chlorella sp. in BG 11 media with a) standard $\mathrm{ZnSO}_{4}$ b) Bulk $\mathrm{ZnO} 20$ ppm c) Nano

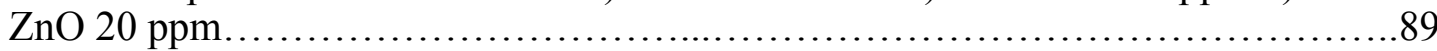

74. Chlorococcum sp. in $\mathrm{BG} 11$ media with a) standard $\mathrm{ZnSO}_{4}$ b) Bulk $\mathrm{ZnO} 20$ ppm c)

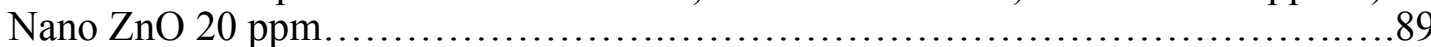

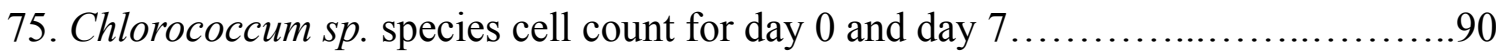

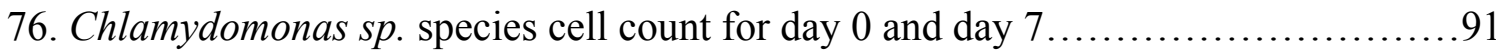

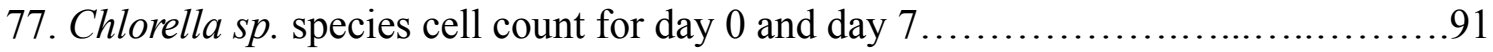

78. Chlorococcum sp. in flask in $\mathrm{BG} 11$ media with a) standard $\mathrm{ZnSO}_{4}$ b) Bulk $\mathrm{ZnO} 20$

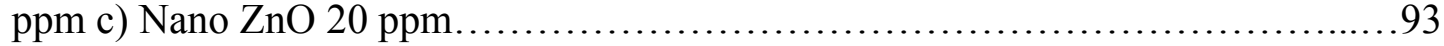

79. Chlorococcum sp. EDS results of $\mathrm{Zn}$ concentrations in different treatments..........93

80. Chlamydomonas sp. in $\mathrm{BG} 11$ media with a) standard $\mathrm{ZnSO}_{4}$ b) Bulk $\mathrm{ZnO} 20$ ppm

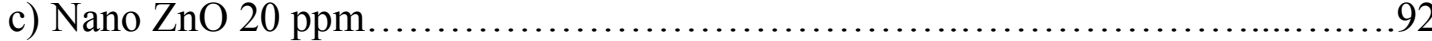

81. Chlamydomonas sp. EDS results of $\mathrm{Zn}$ concentrations in different treatments.....92

82. Chlorella sp. in flask in BG 11 media with a) standard $\mathrm{ZnSO}_{4}$ b) Bulk $\mathrm{ZnO} 20$ ppm c) Nano ZnO 20 ppm............................................. 94

83. Chlorella sp. EDS results of Zn concentrations in different treatments...............94

84. Box's plot's shows the effects of ZnO Nano and bulk particles on Chlorococcum sp., growth at day 7 ....

85. The effects of $\mathrm{ZnO}$ Nano and bulk particles on Chlorococcum sp., growth. .97

86. Box's plot's shows the effects of ZnO Nano and bulk particles on Chlamydomonas sp., growth at day 7

87. The effects of $\mathrm{ZnO}$ Nano and bulk particles on Chlamydomonas sp., growth 
88. Box's plot's shows the effects of $\mathrm{ZnO}$ Nano and bulk particles on Chlorella sp.,

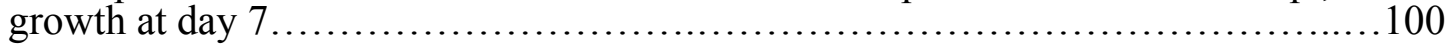

89. The effects of $\mathrm{ZnO}$ Nano and bulk particles on Chlorella sp. , growth .............100

90. All the images were taken from South Pointe Park Beach and exposed to 100

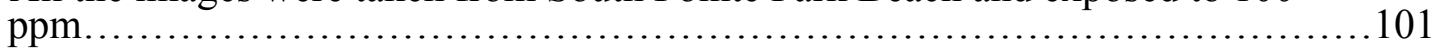




\section{ABBREVIATIONS AND ACRONYMS}

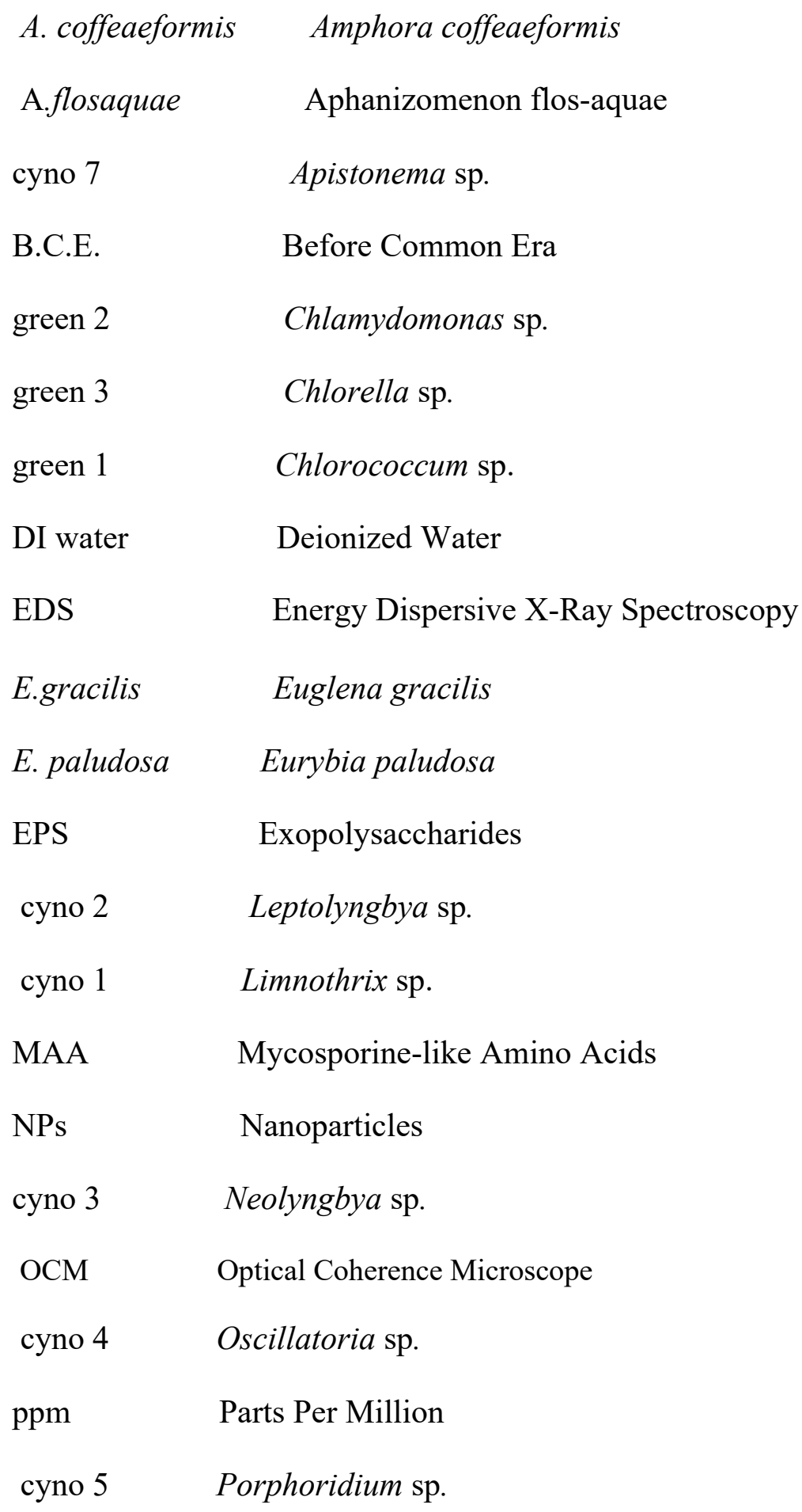




\section{Section 1: INTRODUCTION}

\subsection{Significance of Research}

Nanotechnology may seem like a new futuristic concept. The reality is that nanotechnology has always existed, even when humans were not aware of it. Nanoparticles (NPs), which are found in nature, have been used as far back as 1,000 B.C.E. to change the color of pottery (Binns, 2010). It was in 1959 that the American physicist Richard Feynman defined the concept of nanotechnology in his talk, "There's Plenty of Room at the Bottom" (Feynman, 1959). Nanotechnology is one of the fastest growing markets in the world; worldwide investments estimate to be close to a quarter of a trillion USD (Adeel Irfan, 2014). Due to their fast-growing and enhancing properties, nanoparticles are being used in many commercially available products such as paint, sunblock, foods, and cosmetics. Some of these products may come in direct contact with aquatic ecosystems, for example, when we put on sunblock and go into the ocean. (Colvin, 2004; Kahru \& Dubourguier, 2010).

The third highest used nanoparticle is ZnO NPs. These NPs are being used in products (cosmetics and sunblock) that have a direct contact with the aquatic ecosystem. There have been several studies on the effects of $\mathrm{ZnO}$ NPs on marine and freshwater life, especially on smaller organisms like microalgae (Aravantinou, Tsarpali, Dailianis, \& Manariotis, 2015; Wu, Torres-Duarte, Cole, \& Cherr, 2015). Microalgae produces more than half of the oxygen humans breathe, demonstrating the direct and powerful impact they have on human oxygen consumption (Hall \& Benemann, 2011). Microalgae has a future potential for renewable energy, food, fertilizer and ecofriendly sunblock. However, the research has been inconsistent regarding the toxicity of ZnO NPs on microalgae. 
As the microalgae growth conditions and the size of $\mathrm{ZnO}$ NPs used is commonly different for each study, it is not possible to make reliable conclusions. There are only a few reports involving more than two microalga species showing variation in response to ZnO NPs (Manzo, Miglietta, Rametta, Buono, \& Francia, 2013). Finding marine microalgae species sensitive to ZnO NPs could help improve the ecotoxicology studies, and it can help regulate nanoparticles in products that have a direct contact with aquatic systems. On the other hand, finding tolerant microalgae species may provide an impetus for future studies to understand the mechanism of tolerance and potential applications for NPs bioremediation in aquatic systems.

\subsection{Statement of Research}

Through the increasing use and application of $\mathrm{ZnO}$ NPs, the potential for negative environmental impacts on aquatic phototrophic organisms is quite considerable. It is known that microalgae species differ in their response to various abiotic and biotic sources of stress. However, serious research on variation in tolerance among species to NPs is very limited. Therefore, it is predicted that by screening microalgae species for tolerance to $\mathrm{ZnO} N$ Ps, it is possible to identify tolerant and sensitive species. Among the potential prospects, a greater understanding of the mechanisms involved will improve bioremediation of nanoparticle pollution using tolerant species. It would, therefore, be interesting to investigate the variation in tolerance to $\mathrm{ZnO}$ NPs among different marine microalgae species.

\subsection{Objectives}

1. To assess the variation in growth response to various levels of $\mathrm{ZnO}$ NPs amongst marine microalgae species by comparison to bulk $\mathrm{ZnO}$. 
2. To evaluate tolerance of marine microalgae species to ZnO NPs by screening microalgae species for growth response to higher levels of $\mathrm{ZnO}$ NPs.

3. To determine whether the growth response of selected $\mathrm{ZnO}$ NPs tolerant marine microalgae species will remain unchanged when exposed to ZnO NPs of different sizes.

4. To characterize the variation in cell morphology of $\mathrm{ZnO}$ NPs tolerant and sensitive marine microalgae species in response to exposure to $\mathrm{ZnO}$ NPs.

\subsection{Hypotheses}

1- Some species of marine microalgae are more tolerant to $\mathrm{ZnO}$ NP exposure than other species.

2- The cell morphology of various species of marine microalgae will differ. 


\section{Section 2: LITERATURE REVIEW}

\subsection{Coastal systems}

Marine aquatic systems are vulnerable to anthropogenic effects due to human impacts both directly, through fishing, boating and sunscreens, and indirectly such as through events like chemical runoff (Hazeem, et al., 2015). Coastal environments that are the most vulnerable to pollution are those that are most visited by tourists. Miami's beaches in Florida are some of the most popular beaches in the United States of America, which makes them extremely vulnerable to direct and indirect pollution (U.S. Census Bureau). There have been many routine studies done on the quality of the coastal environment along Miami beaches, but the concentration of Zinc and other metals has not yet been measured. In addition, there is limited research on pollution caused by nanoparticles (NPs). NPs can leech into the coastal environment both directly and indirectly through products like boat paints, bathing suits and sunscreen. $\mathrm{ZnO}$ and $\mathrm{ZnO}$ NPs and its ecotoxicity was one of the focuses of this study.

\subsection{Nanoparticles (NPs)}

NPs are particles that are from 1 to $100 \mathrm{~nm}$ in size. Due to their minute size, they exhibit unique properties that affect physical, chemical, and biological behavior (Brauer, 2016). Some NPs can be found naturally in the environment and are a product of natural physical and biogeochemical processes. These NPs can be found in volcanic ash, ocean spray, fine sand, dust, and in biological matter. Some organisms, like microalgae, may also be able to produce them. There are also human made NPs, which can be synthesized intentionally and unintentionally. Unintentional NPs can be formed as a byproduct of 
anthropogenic activities, such as running diesel engines, large-scale mining operations, and other processes (Binns, 2010). The intentionally made NPs are synthesized for various commercial and research purposes such as cosmetics.

Some of the properties that NPs have are: UV-absorbance, transparency, highstrength, and water and strain repulsion (Nagarajan, 2008; Woomer, et al., 2015). The increased use of purposely synthesized NPs is increasing exponentially, which may be dangerous for the aquatic ecosystem, especially since NPs have a direct impact on the costal environment.

\subsubsection{Zinc Oxide (ZnO) NPs}

Zinc is one of the most abundant elements found in the earth's crust. Although $\mathrm{ZnO}$ is found in nature (Zincite), synthetic $\mathrm{ZnO}$ is the variety used most. Macroscale or bulk $\mathrm{ZnO}$ is an inorganic compound, in the form of a white colored powder, that is insoluble in water but soluble in acid or alkaline solutions (Moezzi, et al., 2012). ZnO is popularly used in sunblock, other cosmetics, pharmaceuticals, and other products due to its high absorption along the entire UV spectrum and its good photo stability (Klingshirn, Waag, Hoffmann, \& Geurts, 2013).

NPs do not exhibit the same properties as macro (bulk) particles. NPs have a

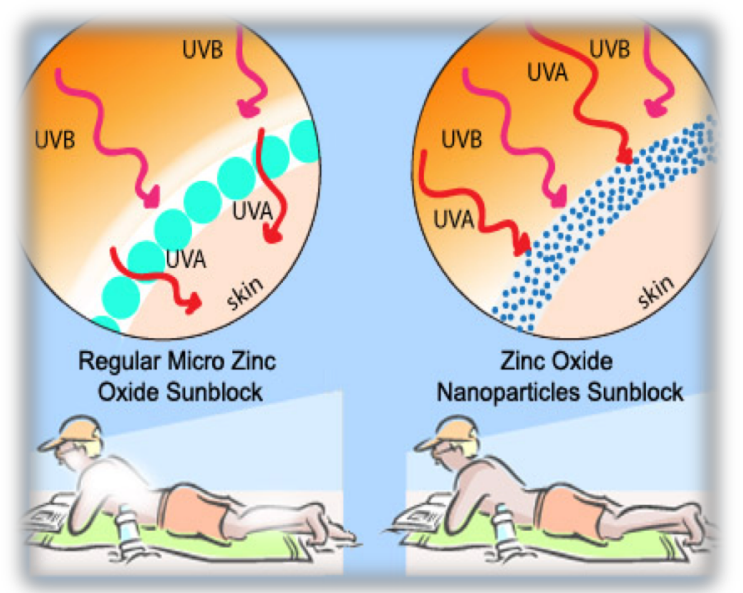
large surface area-to-volume ratio and varying surface charges that give them unique characteristics (Auffan, et al., 2009). This principle can be seen in the difference between $\mathrm{ZnO}$ nanoparticles and Figure 1: Compress the regular micro $\mathrm{ZnO}$ sunblock to $\mathrm{ZnO}$ NPs sunblock. 
bulk ZnO (Figure 1). Zinc Oxide NPs are used in sunblock because the particles scatter the ultraviolet light in sunlight, assuring a broad-band UV protection.

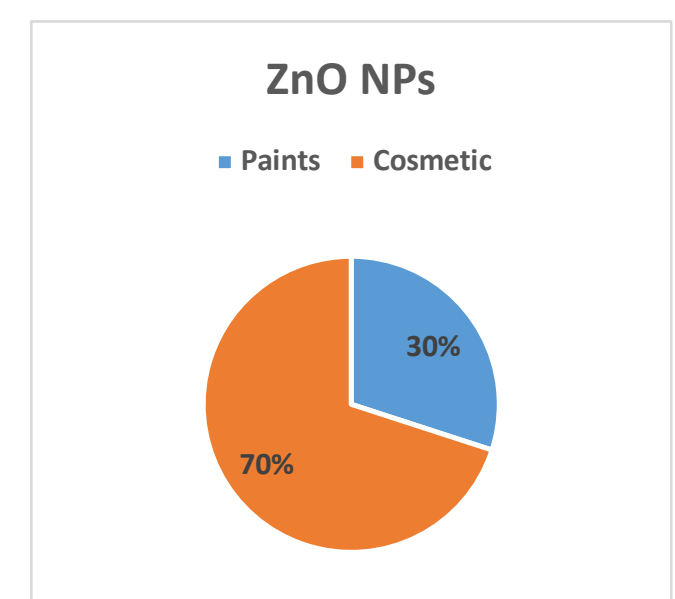

Figure 2: The percentage of $\mathrm{ZnO}$ NPs usage
ZnO NPs are one of the most popular heavy metals, and are the third highest heavy metal used in annual production volume with 550 tons estimated per year (Piccinno, Gottschalk, Seeger, \& Nowack, 2012). Even though $\mathrm{ZnO}$ NPs have uses other than sunscreen, like for example paint, sunblock is the most popular with $70 \%$ of $\mathrm{ZnO}$ NPs being used in cosmetics (including sunscreens). In comparison, only

$30 \%$ of $\mathrm{ZnO}$ NPs are being used in paints (Figure 2) (Piccinno, Gottschalk, Seeger, \& Nowack, 2012).

The excessive use of $\mathrm{ZnO}$ NPs in sunblock is alarming because of its direct exposure to the aquatic system. Even though these NPs have some benefits to human health, they may also have a negative impact on the environment. When the sunblock washes off the skin during recreational activities, it can reach the aquatic environment directly and can potentially affect marine organisms. In fact, $25 \%$ of sunscreens will be washed off upon immersion (Danovaro et al. 2008) and 250 tons of sunscreen-originated NPs enter the marine environment each year (Wong et al. 2010). As the impact of NPs becomes a growing concern, studies on sunblock suggest that caution should be used as new sunscreens are being developed and more detailed research should be done on NPs 
stabilization, chronic exposures, and reduction of NPs free-radical production (Smijs, T., \& P., 2011).

\subsection{Ecotoxicology}

Many recent studies have proven that $\mathrm{ZnO}$ NPs, and even bulk $\mathrm{ZnO}$, may be toxic to many organisms, especially aquatic ones. Bondarenko, et al., (2013) compares levels of toxicity within numerous aquatic organisms. Their research indicated that crustaceans, Daphnia sp., showed a $100 \%$ toxicity at $100 \mathrm{mg} / \mathrm{L}$ of ZnO NPs (Blinova et al., 2010, Akhil \& S., 2016); algae, Pseudokirchneriella subcapitata, showed a comparable toxicity for $\mathrm{NPs} \mathrm{ZnO}$, bulk $\mathrm{ZnO}$, and $\mathrm{ZnCl}$, with a 72-h IC50 value near $60 \mu \mathrm{g} \mathrm{Zn/L,} \mathrm{attributable}$ solely to dissolved zinc (Linkous et al., 2000; Franklin et al., 2007); and fish, zebrafish, showed acute toxicity during $96-\mathrm{h} \mathrm{LC}(50)$ at $4.92 \mathrm{mg} / \mathrm{L}$ ZnO NPs, at $3.31 \mathrm{mg} / \mathrm{L}$ bulk $\mathrm{ZnO}$ suspension, and at $8.06 \mathrm{mg} / \mathrm{L} \mathrm{Zn(2+)} \mathrm{solution} \mathrm{(Zhu} \mathrm{et} \mathrm{al.} \mathrm{2008,} \mathrm{Xiong} \mathrm{et} \mathrm{al.,} \mathrm{2011).}$

In addition, research also indicates that although the survivability of nematodes, specifically C. elegans, was not significantly affected by the exposure of $50 \mathrm{~nm}$ and 100 $\mathrm{nm} \mathrm{ZnO}$ NPs, their reproduction was affected in a low concentration as compared to their survivability. Nematode exposure to $10 \mathrm{~nm}$ of $\mathrm{ZnO}$ NPs had shown even distribution extended nearly the entire length of the body, which means that the intestine is the major target tissues for NP toxicity (Gupta, Kushwah, Vishwakarma, \& Yadav, 2016).

Several studies demonstrated high toxicity among bacteria. Damage within the $E$. coli cells was shown in the gram-negative triple membrane disorganization (Brayner, et al., 2006), while research using Streptococcus agalactiae and Staphylococcus aureus demonstrated both gram-negative membrane and gram-positive membrane disorganization when exposed to ZnO NPs. The ZnO NPs do a surface modification which causes an increase in membrane permeability of these NPs (Huang, et al., 2008). 
Some research has had different results that proves that $E$. coli can have an adaptive resistance to the ZnO NPs in long periods of time (Zhang, et al., 2018).

Testing of yeast/fungi, Aspergillus Fumigatus Fungus and Candida Albicans Yeast, with a ZnO NPs concentration of 0, 3, 6 and 12 mmll-1 showed ZnO NPs have considerable antifungal activity (Jasim, 2015), while mammalian cells In Vitro were exposed to $\mathrm{ZnO}$ Macro and Nano particles with various concentrations $(5-500 \mu \mathrm{g} / \mathrm{mL})$ for $24 \mathrm{~h}$. Zinc Oxide particles showed concentration-dependent cytotoxicity, but nano $\mathrm{ZnO}$ showed more toxicity than its macro size (Sahu, Kannan, Tailang, \& Vijayaraghavan, 2016). In the Heinlaan, Ivask, Blinova, Dubourguier, and Kahru (2008) study, vibrio fishes were found to be very toxic for all three (bulk $\mathrm{ZnO}$, nano $\mathrm{ZnO}$ and $\mathrm{ZnSO} 4.7 \mathrm{H} 2 \mathrm{O})$ at low concentrations $(1.8,1.9$, and 1.1). Finally, protozoa, Tetrahymena thermophila, show toxicity for bulk and nano $\mathrm{ZnO}$ while $\mathrm{Zn}(2+)$ had of similar toxicity to ZnO NPs and salts (Mortimer, Kasemets, \& Kahru, 2010) (Figure 3). 


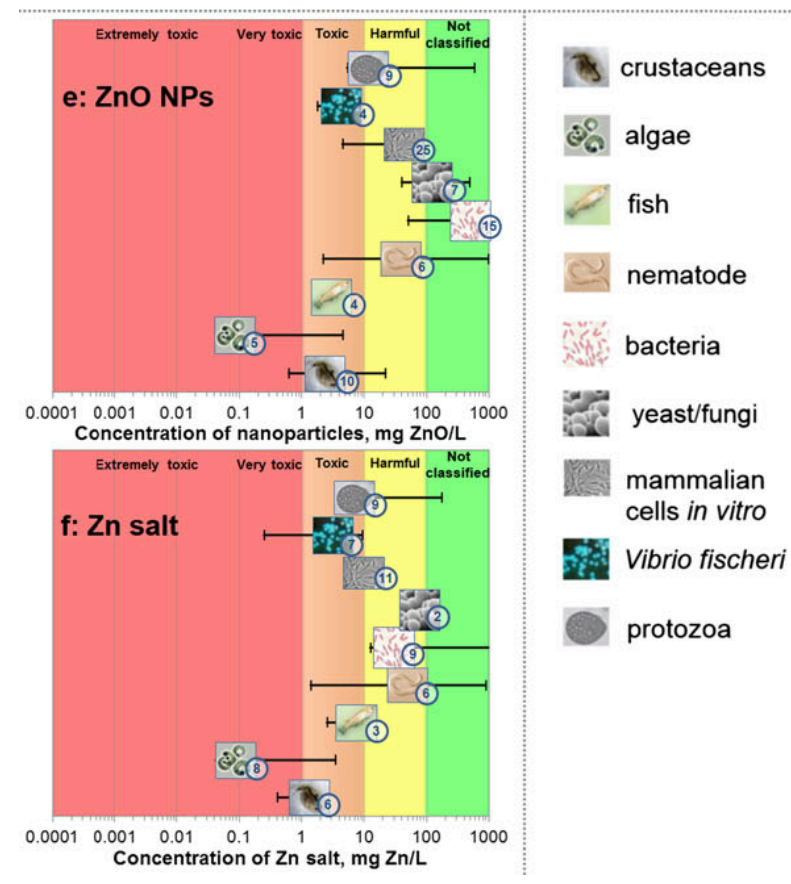

Figure 3: The toxicity effects of $\mathrm{ZnO}$ NPs and $\mathrm{Zn}$ salts (Bondarenko, et al., 2013).

For this research, we will be focusing on the results for ZnO NPs and salts. The more sensitive organism to $\mathrm{ZnO}$ NPs and salts is the aquatic organism including: Crustaceans, algae and fish (Table 1). Out of these aquatic organisms, algae are the most sensitive to $\mathrm{ZnO}$ NPs and salts showing toxicity at only $5 \mathrm{mg} / 1 \mathrm{NPs}$ and $8 \mathrm{mg} / \mathrm{L}$ of salts. The ZnO NPs and Zn salts are classified as extremely toxic (Sanderson, 2003; Blaise, Gagné, Férard, \& Eullaffroy, 2008).

Other aquatic organisms affected by ZnO NPs are water fleas, crustaceans, mussels, and sea urchins. The ZnO NPs have shown unusual patterns of development in marine life. The nanoparticles make the embryos more susceptible to damage from other toxic compounds. For example, some urchin embryos exposed to nano $\mathrm{ZnO}$ in sunscreen never grew to become larvae or appeared to grow normally but were unable to eat and 
died (Wu, Torres-Duarte, Cole, \& Cherr, 2015). Finally, many studies have proven that NPs are toxic to marine algae. Nanoparticles of $\mathrm{ZnO}$ affects the algal growth rate starting from lower tested concentrations (Manzo, Miglietta, Rametta, Buono, \& Francia, 2013).

Table 1 Median L(E)C50 values for all organisms except bacteria and median MIC for bacteria for Ag, CuO and $\mathrm{ZnO}$ nanoparticles (NPs) and the respective metal salts

\begin{tabular}{|c|c|c|c|c|c|c|}
\hline \multirow[t]{2}{*}{ Group of organisms } & \multicolumn{3}{|c|}{$\begin{array}{l}\text { Median } \mathrm{L}(\mathrm{E}) \mathrm{C} 50 \text { or } \mathrm{MIC} \text {, on compound } \\
\text { basis, } \mathrm{mg} / \mathrm{L} \text { (number of data)* }\end{array}$} & \multicolumn{3}{|c|}{$\begin{array}{l}\text { Median } \mathrm{L}(\mathrm{E}) \mathrm{C} 50 \text { or MIC, on metal basis, mg } \\
\text { metal/L (number of data)* }\end{array}$} \\
\hline & Ag NPs & $\mathrm{CuO}$ NPs & $\mathrm{ZnO}$ NPs & Ag salt & $\mathrm{Cu}$ salt & Zn salt \\
\hline Crustaceans & $0.01(17)$ & $2.1(8)$ & $2.3(10)$ & $0.00085(8)$ & $0.024(8)$ & $1.3(6)$ \\
\hline Algae & $0.36(17)$ & $2.8(5)$ & $0.08(5)$ & $0.0076(10)$ & $0.07(20)$ & $0.09(8)$ \\
\hline Fish & $1.36(17)$ & $100(1)$ & $3.0(4)$ & $0.058(4)$ & $0.28(19)$ & $7.5(3)$ \\
\hline Bacteria & $7.10(46)$ & $200(13)$ & $500(15)$ & $3.3(27)$ & $32(13)$ & $30(9)$ \\
\hline Yeast & $7.90(14)$ & $17(4)$ & $121(7)$ & $2.16(5)$ & $11.1(4)$ & $78(2)$ \\
\hline Mammalian cells in vitro & $11.3(25)$ & $25(21)$ & $43(25)$ & $2(18)$ & $53(10)$ & $9.8(11)$ \\
\hline V. fischeri ${ }^{\mathrm{a}}$ & $32(2)$ & $73.6(4)$ & $4.3(4)$ & $5.7(2)$ & $0.78(7)$ & $3.2(7)$ \\
\hline $\begin{array}{l}\text { Classification } \\
\text { (EU-Directive 93/67/EEC (CEC 1996) }^{\text {b }}\end{array}$ & Very toxic & Toxic & Very toxic & Very toxic & Very toxic & Very toxic \\
\hline $\begin{array}{l}\text { Classification (Sanderson et al. 2003; Blaise } \\
\text { et al. 2008) }\end{array}$ & $\begin{array}{l}\text { Extremely } \\
\text { toxic }\end{array}$ & Toxic & $\begin{array}{l}\text { Extremely } \\
\text { toxic }\end{array}$ & $\begin{array}{l}\text { Extremely } \\
\text { toxic }\end{array}$ & $\begin{array}{l}\text { Extremely } \\
\text { toxic }\end{array}$ & $\begin{array}{l}\text { Extremely } \\
\text { toxic }\end{array}$ \\
\hline
\end{tabular}

"In the brackets next to the median value, the number of data used to derive the median value is presented

\subsection{Marine Photosynthetic Microorganism}

Photosynthetic microorganism (photoautotrophs) are organisms that are capable of to do photosynthesis. All of this organism contain chlorophyll, which is a pigment able to absorbs light energy. In this research two types of marine photosynthetic organism were used green microalgae and cyanobacteria. Even do these two organisms are photosynthetic, the have key major differences. Cyanobacteria are prokaryotes while green microalgae are eukaryotic. 


\subsubsection{Cyanobacteria}

Cyanobacteria are prokaryotic gram-negative oxygenic photosynthetic autotrophic organisms (Schopf, 2000). Cyanobacteria have various morphologies: unicellular, colonial, filamentous, and branched filamentous forms. Cyanobacteria are important in the biogeochemical cycles of nitrogen, carbon, and oxygen.

Cyanobacteria can also be used for food and has biologically active compounds that are valuable for medicinal purposes (Sharma, Rai, \& Stal, 2014). Even though cyanobacteria have many beneficial properties, they can also be toxic; the most common toxic algae are blue-green algae (cyanobacteria).

Cyanobacteria have metal requirements different from other bacteria: copper in thylakoidal plastocyanin, zinc in carboxysomal carbonic anhydrase, cobalt in cobalamin, magnesium in chlorophyll, molybdenum in heterocystous nitrogenase, manganese in thylakoidal water-splitting oxygen-evolving complex (Cavet, Borrelly, \& Robinson, 2003). The zinc stress response in Cyanobacterium Synechococcus sp. was toxic when exposed to $50 \mathrm{mg} / \mathrm{L} \mathrm{ZnCl} 2$ (Newby, Lee, Perez, Tao, \& Chu, 2017).

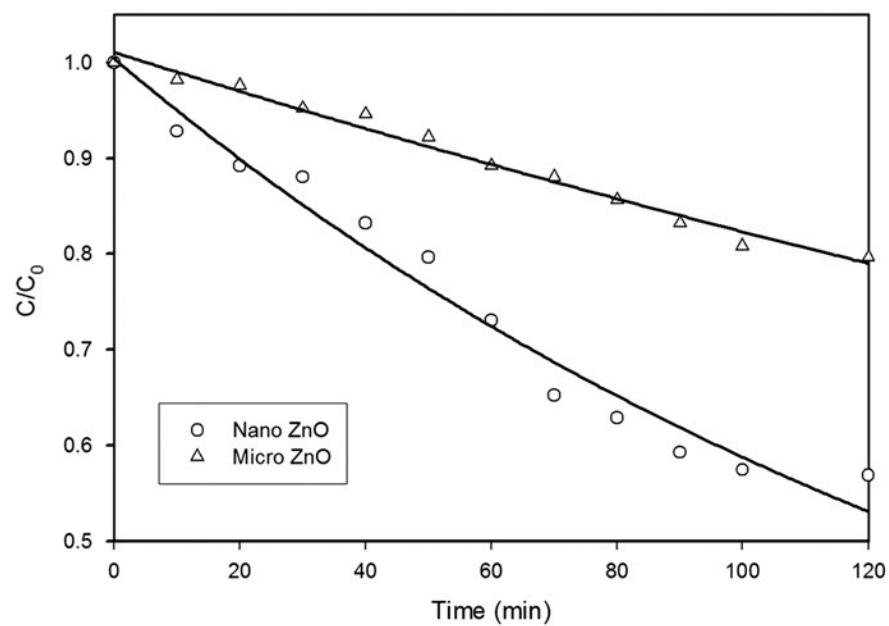

Figure 4: Show the results of Nano $\mathrm{ZnO}$ and Micro $\mathrm{ZnO} 50 \mathrm{ppm}$.
An ecotoxicity study using A.flosaquae and E.gracilis showed a decrease of photosynthetic activity for both in the first 10 days when exposed to ZnO NPs (Brayner, 2010). In another study, using the microalgae A.flosaquae was compared to the control, 
micro and nano $\mathrm{ZnO}$. The control showed an increment in algal growth. The micro and nano $\mathrm{ZnO}$ showed a lowered growth than the control. The research also showed (Figure 4) how nano $\mathrm{ZnO}$ have a lower growth than the micro $\mathrm{ZnO}$ (Nandi, et al., 2012).

Djearamane, Lim, Wong, and Lee (2018) conducted a study of cyanobacterium Spirulina (Arthrospira) platensis using different concentrations of ZnO NPs (10-200 $\mathrm{mg} / \mathrm{L}$ ) from 6 to $96 \mathrm{~h}$ to explore the dose- and time-dependent cytotoxic effects. They discovered that ZnO NPs triggered substantial cytotoxicity within the S. platensis and caused cell death. The maximum cell death occurred at $96 \mathrm{~h}$ cell death of $44.3 \pm 4 \%$ for $10 \mathrm{mg} / \mathrm{L}, 69.7 \pm 2.1 \%$ for $50 \mathrm{mg} / \mathrm{L}, 83.8 \pm 0.9 \%$ for $100 \mathrm{mg} / \mathrm{L}, 86.7 \pm 1.2 \%$ for $150 \mathrm{mg} / \mathrm{L}$, and $87.3 \pm 1 \%$ for $200 \mathrm{mg} / \mathrm{L}$ of $\mathrm{ZnO}$ NPs. The cyanobacteria used in this study included: Limnothrix sp., Leptolyngbya sp., Lyngbya 1 sp., Lyngbya 2 sp., Porphyridium sp., Roseofilum sp. and Apistonema sp.

\subsubsection{Green Microalgae (Chlorophytes and Charophytes)}

Green microalgae are one of the most common types of algae and have chlorophylls a and b. Green algae are the only algae that store their photosynthates within the chloroplast (Chapman, 2013). The green microalgal cells are negatively charged, providing a set of binding sites for metal cations like $\mathrm{Zn}^{+2}$, which have the potential to lower toxicity in the microalgae (Monteiro, Fonseca, Castro, \& Malcata, 2010). Despite this, there has been research showing $\mathrm{Zn}$ toxicity. In a study where both S. obliquus and D. pleiomorphus were exposed to $\mathrm{Zn}$ concentrations, researchers discovered levels of toxicity; although, S. obliquus can tolerate higher Zn concentrations than D. pleiomorphus (Monteiro, Fonseca, Castro, \& Malcata, 2010). Surprisingly, 
Raphidocelis subcapitata and Chlorella vulgaris are proven to have a tolerance to Zinc within a 72-hour exposure (Muyssen \& Janssen, 2001).

There have been inconsistent results with the toxicity of $\mathrm{ZnO}$ NPs among some green microalgae. For example, the green microalgae Dunaliella tertiolecta of the order of Chlamydomonadales demonstrated different results in three different studies. In the first study, there was no conclusion as a consequence to the low estimate samples (Miller, 2010). When the experiment was repeated, it showed an inhibition growth at $96 \mathrm{~h}$ with the concentration of $133 \mathrm{mg} / \mathrm{L}$ ZnO NPs (Miglietta, et al., 2011). Finally, when the experiment was last conducted, there was also an inhibition growth at $96 \mathrm{~h}$, but in a smaller concentration of $2.42 \mathrm{mg} / \mathrm{L} \mathrm{ZnO}$ NPs (Manzo, Miglietta, Rametta, Buono, \& Francia, 2013).

Results of other green microalgae that show inhibition at low and high concentrations are classified in tables 2 and 3. For the Tetraselmis sucica, there was no effect in a high concentration of $100 \mathrm{mg} / \mathrm{L}$ ZnO NPs (Castro-Bugallo, GonzálezFernández, Guisande, \& Barreiro, 2014). While for Scenedemus rubescens there was a $50 \%$ inhabitation rate at $14.27 \mathrm{mg} / \mathrm{L}$ ZnO NPs (Aravantinou, Tsarpali, Dailianis, \& Manariotis, 2015). With Chlorella vulgaris there was a 35\% cell viability in a high concentration of $200 \mathrm{mg} / \mathrm{L}$ ZnO NPs (Suman, Rajasree, \& Kirubagaran, 2015). Pseudokirchneriella subcapitata had a high inhibition of $80 \%$ with a very low concentration of $0.1 \mathrm{mg} / \mathrm{L} \mathrm{ZnO}$ NPs (Lee \& An, 2013). All of these experiments included: Chlorococcum, Chlamydomonas, and Chlorella. 
Table 2

Nano $\mathrm{ZnO}$ effects upon microalgae.

\begin{tabular}{|c|c|c|c|}
\hline Algae & Endpoint/s & $\begin{array}{l}\mathrm{ZnO} \text { effect } \\
\text { concentration } \\
\left(\mathrm{mg} \mathrm{L}^{-1}\right)\end{array}$ & Reference \\
\hline \multicolumn{4}{|l|}{ Marine species } \\
\hline T. pseudonana & Growth rate inhibition & 0.5 & Miller et al. \\
\hline S. marinoi & $\left(\mathrm{LOEC}^{\mathrm{a}}\right)$ & 1 & $(2010)$ \\
\hline D. tertiolecta & & NA & \\
\hline I. galbana & & NA & \\
\hline T. pseudonana & $\begin{array}{l}\mathrm{Fv} / \mathrm{Fm} \\
\text { growth rate } \\
\text { Chl a }\end{array}$ & 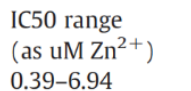 & $\begin{array}{l}\text { Miao et al. } \\
\text { (2010) }\end{array}$ \\
\hline $\begin{array}{l}\text { T. pseudonana } \\
\text { C. gracilis } \\
\text { P. tricormutum }\end{array}$ & $\begin{array}{l}\text { Growth rate inhibition } \\
\text { (EC100) }\end{array}$ & 10 & $\begin{array}{l}\text { Peng et al. } \\
\text { (2011) }\end{array}$ \\
\hline S. costatum & 96 h growth inhibition & $2.36(2.11-2.64)$ & Wong et al. \\
\hline T. pseudonana & $(\mathrm{EC} 50)$ & $4.56(4.06-5.11)$ & $(2010)$ \\
\hline D. tertiolecta & $\begin{array}{l}96 \text { h growth inhibition } \\
\text { (EC50) }\end{array}$ & $2.42(0.97-2.87)$ & Present work \\
\hline D. tertiolecta & 96 h growth inhibition ${ }^{\mathrm{b}}$ & 133 & $\begin{array}{l}\text { Miglietta et al. } \\
\text { (2011) }\end{array}$ \\
\hline \multicolumn{4}{|c|}{ Freshwater species } \\
\hline P. subcapitata & $\begin{array}{l}72 \mathrm{~h} \text { growth inhibition } \\
\text { (IC50) }\end{array}$ & $\begin{array}{l}\text { about } 0.04 \\
\text { (as } \mathrm{Zn}^{2+} \text { ) }\end{array}$ & $\begin{array}{l}\text { Aruoja et al. } \\
\text { (2009) }\end{array}$ \\
\hline P. subcapitata & $\begin{array}{l}72 \text { h growth inhibition } \\
\text { test (IC50) }\end{array}$ & $0.06\left(\right.$ as $\mathrm{Zn}^{2+}$ ) & $\begin{array}{l}\text { Franklin et al. } \\
\text { (2007) }\end{array}$ \\
\hline Chlorella sp. & $\begin{array}{l}6 \text { d growth inhibition } \\
\text { (EC30) }\end{array}$ & 20 & Ji et al. (2011) \\
\hline C. reinhardtii & $\begin{array}{l}12 \text { d growth inhibition } \\
\left(\mathrm{LOEC}^{\mathrm{a}}\right)\end{array}$ & 1 & Luo (2007) \\
\hline
\end{tabular}

NA: not available.

a Lowest observed effect concentration.

b $100 \%$ effect at single limit test concentration.

Table 3: NPs $\mathrm{ZnO}$ effects upon microalgae (Miazek, Iwanek, Remacle, Richel, \& Goffin, 2015).

\begin{tabular}{|c|c|c|c|c|c|}
\hline Metal & Microalgae Strain & $\begin{array}{c}\text { Cultivation } \\
\text { Time }\end{array}$ & Concentration & $\begin{array}{l}\text { Effect on } \\
\text { Growth }\end{array}$ & Ref. \\
\hline & Phaeodactylum tricormutum & & $100 \mathrm{mg} / \mathrm{L}$ & $80 \%$ inhibition & \\
\hline $\mathrm{ZnO}-\mathrm{NPs}$ & $\begin{array}{l}\text { Alexandrium mimutum } \\
\text { Tetraselmis suecica }\end{array}$ & - & $\begin{array}{l}100 \mathrm{mg} / \mathrm{L} \\
100 \mathrm{mg} / \mathrm{L}\end{array}$ & $\begin{array}{l}80 \% \text { inhibition } \\
\text { No effect }\end{array}$ & [51] \\
\hline $\mathrm{ZnO}-\mathrm{NPs}$ & Scenedesmus rubescens & $96 \mathrm{~h}$ & $\begin{array}{l}14.27 \mathrm{mg} / \mathrm{L} \text { or } \\
>810 \mathrm{mg} / \mathrm{L}^{\mathrm{cM}}\end{array}$ & $50 \%$ inhibition & [53] \\
\hline $\mathrm{ZnO}-\mathrm{NPs}$ & Chlorella vulgaris & $72 \mathrm{~h}$ & $200 \mathrm{mg} / \mathrm{L}$ & $35 \%$ cell viability & [50] \\
\hline $\mathrm{ZnO}-\mathrm{NPs}$ & Dunaliella tertiolecta & $96 \mathrm{~h}$ & $2.4 \mathrm{mg} / \mathrm{L}$ & $50 \%$ inhibition & [56] \\
\hline $\mathrm{ZnO}$-NPs & $\begin{array}{c}\text { Pseudokirchneriella } \\
\text { subcapitata }\end{array}$ & $72 \mathrm{~h}$ & $0.1 \mathrm{mg} / \mathrm{L}$ & $80 \%$ inhibition & [52] \\
\hline
\end{tabular}




\subsubsection{Diatoms}

Diatoms are the only organisms with cell walls composed of transparent, opaline silica. This silica comprises their cell wall, making them useful in the manufacturing of pool filters. Diatoms are a type of plankton called phytoplankton, which store carbon in the form of natural oil or as a polymer of carbohydrate (Chapman, 2013). Diatoms are unicellular organisms that exist as solitary cells or in colonies which form various shapes like ribbons, fans, zigzags, and stars (Tomas \& Hasle, 1997).

There have also been studies conducted with the toxicity Zn to different types of diatoms. Zinc (Zn) ions can be chelated by exopolysaccharides as in Skeletonema costatum or in the cytoplasm by phytochelatins, which are cysteine-rich pseudopeptides (Imber, Robinson, Ortega, \& Burton, 1985). After comparing four marine diatoms (Amphora acutiuscula, Nitzschia palea, Amphora coffeaeformis and Entomoneis paludosa) some show tolerance and others sensitivity to Zn. E. paludosa was found to be the most sensitive to $\mathrm{Zn}$ since growth is drastically decreased (figure 5), while $A$. coffeaeformis is the most tolerant species (Nguyen-Deroche, et al., 2012).

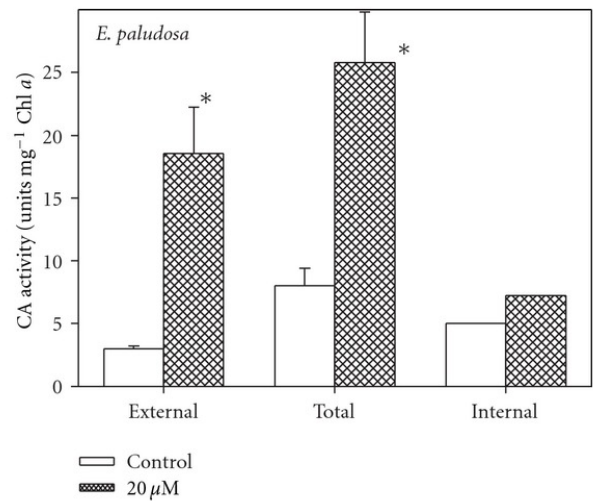

Figure 5: E. paludosa grown in (control) or in the presence of $20 \mu \mathrm{M}$ Zn.

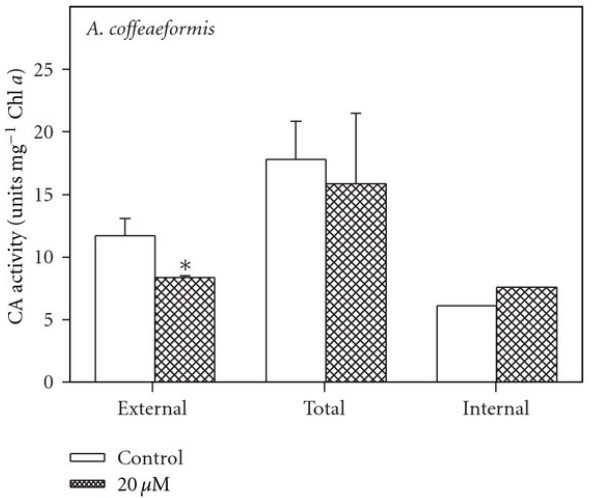

Figure 6: $A$. coffeaeformis grown in (control) or in the presence of $20 \mu \mathrm{M}$ Zn. 
Another study used the diatoms, T. pseudonana and S. marinoi which show inhibition in low concentrations of ZnO NPs at 0.5 and $1 \mathrm{mg} / \mathrm{L}$ (Miller, 2010), while another study shows growth rate inhibition in a much higher concentration for T. pseudonana at 10 mg/L ZnO NPs (Peng, Palma, Fisher, \& Wong, 2011). Finally, the results of a 2014 study of the same microalgae shows $80 \%$ inhibition, but in a high concentration of 100 0.5 and $1 \mathrm{mg} / \mathrm{L}$ (Castro-Bugallo, González-Fernández, Guisande, \& Barreiro, 2014). The marine diatom Thalassiosira pseudonana was exposed to ZnO NPs with a higher temperature and salinity. ZnO NPs exposed to greater temperature formed larger aggregations and released less zinc ions $(\mathrm{Zn} 2+)$. The toxicity of $\mathrm{ZnO}$ NPs to $T$.

pseudonana was less at $25^{\circ} \mathrm{C}$ than at $10^{\circ} \mathrm{C}$, but the toxicity was significantly greater at $30{ }^{\circ} \mathrm{C}$ (Yung, Kwok, Djurišić, Giesy, \& Leung, 2017).

\subsection{Toxicity Mechanism}

Information about the toxicity mechanism of NPs has been lacking, but there are many suggestions. The top four most suggested mechanisms are: reactive oxygen species (ROS) generation, metal ion release, nanomaterials accumulation on member surface, and internalization of nanomaterials (Figure 7). It is important to note that these are toxic mechanisms to bacteria and not to the actual microalgae (Djurišić, et al., 2014). 


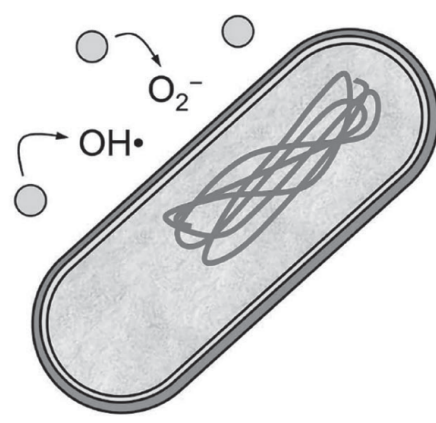

ROS generation

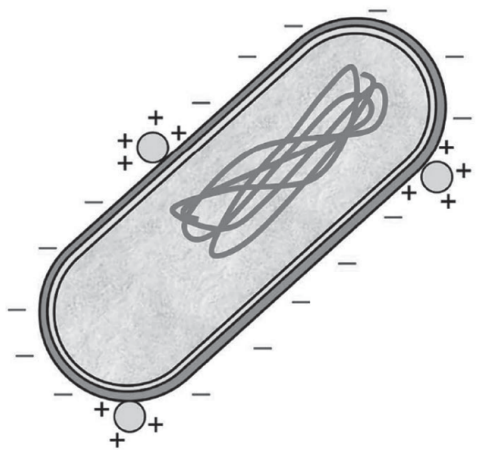

Nanomaterials accumulation on membrane surface

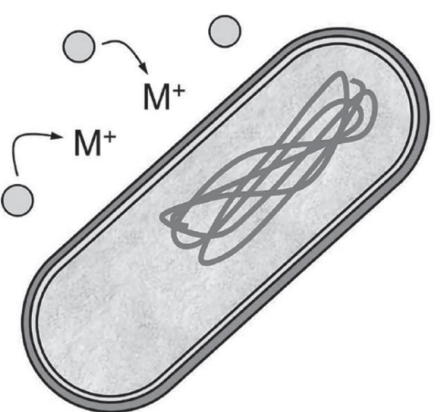

Metal ion release

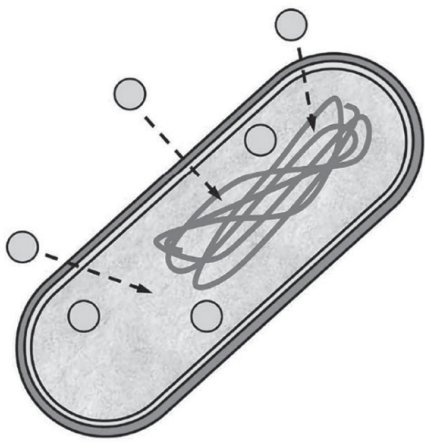

Internalization of nanomaterials

Figure 7: Possible toxicity mechanisms against bacteria cells.

\subsubsection{ROS Induce Damage}

Reactive oxygen species (ROS) is one of the most studied toxicity mechanisms.

Reactive oxygen species (ROS) are species containing oxygen that are chemically reactive. Reactive oxygen species (ROS) levels can increase dramatically when there is environmental stress that could result in damage to cell structures. Nnaoparticles (NPs) induce ROS damage because of the unique factors NPs have: NPs internalization, particle chemistry, and physical properties. The NPs unique physicochemical properties, like their size, have the potential to generate ROS (Ray, Yu, \& Fu, 2009). 
Charge transfer of photogenerated charge between NPs and the bacteria can cause cell membrane damage. Nanoparticles (NPs) can trigger increased expression of proinflammatory, fibrotic cytokines and activation of inflammatory cells, which can influence

the enhanced generation of ROS. Some metal oxide NPs can incite free-radical-facilitated toxicity via Fenton-type reactions (Abdal, et al. 2017).

\subsubsection{Metal Ion Toxicity}

Metal toxicity is the toxic effect of certain metals in certain forms. Some metals are toxic when they form lethal soluble compounds. The toxicity of NPs which are moderately soluble is often attributed to the metal ion release (Tyupa, 2016).

\subsubsection{NPs accumulation on membrane surface}

The integration between the membrane surface and NPs may be another mechanism. In research by Applerot, et al. (2009), the NPs remained firmly attached to the bacteria membrane even after washing the bacteria.

\subsubsection{Internalization of NPs}

When the NPs are attached on the cell surface, redox reactions on the surface of adsorbed NPs can result in oxidative stress to the bacteria and cytotoxicity (Handy, Owen, \& Valsami-Jones, 2008). Another mechanism involves NPs adhesion to the membrane in combination with ROS generation, resulting in a change in membrane permeability and cell death. The adsorption of NPs on the cell membrane can affect the membrane viscosity and the transport exchanges (Guarnieri, et al., 2014). 


\subsection{Toxic mechanism of ZnO NPs}

Since $\mathrm{ZnO}$ NPs are the particles studied in this research, their toxicity mechanism must be discussed. Wang, Gao, Lin, Yao, \& Zhang (2014) found that mixtures of different types of NPs and surfactants revealed aggressive and additive effects, with the highest toxicity of $\mathrm{ZnO}$ was mainly the results of dissolved $\mathrm{Zn}$ ions. Another reason for ZnO NPs toxicity may be environmental factors such as temperature or organic acid. The mechanism is composed of the dissolution of $\mathrm{ZnO}$ and release of $\mathrm{Zn}^{2+}$. They increase temperature, decrease dissolution, and increase aggregation (Majedi, Kelly, \& Lee, 2014).

\subsubsection{Toxic mechanism of ZnO NPs on microalgae}

Chlamydomonas reinhardtii was exposed to various coated $\mathrm{ZnO}$ NPs showed the highest toxicity was from bare $\mathrm{ZnO}$ NPs, suggesting possible mechanisms such as particle solubilization, metal complexation, and metal bio-uptake (Merdzan, Domingos, Monteiro, Hadioui, \& Wilkinson, 2014). Research using T. pseudonana, Skeletonema marinoi and Dunaliella tertiolecta indicated that the reason for the ecotoxicity is the competition between $\mathrm{ZnO}$ NPs and nutrients, thereby inhibiting growth and nutrient uptake (Matranga \& Corsi, 2012; Peng, Palma, Fisher, \& Wong, 2011).

\subsection{Bioremediations}

Bioremediation is the process that uses organisms, such as microorganisms, to degrade and reduce or detoxify waste products and pollutants (Prasad, M. V., 2016). Microalgae have the potential to serve as a method of bioremediation for the toxicity of $\mathrm{ZnO}$ NPs for several reasons. One of the reasons discussed in the research of Hazeem et al. (2015) is the marine microalgae's (Picochlorum sp.) ability to adapt to long term 
exposure of ZnO NPs. In this study, the toxicity of NPs in marine microalgae was reduced by aggregation and sedimentation.

\subsubsection{Biosorbent}

Biosorption, for these purposes, is the removal of metal or metalloid species, compounds, and particulates from a solution by a biological organism (Wang \& Chen, 2009). An ideal biosorbent should possess features like availability, non-toxicity, high metal binding capacity, large-scale usability, and regeneration/re-usability (Wang \& Chen, 2009). Microalgae are considered a low-cost biosorbent, and the cell wall characteristics give them a high metal ion binding capacity (Anastopoulos \& Kyzas, 2015; Gong, et al. 2005; Tien 2002). A non-living algal mass can be an even better biosorbent since it has a higher metal ion sorption capacity at a higher rate, and it does not require nutrients grown in a medium. Furthermore, a dead algal mass can be removed using de-ionized water (Zeraatkar, Ahmadzadeh, Talebi, Moheimani, \& Mchenry, 2016).

Many algae have been found to be good biosorbents. For example, brown algae have good biosorption capacity as consequences of the presence of alginates in their cell walls (Demey, Vincent, \& Guibal, 2018). The microalgae Chlorella miniata (Tam et al., 2001), and Chlamydomonas acidophila (Nishikawa and Tominaga 2001) have demonstrated a high resistance to toxic metals present in their surrounding habitat. $P$. lanceolatum algae can remove zinc metal up to $118.66 \mathrm{mg} \mathrm{g}^{-1}$ (Sbihi, K., Cherifi, O., El Gharmali, A., Oudra, B., Aziz, F., 2012). 


\subsubsection{Sunscreens}

Another way microalga can be used as bioremediation is with sunscreen. Mycosporine-like amino acids (MAA) extracted from cyanobacteria, absorbing maximally at $335 \mathrm{~nm}$, are encapsulated into liposomes where they have been shown to be photostable and photoprotective in vitro (Schmid, Schurch, and Zulli, 2006). Another study showed that MAA are biocompatible, photoresistant, and thermoresistant, and exhibit a highly efficient absorption of both UV-A and UV-B radiations (Fernandes, et al., 2015).

\subsubsection{Microalgae Synthesis NPs}

Research published by Singh et al. (2014) discusses the synthesis of ZnO NPs using the cell extract of the cyanobacterium, Anabaena strain. The natural synthesis of $\mathrm{ZnO}$ NPs serves as bioremediation for the NPs toxicity. The aim of this research was not only to study the toxicity of the NPs, but the potential bioremediation that microalgae can potentially have.

Diatoms that produce valves could be evolved for cultivation in chemostat cultures to mass-produce nanoscale components. Diatoms can also synthesis micro- and nano-scale structures which may be of use in a range of devices, including: optical systems, semiconductor nanolithography, and even vehicles for drug delivery (Bradbury, 2004). In addition, diatoms can substitute photosensitive titanium dioxide for the silicon dioxide component of solar cells (Johnson, R.C., 2009).

Even though $\mathrm{ZnO}$ NPs can be potentially harmful to microalgae, eco-NPs can be synthesized from microalgae, and these microorganisms can even be used for sunblock, which is a product of major concern. 


\section{Section 3: Materials and Methods}

\subsection{Marine Algae Culture}

\subsubsection{Algal Species}

Ten South Florida marine microalgae strains, three green microalgae:

Chlorococcum sp. (146-2-6), Chlamydomonas sp. (146-2-10), and Chlorella sp. (146-2-

16) (Figure 8), and seven cyanobacteria Limnothrix sp. (173-10-1), Leptolyngbya (146-5-

2), Lyngbya 1 sp. (EK17-3A), Lyngbya 2 sp. (Bpm 173F), Porphoridium sp. (173-10-2), Roseofilum sp. (101-1), Nannochloris sp. (146-2-11) were used in this project. All of them were obtained from Dr. Miroslav Gantar's culture collection. These marine strains were isolated from the South Florida region.
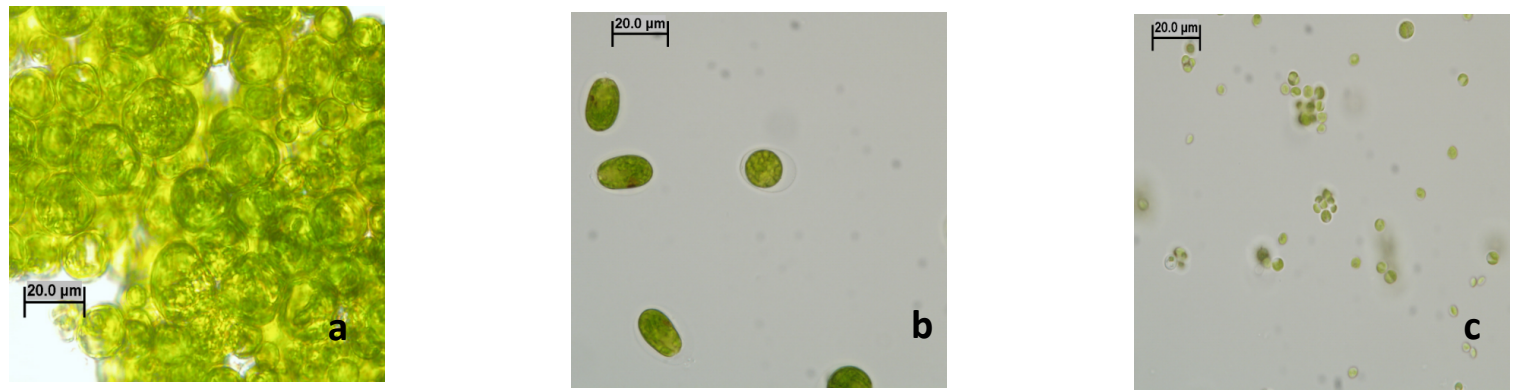

Fig 8. Green Microalgae strains used in this research: a) 146-2-6 Chlorococcum sp. $b$ ) 146-2-10 Chlamydomonas sp. and c)146-2-16 Chlorella sp. 100X magnification, scale bar represents $20 \mu \mathrm{m}$. 


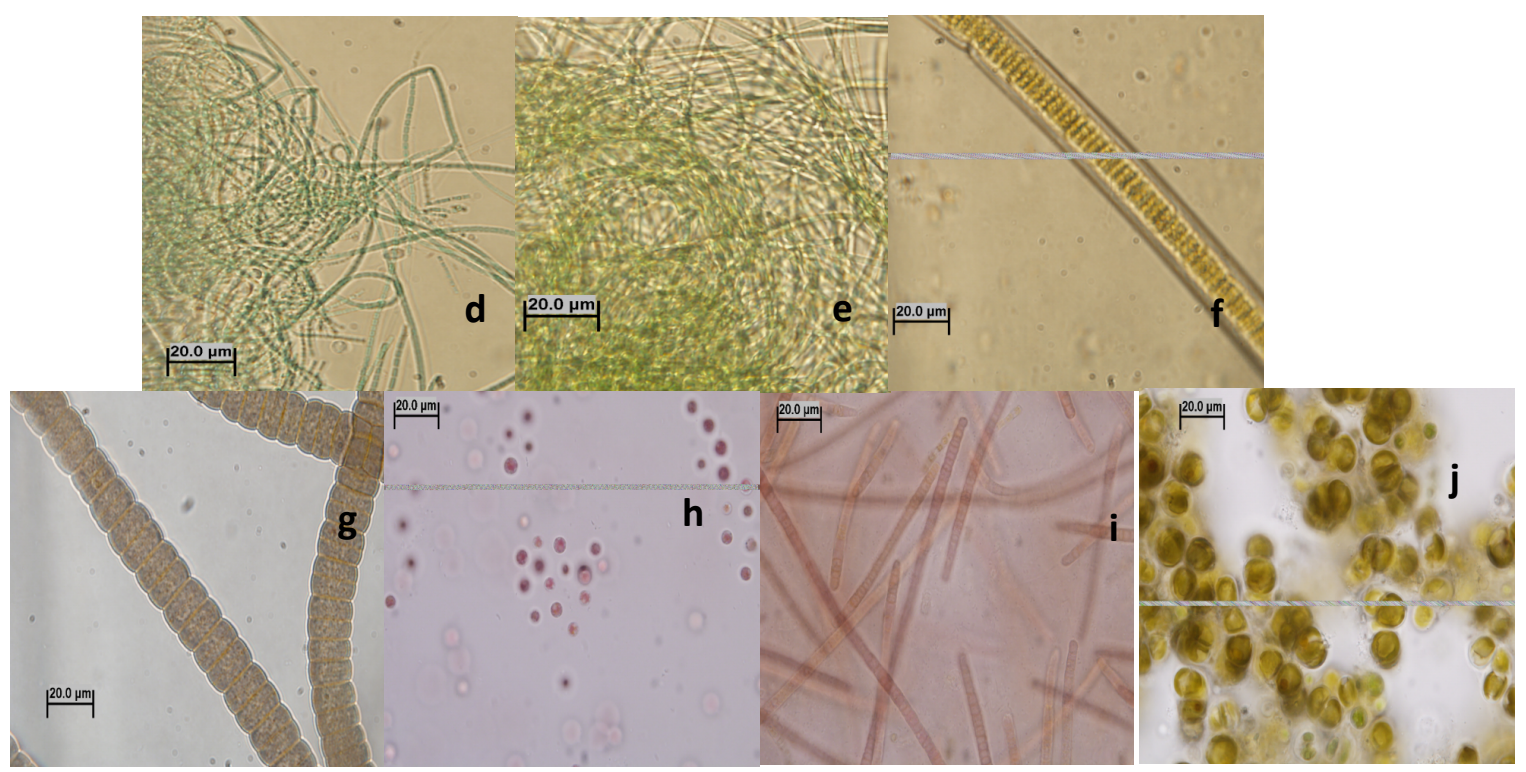

Figure 9. Cynobacteria strains used in this research: d) Limnothrix sp. (173-10-1), e) Leptolyngbya sp. (146-5-2), f) Lyngbya 1 sp. (EK17-3A), g) Lyngbya 2 sp. (Bpm 173F), h) Porphoridium sp. (173-10-2), i) Roseofilum sp. (101-1), j) Apistonema sp. 146-2-11 sp. 100X magnification, scale bar represents $20 \mu \mathrm{m}$.

\subsubsection{Microalgae Culture Conditions}

All of the microalgae were cultivated in flasks with marine BG-11 Medium. The marine BG-11 Medium was prepared with one-liter distilled water and six stock solutions (Tasic, Rios, Santos, Filipini, \& Maciel 2016). The six stock solutions were diluted with $500 \mathrm{~mL}$ : Dipotassium phosphate $\left(\mathrm{K}_{2} \mathrm{HPO}_{4}\right)$ - $15.25 \mathrm{~g}$, Magnesium sulfate heptahydrate $\left(\mathrm{MgSO}_{4} \cdot 7 \mathrm{H}_{2} \mathrm{O}\right)-37.5 \mathrm{~g}$, Sodium carbonate $\left(\mathrm{Na}_{2} \mathrm{CO}_{3}-10 \mathrm{~g}\right)$, Fe-Chelate ( Fe(III) Citrate- 3 g, Citric Acid $3 g$ and $\mathrm{Na}_{2}$ EDTA $\left.0.5 \mathrm{~g}\right)$ and Micro-elements $\left(\mathrm{H}_{3} \mathrm{BO}_{3}-1.43 \mathrm{~g}\right.$, $\mathrm{MnCl}_{2} \cdot 4 \mathrm{H}_{2} \mathrm{O}-0.90 \mathrm{~g}, \mathrm{ZnSO}_{4} \cdot 7 \mathrm{H}_{2} \mathrm{O}-0.111 \mathrm{~g}, \mathrm{Na}_{2} \mathrm{MoO}_{4} \cdot 2 \mathrm{H}_{2} \mathrm{O}-0.195 \mathrm{~g}, \mathrm{CuSO}_{4} \cdot 5$ $\left.\mathrm{H}_{2} \mathrm{O}-0.040 \mathrm{~g}, \mathrm{Co}\left(\mathrm{NO}_{3}\right)_{2} \cdot 6 \mathrm{H}_{2} \mathrm{O}-0.025 \mathrm{~g}\right)$. After adding the six stock solutions and $1 \mathrm{~mL}$ of Deionized water (DI water), $35 \mathrm{~g}$ of marine salt water and $1.5 \mathrm{~g}$ of sodium nitrate 
$\left(\mathrm{NaNO}_{3}\right)$ were added. This solution was then stirred to make it homogenous. After verifying the marine medium was at $8 \mathrm{pH}$, the medium was autoclaved.

All of the medium was transferred into $125 \mathrm{~mL}$ flasks. Isolate culture was then added into every flask. The microalgae were incubated with New Brunswick Scientific Excella E24 Incubator Shaker Series at $25^{\circ} \mathrm{C}$ degrees under continuous lighting of $50 \mu \mathrm{mol}$ of photons $\mathrm{m}^{-2} \mathrm{~s}^{-1}$ for with and continuous shaking of $155 \mathrm{rpm}$ for a week or more (Figure 10).

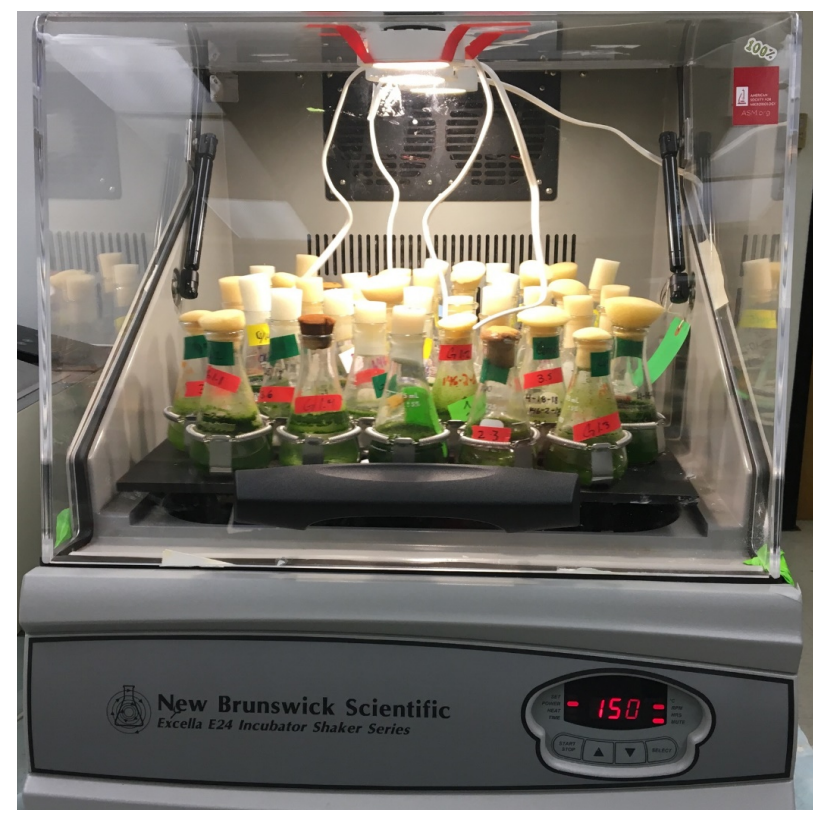

Figure 10: The incubator used to grow the microalgae.

\subsection{Microplate Experiment}

\subsubsection{Stock solution}

ZnO Bulk (Sigma-Aldrich Zinc Oxide) and ZnO Nano Zinc oxide (Sigma-Aldrich nanoparticles, $<100 \mathrm{~nm}$ particle size), stock solutions were used in the experiments. For the Bulk stock solution, the concentrations were: $0.125 \mathrm{ppm}, 0.25 \mathrm{ppm}, 0.5 \mathrm{ppm}, 1 \mathrm{ppm}$, $2.5 \mathrm{ppm}, 5 \mathrm{ppm}, 7.5 \mathrm{ppm}, 10 \mathrm{ppm}$, and 20ppm. 
For the preparation of bulk zinc oxide stock solution for low $\mathrm{Zn}$ concentration treatments (0.125 ppm, $0.25 \mathrm{ppm}, 0.5 \mathrm{ppm}$, and $1 \mathrm{ppm})$, a solution of $4.669 \mathrm{mg}$ Bulk $\mathrm{ZnO}$ and $20 \mathrm{~mL}$ DI water was made. Then, $3 \mathrm{~mL}$ of this solution was combined with $27 \mathrm{~mL}$ of BG11 medium without zinc $\left(\mathrm{ZnSO}_{4} \cdot 7 \mathrm{H}_{2} \mathrm{O}-0.111 \mathrm{~g}\right)$ to create $0.0155 \mathrm{mg} \mathrm{Zn} / \mathrm{mL}$. Using a pipette $1 \mathrm{~mL}$ of the previous solution and $99 \mathrm{~mL}$ BG-11 Media without zinc were combined, creating the $0.125 \mathrm{ppm}$ bulk $\mathrm{Zn}$ stock solution. For the $0.25 \mathrm{ppm} \mathrm{Zn} \mathrm{bulk}$ solution, $2 \mathrm{~mL}$ of the of solution of $4.669 \mathrm{mg}$ Bulk $\mathrm{ZnO}$ and $20 \mathrm{~mL}$ DI solution was pipetted and combined with $98 \mathrm{~mL} \mathrm{BG}-11$ Media without zinc. For the $0.5 \mathrm{ppm}$ bulk $\mathrm{Zn}$ stock solution, $4 \mathrm{~mL}$ of the pervious solutions was pipetted and combined with $96 \mathrm{~mL}$ BG-11 Media without zinc. Finally, for the bulk zinc oxide stock solution of $1 \mathrm{ppm}, 8 \mathrm{~mL}$ Zn was pipetted and combined with $92 \mathrm{~mL} \mathrm{BG-11} \mathrm{Media} \mathrm{without} \mathrm{zinc.} \mathrm{All} \mathrm{of} \mathrm{the} \mathrm{stock}$ solutions were then put into individual flasks and autoclaved. For the stock solution of $2.5 \mathrm{ppm} \mathrm{Zn}, 5 \mathrm{ppm} \mathrm{Zn}, 7.5 \mathrm{ppm} \mathrm{Zn}$, and $10 \mathrm{ppm} \mathrm{Zn}$, another solution was created. First, a solution of $3.11 \mathrm{mg} \mathrm{ZnO/mL} 62.20 \mathrm{mg}$ bulk $\mathrm{ZnO}$ was added to $20 \mathrm{~mL}$ DI Water. Using a pipette, $2 \mathrm{~mL}$ of the previous solution and $18 \mathrm{~mL}$ DI Water was combined to create a stock solution of $0.311 \mathrm{mg} \mathrm{ZnO/mL}$. Next, four flasks were used for the $2.5 \mathrm{ppm} \mathrm{Zn,} 5$ ppm Zn, $7.5 \mathrm{ppm} \mathrm{Zn,} \mathrm{and} 10 \mathrm{ppm} \mathrm{Zn}$ bulk stock solutions. For the $2.5 \mathrm{ppm} \mathrm{Zn,} 1 \mathrm{~mL}$ of the previous solution was pipetted and combined with $99 \mathrm{~mL}$ BG-11 Media without zinc. For the $5 \mathrm{ppm} \mathrm{Zn}$ bulk solution, $2 \mathrm{~mL}$ of the pervious solution was pipetted and combined with add $98 \mathrm{~mL}$ BG-11 Media without zinc. For the $7.5 \mathrm{ppm} \mathrm{Zn}$ bulk solution, $3 \mathrm{~mL}$ of the previous solution was pipetted and combined with $97 \mathrm{~mL}$ BG-11 Media without zinc. For the $10 \mathrm{ppm} \mathrm{Zn}$ bulk solution, $4 \mathrm{~mL}$ of the previous solution was pipetted and combined with $96 \mathrm{~mL}$ BG-11 Media without zinc. Finally, for the $20 \mathrm{ppm}$ 
$\mathrm{Zn}$ bulk solution, $8 \mathrm{~mL}$ of the previous solution was pipetted and combined with $92 \mathrm{~mL}$ BG-11 Media without zinc. All of the flasks were then autoclaved.

For nano stock solution, similar steps were followed except for the two additional steps, the use of a surfactant Igepal CA630 and sonication to prevent aggregation of nano particles. To prepare the Igepal solution, $.734 \mathrm{~mL}$ Igepal was pipetted into 1L DI water. This solution is called IgM solution. From the IgM solution two other solutions were made: the IgA was done by pipetting $1 \mathrm{~mL}$ of IgM and adding $9 \mathrm{~mL}$ DI Water and the IgB was done by pipetting $1 \mathrm{~mL}$ of IgM and adding $99 \mathrm{~mL}$ DI Water. After creating the $\operatorname{IgM}$, IgB and IgA solutions, the nano stock solution made. First, $4.669 \mathrm{mg}$ Nano size $10 \mathrm{~nm} \mathrm{ZnO}$ was mixed with $18 \mathrm{~mL}$ DI Water to create a stock solution. This solution was sonicated for 30 minutes to keep the nanoparticles separated. After the solution was sonicated, $2 \mathrm{~mL}$ of IgA solution was added. Using a pipette, $2 \mathrm{~mL}$ of the sonicate solution was added to $18 \mathrm{~mL} \operatorname{IgB}$ solution $(0.155 \mathrm{mg} \mathrm{ZnO} / \mathrm{mL})$. Out of this solution, four stock solutions were made: $.125 \mathrm{ppm} \mathrm{Zn}, 0.25 \mathrm{ppm} \mathrm{Zn}, 0.5 \mathrm{ppm} \mathrm{Zn}$, and $1 \mathrm{ppm}$. For the $125 \mathrm{ppm} \mathrm{Zn}$ nano solution, $1 \mathrm{~mL}$ of the previous solution was pipetted and combined with 98 BG-11 Media without zinc and $1 \mathrm{~mL}$ IgM solution. For the $0.25 \mathrm{ppm}$ Zn nano solution, $2 \mathrm{~mL}$ of the previous solution was pipetted and combined with 97 BG-11 Media without zinc and $1 \mathrm{~mL}$ IgM solution. For the $0.5 \mathrm{ppm} \mathrm{Zn}$ nano solution, $4 \mathrm{~mL}$ of the previous solution was pipetted and combined with 95 Medium BG-11 Media Zinc and 1 $\mathrm{mL}$ IgM. Finally, for the $1 \mathrm{ppm} \mathrm{Zn}$ nano solution, $8 \mathrm{~mL}$ of the previous solution was pipetted and combined with $91 \mathrm{~mL}$ Medium BG-11 Media Zinc and $1 \mathrm{~mL}$ IgM. All of the stock solutions were then autoclaved. The next set of nano stock solutions were 2.5 ppm Zn, 5 ppm Zn, 7.5 ppm Zn, 10 ppm Zn, and 20ppm Zn. First, 62.20 mg Nano ZnO was mixed in $18 \mathrm{~mL}$ DI Water. This solution was sonicating for 30 minutes to keep the 
nanoparticles separated. After the solution was sonicated $2 \mathrm{~mL}$ of IgA solution was added. Using a pipette, $2 \mathrm{~mL}$ of the pervious solution was combined with $18 \mathrm{~mL} \mathrm{IgB}$ solution to create $0.155 \mathrm{mg} \mathrm{ZnO} / \mathrm{mL}$. For the $2.5 \mathrm{ppm} \mathrm{Zn}$ nano solution, $1 \mathrm{~mL}$ of the previous solution was pipetted and combined with 98 BG-11 Media without zinc and $1 \mathrm{~mL}$ IgM solution. For the $5 \mathrm{ppm} \mathrm{Zn}$ nano solution, $2 \mathrm{~mL}$ of the previous solution was pipetted and combined with 97 BG-11 Media without zinc and 1mL IgM solution. For the $7 \mathrm{ppm} \mathrm{Zn}$ nano solution, $3 \mathrm{~mL}$ of the previous solution was pipetted and combined with 96 Medium BG-11 Media Zinc and 1mL IgM. For the 10 ppm Zn nano solution, 4 $\mathrm{mL}$ of the previous solution was pipetted and combined with $95 \mathrm{~mL}$ Medium BG-11 Media Zinc and $1 \mathrm{~mL}$ IgM. Finally, for the $20 \mathrm{ppm} \mathrm{Zn}$ nano solution, $8 \mathrm{~mL}$ of the previous solution was pipetted and combined with $91 \mathrm{~mL}$ Medium BG-11 Media Zinc and $1 \mathrm{~mL}$ IgM. All of the stock solutions were then autoclaved.

The last stock solution was high concentration of zinc ( $\mathrm{ZnSO} 4$ x $7 \mathrm{H} 2 \mathrm{O})$. Measure $65.97 \mathrm{mg} \mathrm{ZnSO} 4$ x $7 \mathrm{H} 2 \mathrm{O}$ and add $10 \mathrm{~mL}$ DW. Pipette $1 \mathrm{~mL}$ and add $9 \mathrm{~mL}$ DW (6.597 mg ZnSO4 x $7 \mathrm{H} 2 \mathrm{O} / \mathrm{mL})$. Out of this pippete $1 \mathrm{~mL}$ and add $99 \mathrm{~mL}$ BG-11 no $\mathrm{Zn}$ (0.6597 mg ZnSO4 x 7 H2O /mL). Finally autoclave.

All of the stock solutions were used for both the microplate experiment and flask experiments.

\subsubsection{Exposure to Low Zn Concentrations}

The microplate reader Synergy ${ }^{\mathrm{TM}}$ HT was use with the Falcon ${ }^{\mathrm{TM}}$ Polystyrene Microplates (Figure 3) of 24 wells was used for all of the bulk microplate experiments (Figure 4); the same format was used in all experiments. The lower concentrations (0.125 ppm Zn, 0.25 ppm Zn, 0.5 ppm Zn, and $1 \mathrm{ppm}$ ) for bulk and NPs were arranged as shown in Figure 3 (Figure 3). The blank concentration contained $3 \mathrm{~mL}$ of BG-11 media 
with micro-element $\mathrm{Zn}$. The control contained $2 \mathrm{~mL}$ of BG-11 media with micro-element $\mathrm{Zn}$ and $1 \mathrm{~mL}$ of the selected algae. The lower concentrations were then prepared as follows: 1) $2 \mathrm{~mL}$ stock solution $0.125 \mathrm{ppm} \mathrm{Zn}$ (NPs or bulk particle) was combined with $1 \mathrm{~mL}$ of the selected algae, 2) $2 \mathrm{~mL}$ stock solution $0.25 \mathrm{ppm} \mathrm{Zn}$ (NPs or bulk particle) was combined with $1 \mathrm{~mL}$ of the selected algae, 3) $2 \mathrm{~mL}$ stock solution $0.5 \mathrm{ppm} \mathrm{Zn}$ (NPs or bulk particle) was combined with $1 \mathrm{~mL}$ of the selected algae, 4) $2 \mathrm{~mL}$ stock solution 1 ppm Zn (NPs or bulk particle) was combined with $1 \mathrm{~mL}$ of the selected algae. The vertical lines are the different algae used, from green micro algae to cyanobacteria. Five 24-well plates were used for bulk particles and five 24-well plates for NPs. The plates were then incubated at $25^{\circ} \mathrm{C}$ degrees under continuous lighting of $50 \mu \mathrm{mol}$ of photons $\mathrm{m}^{-}$ ${ }^{2} \mathrm{~s}^{-1} \mathrm{f}$ for one week. Algal growth was assessed by using a microplate reader at 600 on days $0,1,2,3,4,5,6$, and 7 . To avoid contamination of the original 24-well plate, a minimal quantity of culture samples was transferred to a 24 -well plate under sterile conditions during each observation period and the OD recording was made using Biotek $^{\mathrm{TM}}$ plate reader (Figure 11).

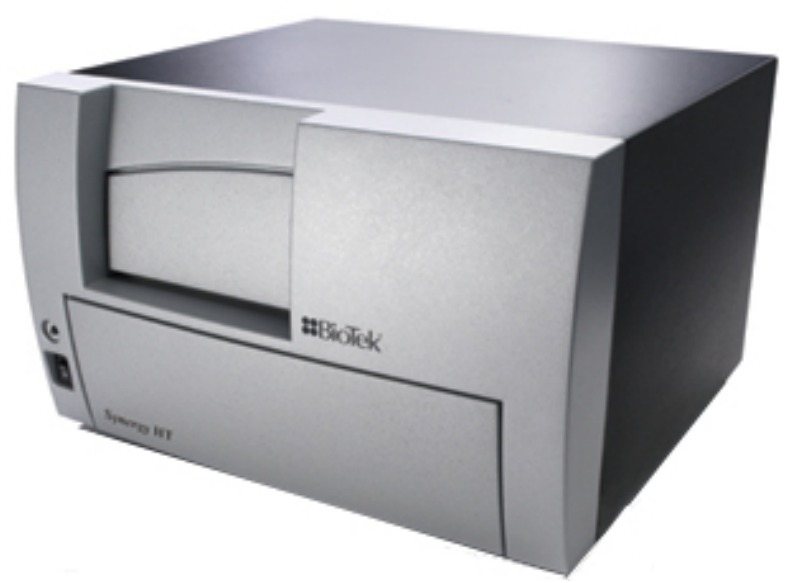

Figure 11: The Biotek ${ }^{\mathrm{TM}}$ microplate reader. 


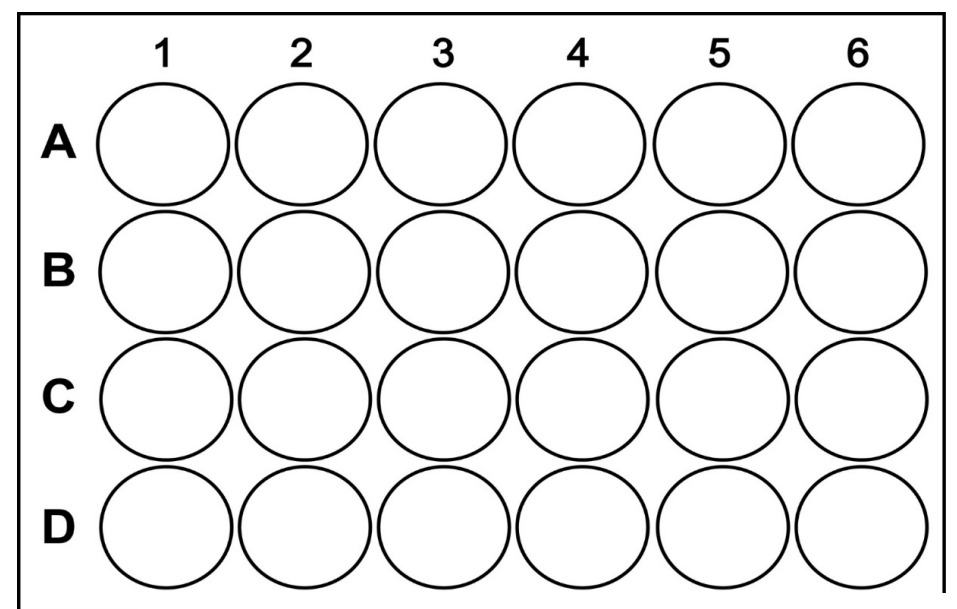

Fig 12: The 24-well microplate

\subsubsection{Exposure to High Zn Concentrations}

The higher concentrations (2.5 ppm Zn, 5 ppm Zn, 7.5 ppm Zn, and 10 ppm Zn) for bulk and NPs were also arranged as shown in Figure 3. The blank concentration contained $3 \mathrm{~mL}$ of BG-11 media with micro-element $\mathrm{Zn}$. The control contained $2 \mathrm{~mL}$ of BG-11 media with micro-element $\mathrm{Zn}$ and $1 \mathrm{~mL}$ of the selected algae. The higher concentrations were then prepared as follows: 1) $2 \mathrm{ml}$ stock solution $2.5 \mathrm{ppm} \mathrm{Zn} \mathrm{(NPs} \mathrm{or}$ bulk particle) and $1 \mathrm{~mL}$ of the selected algae, 2) $2 \mathrm{ml}$ stock solution $5 \mathrm{ppm} \mathrm{Zn}$ (NPs or bulk particle) was combined with $1 \mathrm{~mL}$ of the selected algae, 3) $2 \mathrm{ml}$ stock solution 7.5 ppm Zn (NPs or bulk particle) was combined with $1 \mathrm{~mL}$ of the selected algae, 4) $2 \mathrm{ml}$ stock solution $1 \mathrm{ppm} \mathrm{Zn}$ (NPs or bulk particle) was combined with $1 \mathrm{~mL}$ of the selected algae. The vertical lines are the different algae used, from green micro algae to cyanobacteria. Five 24-well plates (Figure4) were used for each experiment representing the 5 replicas. The plates were then incubated at $25^{\circ} \mathrm{C}$ degrees under continuous lighting of $50 \mu \mathrm{mol}$ of photons $\mathrm{m}^{-2} \mathrm{~s}^{-1} \mathrm{f}$ for one week. Algal growth was assessed by using a microplate reader at 600 on days $0,1,2,3,4,5,6$, and 7 . To avoid contamination of the original 24-well plate, a minimal quantity of culture samples was transferred to a 24 -well 
plate under sterile conditions during each observation period and the OD recording was made using Biotek plate reader.

A final higher concentration was done for the green microalgae with $10 \mathrm{ppm} \mathrm{Zn}$ and $20 \mathrm{ppm} \mathrm{Zn}$ (NPs and bulk particles). The selected algae for the higher concentration were: Algae 1: Chlorococcum sp. 146-2-6, Algae 2: Chlamydomonas sp. 146-2-10, Algae 3: Chlorella sp. 146-2-16, and Algae 4: Nannochloris sp. 146-2. The blank concentration contained $3 \mathrm{~mL}$ of BG-11 media with micro-element $\mathrm{Zn}$. The control contained $2 \mathrm{~mL}$ of BG-11 media with micro-element $\mathrm{Zn}$ and $1 \mathrm{~mL}$ of the selected algae. The higher concentrations for the green microalgae were then prepared as follows: 1) $2 \mathrm{ml}$ stock solution $10 \mathrm{ppm} \mathrm{Zn}$ bulk particle and $1 \mathrm{~mL}$ of the selected algae, 2) $2 \mathrm{~mL}$ stock solution $20 \mathrm{ppm} \mathrm{Zn}$ bulk particle and $1 \mathrm{~mL}$ of the selected algae, 3) $2 \mathrm{~mL}$ stock solution $10 \mathrm{ppm}$ Zn NPs and $1 \mathrm{~mL}$ of the selected algae, 4) $2 \mathrm{~mL}$ stock solution $20 \mathrm{ppm} \mathrm{Zn} \mathrm{NPs} \mathrm{and} 1 \mathrm{~mL}$ of the selected algae. Five 24-well plates were used for each experiment representing the 5 replicas. The plates will then be incubated at $25^{\circ} \mathrm{C}$ degrees under continuous lighting of $50 \mu \mathrm{mol}$ of photons $\mathrm{m}^{-2} \mathrm{~s}^{-1} \mathrm{f}$ for one week. Algal growth will be assessed by using a microplate reader at 600 on days $0,1,2,3,4,5,6$, and 7 . To avoid contamination of the original 24-well plate, a minimal quantity of culture samples was transferred to a 24 -well plate under sterile conditions during each observation period and the OD recording was made using Biotek plate reader.

\subsubsection{Exposure to Low Zn Concentrations with Additional Zn Source}

This experiment was similar to the low concentration but with an extra well containing ZnSO4 (ZnSO4, 0.125 ppm Zn, 0.25 ppm Zn, 0.5 ppm Zn, and 1 ppm Zn) in addition to bulk and NPs were arranged as shown in Figure 3. It is important to note that this experiment was done with only four cynobacteria (Limnothrix sp., Leptolyngbya sp., 
Lyngbya 1 sp., and Lyngbya 2 sp.). The control contained 2 mL of BG-11 media with micro-element $\mathrm{Zn}$ and $1 \mathrm{~mL}$ of the selected algae. The extra zinc contained $2 \mathrm{~mL}$ stock solution ZnSO4. The $0.125 \mathrm{ppm} \mathrm{Zn}$ contained $2 \mathrm{~mL}$ stock solution (NPs or bulk particle) was combined with $1 \mathrm{~mL}$ of the selected algae. The $0.25 \mathrm{ppm} \mathrm{Zn}$ contained $2 \mathrm{~mL}$ stock solution (NPs or bulk particle) was combined with $1 \mathrm{~mL}$ of the selected algae. The 0.5 ppm $\mathrm{Zn}$ contained $2 \mathrm{~mL}$ stock solution (NPs or bulk particle) was combined with $1 \mathrm{~mL}$ of the selected algae. The $1 \mathrm{ppm} \mathrm{Zn}$ contained $2 \mathrm{~mL}$ stock solution (NPs or bulk particle) was combined with $1 \mathrm{~mL}$ of the selected algae. The vertical lines are the different algae used, from green micro algae to cyanobacteria. Five 24-well plates were used for bulk particles and five 24 -well plates for NPs. The plates were then incubated at $25^{\circ} \mathrm{C}$ degrees under continuous lighting of $50 \mu \mathrm{mol}$ of photons $\mathrm{m}^{-2} \mathrm{~s}^{-1} \mathrm{f}$ for one week. Algal growth was assessed by using a microplate reader at 600 on days $0,1,2,3,4,5,6$, and 7 . To avoid contamination of the original 24-well plate, a minimal quantity of culture samples was transferred to a 24-well plate under sterile conditions during each observation period and the OD recording was made using Biotek ${ }^{\mathrm{TM}}$ plate reader. 


\subsubsection{Optical icroscope}

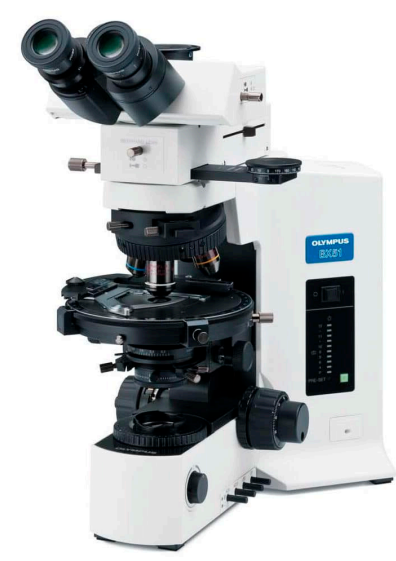

Figure 13: Olympus ${ }^{\mathrm{TM}}$ BX51 research microscope.
Light microscope observations of algal samples under different magnifications $(20 \mathrm{x}-$ 100x) were carried out using an Olympus BX51 microscope equipped with Olympus DP70 digital camera and associated software (DP Controller and DP Manager).

\subsubsection{Statistical Analysis}

The data collected will be tested for statistical significance using two-way mixed (ANOVA), taking the level of $\mathrm{P}<0.05$ as significance according to Tukey multiple comparison test. The within factor being the days $(0,2,5,7)$ and the between-subjects factors the treatments. The codification for low concentration experiment treatments $\mathrm{s}$ was as follow: B1: 0.125ppm Bulk ZnO, B2: 0.25 ppm Bulk ZnO, B3 0.5 ppm: Bulk ZnO, B4: 1 ppm Bulk ZnO, N1: 0.125ppm NPs ZnO, N2: 0.25 ppm NPs ZnO, N3: 0.5 ppm NPs ZnO, N4: 1 ppm NPs ZnO and control. Cyno 1: Limnothrix sp.; Cyno 2: Leptolyngbya sp., Cyno 3: Lyngbya 1 sp., Cyno 4: Lyngbya 2 sp. (Bpm 173F), Cyno 4: Oscillatoria sp. Cyno5: Porphoridium sp. Cyno 6: Roseofilum sp. Cyno 7: Nannochloris sp.; Green 1: Chlorococcum sp., Green 2: Chlamydomonas and Green 3: Chlorella $s p$. The codification for higher concentration experiment treatments $\mathrm{s}$ was as follow: B1: 2.5 ppm Bulk ZnO, B2: 5 ppm Bulk ZnO, B3 7 ppm: Bulk ZnO, B4: 10 ppm Bulk ZnO, N1: 2.5ppm NPs ZnO, N2: 5 ppm NPs ZnO, N3: 7 ppm NPs ZnO, N4: 10 ppm NPs ZnO and control. Finally the codification for the higher $\mathrm{Zn}$ Concentration was: 
B1: 0.125ppm Bulk ZnO, B2: 0.25 ppm Bulk ZnO, B3 0.5 ppm: Bulk ZnO, B4: 1 ppm Bulk ZnO, N1: 0.125ppm NPs ZnO, N2: 0.25 ppm NPs ZnO, N3: 0.5 ppm NPs ZnO, N4: 1 ppm NPs ZnO, control, C2: Higher Zn concentration.

Before running the ANOVA eight assumption had to be met to be able to run the test. Assumption \#1: one dependent variable that is measured at the continuous level. Assumption \#2: one between-subjects' factor that is categorical with two or more categories. Assumption \#3: one within-subjects' factor that is categorical with two or more categories. Assumption \#4: There should be no significant outliers in any cell of the design (Boxplots). Assumption \#5: dependent variable should be approximately normally distributed for each cell of the design (Test normality). Assumption \#6: The variance of dependent variable should be equal between the groups of the betweensubjects' factor (Levene's test for equality of variances). Assumption \#7: There should be homogeneity of covariance (Box's test of equality of covariance matrices). Assumption \#8: The variance of the differences between groups should be equal (Mauchly's test of sphericity). After the assumption was met, procedure for a significant interaction can be done and finally reporting. All statistical analyses were performed using the 22.0 SPSS software package for Windows (SPSS Inc., IL, USA).

\subsection{Flask Experiment}

\subsubsection{Stock Solution}

For the bulk stock solution, $62.20 \mathrm{mg} \mathrm{ZnO}$ bulk particles were added to $20 \mathrm{~mL}$ DI water (3.11 $\mathrm{mg} \mathrm{ZnO} / \mathrm{mL}$ ). Using a pipette, $2 \mathrm{~mL}$ of the previous solution was combined 
with $18 \mathrm{~mL}$ DI water $(0.311 \mathrm{mg} \mathrm{ZnO} / \mathrm{mL})$. Three flasks where then filled with $4 \mathrm{~mL}$ of the previous solution and $96 \mathrm{~mL}$ BG-11 media (10 ppm Zn) bulk particles. Each of the three flasks where then divided in half to create a total of 6 flask with $50 \mathrm{~mL}$ of solution (Figure 14).

Stock Solution Bulk Zno

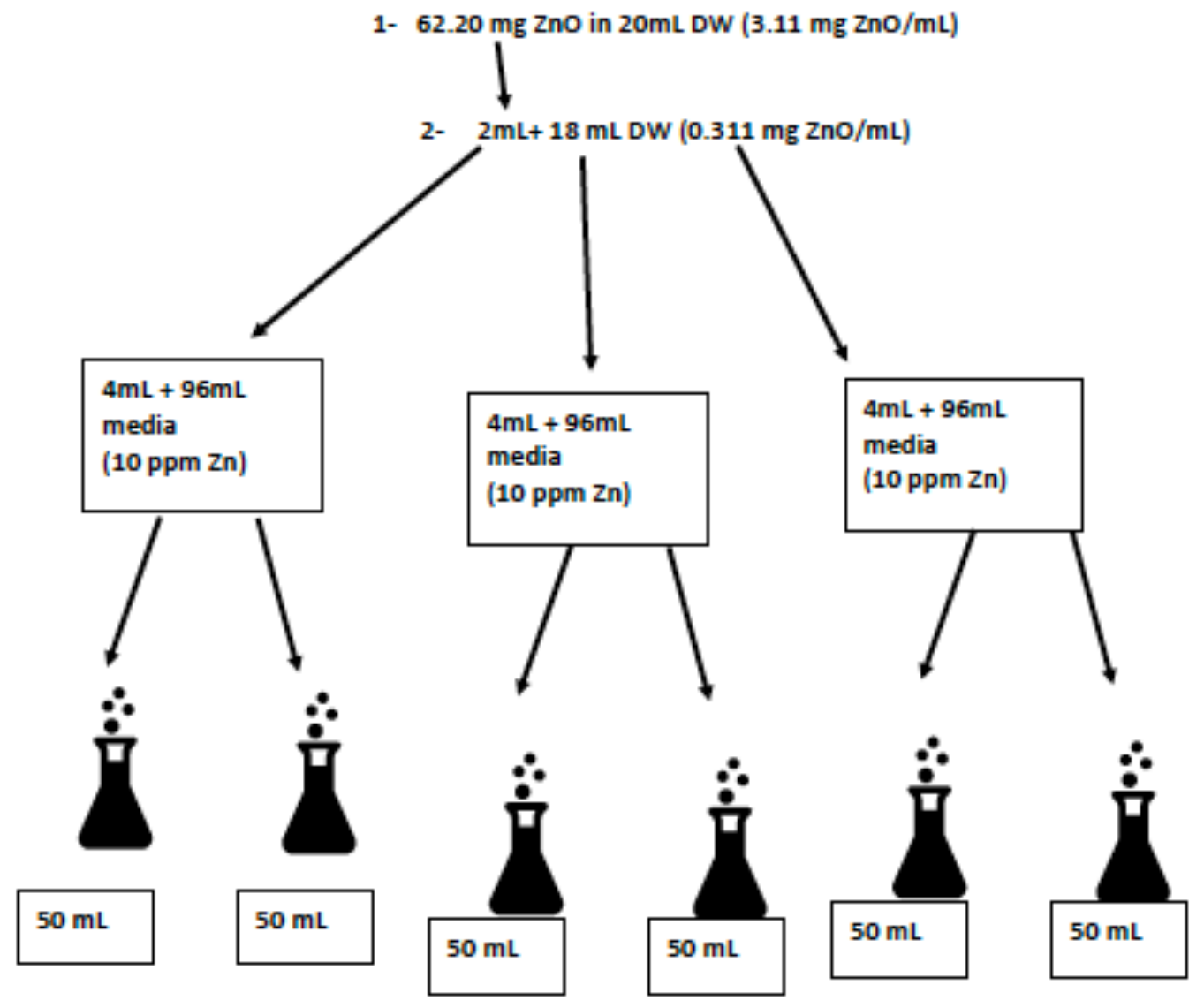

Figure 14: Bulk stock solution. 


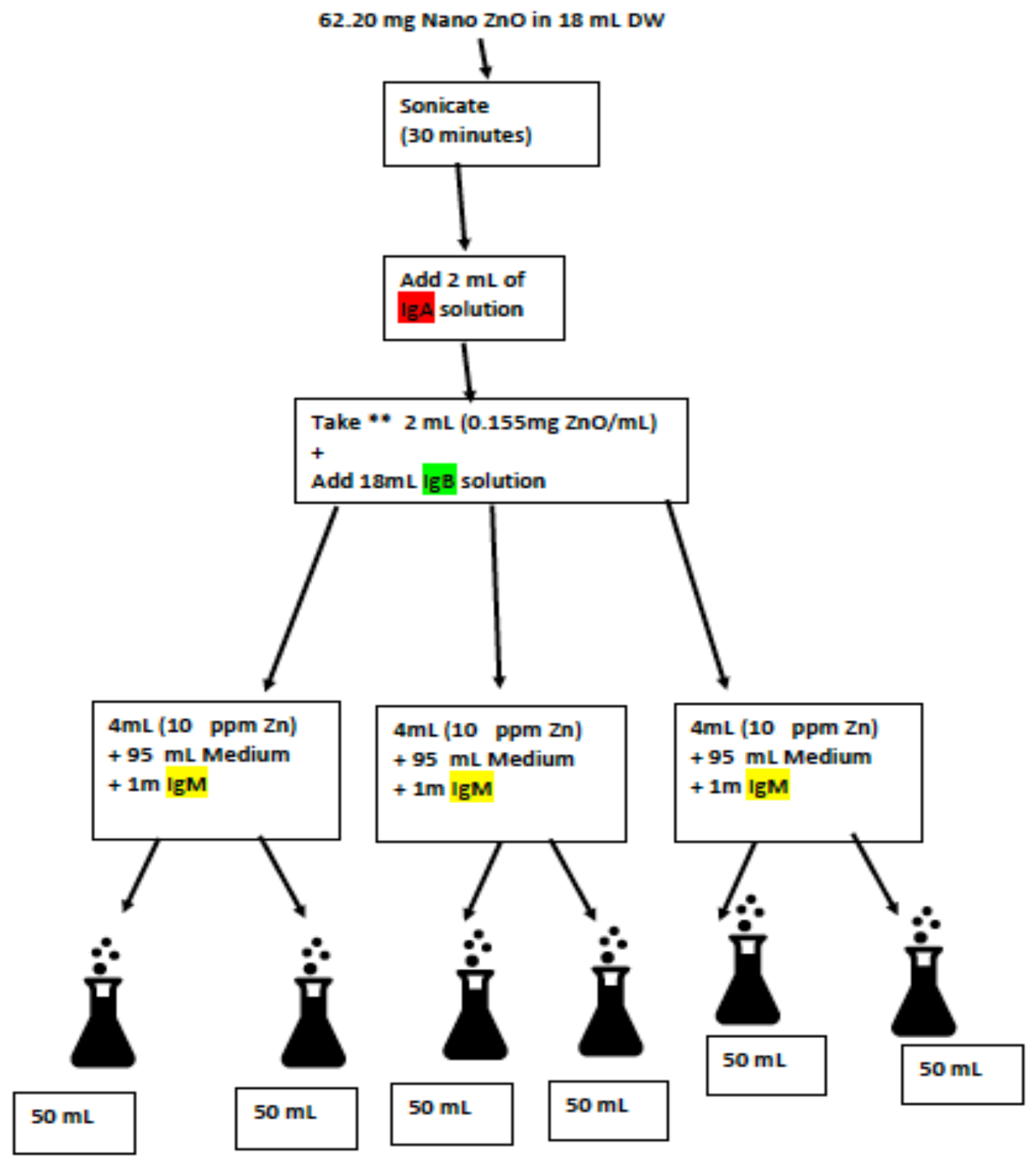

Figure 15: Nano stock solution. 
For the nano stock solution, $62.20 \mathrm{mg} \mathrm{ZnO}$ nano articles were added to $18 \mathrm{~mL} \mathrm{DI}$ water. Sonicate the sample for 30 minutes and add $2 \mathrm{~mL}$ of $\operatorname{IgA}$ solution. Using a pipette, $2 \mathrm{~mL}$ of the previous solution was combined with $18 \mathrm{~mL}$ IgB solution. Three flasks where then filled with $4 \mathrm{~mL}$ of the previous solution and $95 \mathrm{~mL}$ BG-11 media with no $\mathrm{Zn}(10 \mathrm{ppm} \mathrm{Zn})$ bulk particles and add $1 \mathrm{~mL}$ of IgM. Each of the three flasks where then divided in half to create a total of 6 flasks with $50 \mathrm{~mL}$ of solution (Figure 15).

\subsubsection{Cell Counting Chamber}

Before preparing the algal inoculum, cell count in each culture was measured using the cell counting chamber (Neubauer Hemocytometer). The algae used were three green microalgae Chlorococcum sp., Chlamydomonas sp. and Chlorella sp. The glass hemocytometer was cleaned with alcohol before use. The samples were prepared by pipetting $1 \mathrm{~mL}$ of algae to an Eppendorf ${ }^{\mathrm{TM}}$ then exposing it to the vortex for a minute. One $\mathrm{mL}$ of algae was gently added to fill both chambers underneath the coverslip, allowing cell suspension to be drawn out by capillary action. A microscope was used to focus on the grid lines of the hemocytometer with a 10X objective. The number of algae cells were counted in all four outer squares and divided by four (the mean number of cells/square). The number of cells per square $\times 10^{4}=$ the number of cells $/ \mathrm{ml}$ of suspension (Figure 16). After, the hemocytometer and cover slip were sprayed with $70 \%$ ethanol to kill the cells. Both were then washed with deionized water, wiped dry with a Kimwipe $^{\mathrm{TM}}$, wrapped in a clean Kimwipe ${ }^{\mathrm{TM}}$ and returned to the storage box (Privalsky, 2018). 


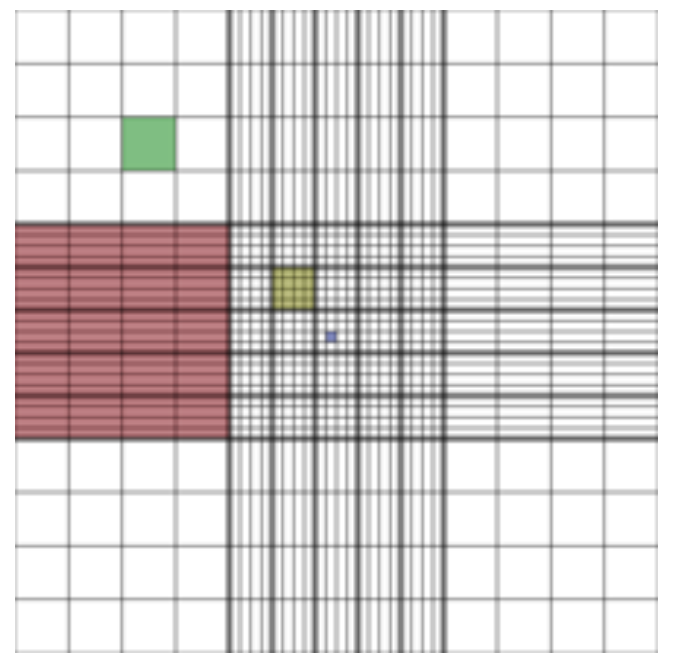

Figure 16: Hemocytometer.

\subsubsection{Chlorophyll Measurements}

After 7 days, the chlorophyll was measured. Using a pipette, $1 \mathrm{~mL}$ of the algae sample was transferred to the Eppendorf ${ }^{\mathrm{TM}}$. The sample was then centrifuged, and the excess water removed. Then, $1 \mathrm{~mL}$ of $95 \%$ methanol was added, and this solution was stored for 24 hours with no light. After 24 hours, the solution was transferred to a cuvette. The absorbance read $600 \mathrm{~nm} / 652.4$ (chlorophyll a) / 665.2 (chlorophyll b) (Ritchie, 2006; Lichtenthaler \& Buschmann, 2001).

\subsubsection{Absorbance Measurements}

After 7 days, the relative amount of biomass cased on chlorophyll was measure. By pipetting $3 \mathrm{~mL}$ of the samples were pipetted into the 24-well plates and placed in the microplate reader at $600 \mathrm{~nm}$ (Ritchie, 2006).

\subsubsection{Optical Microscope}

The two green microalgae that were and were not exposed to the bulk and nano treatments were observe under the Olympus BX51 ${ }^{\mathrm{TM}}$ research microscope under different 
magnifications $(20 \mathrm{x}-100 \mathrm{x})$. This was done by doing slides of each of the algae with and without treatments.

\subsubsection{Scanning Electron Microscope (SEM)}

Throughout this process, pictures were taken under a light microscope. The Scanning Electron Microcopies (SEM) was also used with the cell fixation procedure, dehydration using increasing concentration of ethanol, critical point drying, mounting on the stub, sputter coating and finally processing the sample (Figure 9) (Hughes, 2011).

Preparation of the round slides. Pipetted $1 \mathrm{~mL}$ of polylysine on to microscope glass cover slides, wait until it dries. The cell fixation procedure began with the centrifuge of the samples. Then, add $2 \%$ glutaraldehyde in $0.1 \% \mathrm{Na}$ cacodylate. After an hour, the sample was centrifuged again. After this add $1 \mathrm{~mL}$ medium non-Zn for bulk and Nano and medium with $\mathrm{Zn}$ for the control. After this, it was shaken well and centrifuged again.

Mount the sample with medium to the round slide wait 15 minutes. Then, start dehydration using increasing concentration of ethanol was used $(40 \%, 50 \%, 80 \%$, and $100 \%$ ethanol). After applying the $100 \%$ ethanol put at the fridge.

The critical point drying was done with Samdri-PVT-3D ${ }^{\text {TM }}$. This method is used to preserve the morphology of the algae using $\mathrm{CO}_{2}$ at very high pressure (Ruwin, 2012). The first step using the Samdri-PVT-3D ${ }^{\text {TM: }}$ Turn on the power and then wait 3 minutes for the equipment to warm up. Make sure all metering valves are close. Second step open the main $\mathrm{LCO}_{2}$ tank valve. The third step pour high purity alcohol in the chamber to completely cover the samples before transfer. Transfer your samples into the chamber. For the fourth step open the cool calve to 0.50 positing and turn it off when temperature 0 ${ }^{\circ} \mathrm{C}$. The fifth step Fill Valve adjust by opening the fill metering valve to 0.50 and keep it 
open. The sixth step of Purge-vent valve adjust: slowly open the purge vent and place Erlenmeyer Flask at the end of the clear purge to collect waste alcohol. Close it when all the ethanol is exhausts. The seventh step close the fill metering valve when the meniscuses travel across the viewing window. The eighth step close all the valves and turn on the heat. Wait until it hit critical point at critical pressure for $\mathrm{CO}_{2}(1,072 \mathrm{psi})$ and critical temperature $31^{\circ} \mathrm{C}$. Then wait 4 minutes. The ninth steps start after the 4 minutes pass, turn the bleed flow rate from 8-10 SCFH and close the bleed metering valve at 400 psi. The tenth step open the purge vent metering valve to 0.50 to reduce the chamber at 0 psi, the close. Finally, the eleventh step when the pressure reaches 0 psi, loosen 3 chamber nuts and remove your sample (Tousimis, 2018).

After the sample is critical dried, a sputter coating of gold ( $\mathrm{Au})$ was applied to the sample. (Sputter coating is the process of applying an ultra-thin coating of electricallyconducting metal onto a non-conducting or poorly conducting specimen.) This technique prevents charging of the algae, which would otherwise occur because of the accumulation of static electric fields. It also increases the number of secondary electrons that can be detected from the surface of the specimen in the SEM and, therefore increases the signal to noise ratio.

Sputtered films for SEM typically have a thickness range of 2-20 nm ("Brief Introduction to Coating Technology for Electron Microscopy", 2013).

For the Sputter Coating Procedure: First, Place samples in the chamber, make sure the chamber valve is closed and close the lid. The second step turn the power on and wait for it to pump down. The third step is to open the valves on the argon gas and Pump to below 2 Torr. Slowly bleed in the argon using the gas leak valve until the pump gets noisy then Wait 1 minute, fourth step back off the argon until 2 Torr is reached. Fifth step 
Press the test button and Press the start button. Then continually adjust the argon using the gas leak valve to keep the gauge at 18 mill amperes. The sixth step turn the power off, close the gas leak valve and open the chamber leak valve slightly until air can be heard entering the chamber. Remember to close the argon valve ("Electron Microscopy Sciences", 2018).

Finally, the sample was processed by introducing it to the SEM, capturing pictures and using Energy Dispersive X-Ray Spectroscopy (EDS) analysis. The SEM Loading Procedure starts with venting the instrument so that the door can be opened. Make sure the stage is at a lower position $(30 \mathrm{~mm})$ so that there is less risk of hitting the pole piece or backscatter detector. Once the instrument beeps, open the door and slide the sample holder into place. Slowly close the door to the SEM. Then, evacuate the chamber wait for the beep and for the "HT Ready" button to turn on. And click on "HT Ready" to turn on the beam. Then SEM is ready to be navigating (Robbins, 2015). For the EDS procedure just turn on the program and run the chemical analysis.

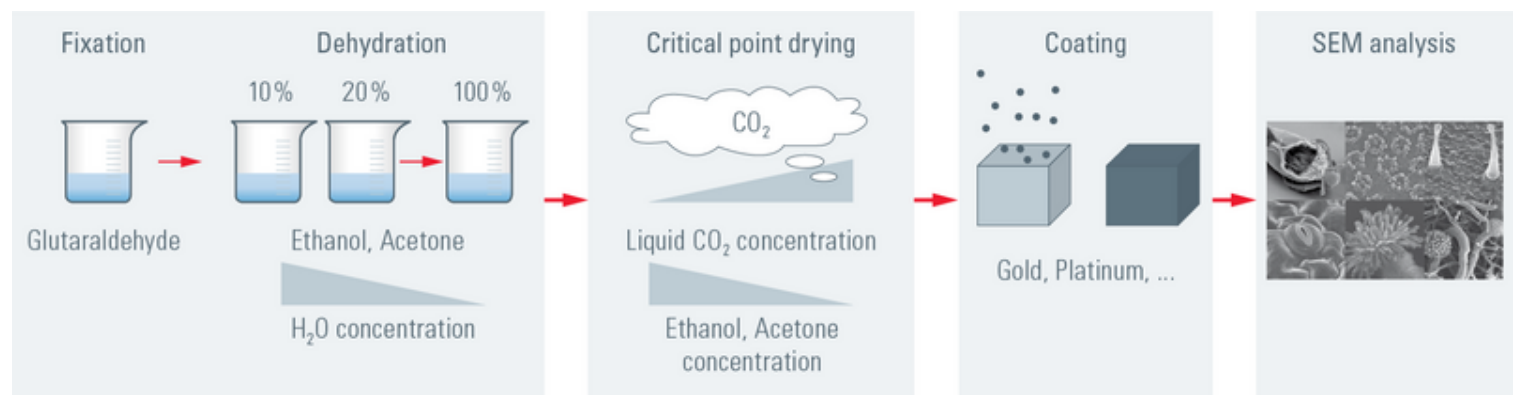

Figure 17: Preparation of the algae sample.

\subsubsection{Statistical Analysis}

The data collected was tested for statistical significance using two-way mixed (ANOVA), taking the level of $p<0.05$ as significance according to Tukey multiple 
comparison test. With the two-way mixed ANOVA is used to understand if there is an interaction between the days and treatments. The between-subjects factor are the treatments of different concentration of bulk and nano particles (B1, B2, B3, B4, N1, N2, N3, N4 and control) and one within-subjects factor being days ( 0 and 7). To analyze the data using a two-way mixed ANOVA we had check that the data can be analyze using this test.

The two-way mixed ANOVA has eight assumptions that you have to consider. Assumption \#1: Have one dependent variable that is measured at the continuous level (i.e. the interval or ratio level). Assumption \#2: Have one between-subjects factor that is categorical with two or more categories. Assumption \#3: Have one within-subjects factor that is categorical with two or more categories. Assumption \#4: There should be no significant outliers in any cell of the design. Assumption \#5: Dependent variable should be approximately normally distributed for each cell of the design. Assumption \#6: The variance of dependent variable should be equal between the groups of the betweensubjects factor. Assumption \#7: There should be homogeneity of covariances. Finally, Assumption \#8: The variance of the differences between groups should be equal ("We make statistics easy. The ultimate IBM® SPSS ${ }^{\circledR}$ Statistics guides."). All statistical analyses were performed using the 22.0 SPSS software package for Windows (SPSS Inc., IL, USA).

\subsection{Enrichment and Isolation of Microalgae Tolerant to High Nano-ZnO \\ Concentration}

\subsubsection{Location}

Ten sea water samples were collected at locations along the South Point Miami Beach, Florida $\left(25.7635^{\circ} \mathrm{N}, 80.1297^{\circ} \mathrm{W}\right)$. This site was selected because is one of 
the most popular beaches in Miami Beach, FL and it also next to the pier. This point is vulnerable to anthropogenic effect.

\subsubsection{Flask experiment}

For the 100ppm ZnO NPs Flask experiment 6.223 mg ZnO NPs, $0.1 \mathrm{~mL}$ $\mathrm{K}_{2} \mathrm{HPO}_{4}$ and $75 \mathrm{mg} \mathrm{NaNO} 3$ added to the $50 \mathrm{~mL}$ of the sample collected. The Erlenmeyer ${ }^{\mathrm{TM}}$ flask left in the incubator for a week with $25^{\circ} \mathrm{C}$ degrees under continuous lighting of $50 \mu \mathrm{mol}$ of photons $\mathrm{m}^{-2} \mathrm{~s}^{-1}$ for with and continuous shaking of $155 \mathrm{rpm}$. After a week optical microscope picture were collected.

\subsubsection{Optical Microscope}

Light microscope observations of algal samples were done using Olympus BX51 microscope. 


\section{Section 4: Results}

\subsection{Cyanobacteria - Exposure to Low Zn Concentrations}

The multi-well plate experimental results from low-level concentrations treatments $(0.125 \mathrm{ppm}, 0.25 \mathrm{ppm}, 0.5 \mathrm{ppm}$, and $1 \mathrm{ppm} \mathrm{Zn})$ are presented for four cyanobacteria: Limnothrix sp. (173-10-1), Leptolyngbya (146-5-2), Neolyngbya sp. (EK17-3A), and Oscillatoria sp. (bpm 173F). Results from studies on three additional cyanobacteria: Porphoridium sp. (173-10-2), i), Roseofilum sp. (101-1), j), and Nannochloris sp. (146-2-11) are also included.

\subsubsection{Optical Microscope}

After seven days of testing, the four cyanobacteria were observed in 100x magnification. For the Limnothrix sp., there was a considerable morphology change. The control was noted at retaining their bright green color. The bulk at $1 \mathrm{ppm} \mathrm{Zn}$ remained green, however was not observed as having as bright a coloring. The nano at $1 \mathrm{pm}$ had no pigmentation (Figure 18). In the trial, two Limnothrix sp. had similar results as for the first trial.
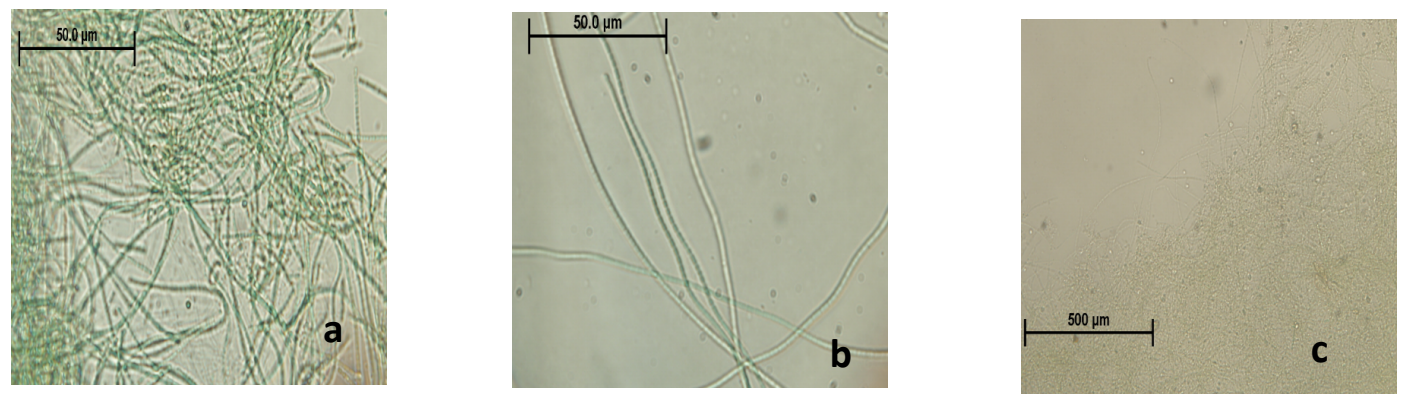

Figure 18: Limnothrix sp., in BG 11 media: a) standard $\mathrm{ZnSO}_{4}$ b) Bulk $\mathrm{ZnO}$ 1ppm c) Nano ZnO 1ppm. 
For the Leptolyngbya sp., there was a notable morphology change from control to nano, but not from control to bulk. The control retained their bright green color; the bulk at $1 \mathrm{ppm} \mathrm{Zn}$ was still green and the nano at $1 \mathrm{ppm}$ displayed no pigmentation (Figure 19). In trial 2, Leptolyngbya sp. had similar results as for trial 1.
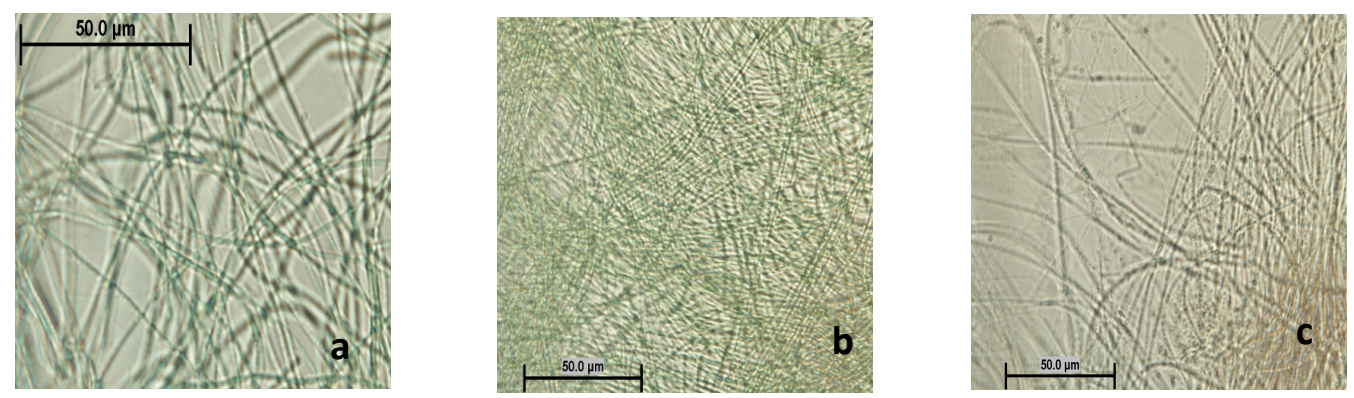

Figure 19: Leptolyngbya sp., in BG 11 media: a) standard $\mathrm{ZnSO}_{4}$ b) Bulk $\mathrm{ZnO} 1 \mathrm{ppm}$ c) Nano ZnO 1ppm.

For the Lyngbya 1 sp., there was a noted morphology change in color and shape. The control had a light green color; the bulk at $1 \mathrm{ppm}$ Zn was still green, but darker while the nano at $1 \mathrm{ppm}$ had change in color to brown. In trial 2, the Lyngbya $1 \mathrm{sp}$. had similar results as for the trial 1.
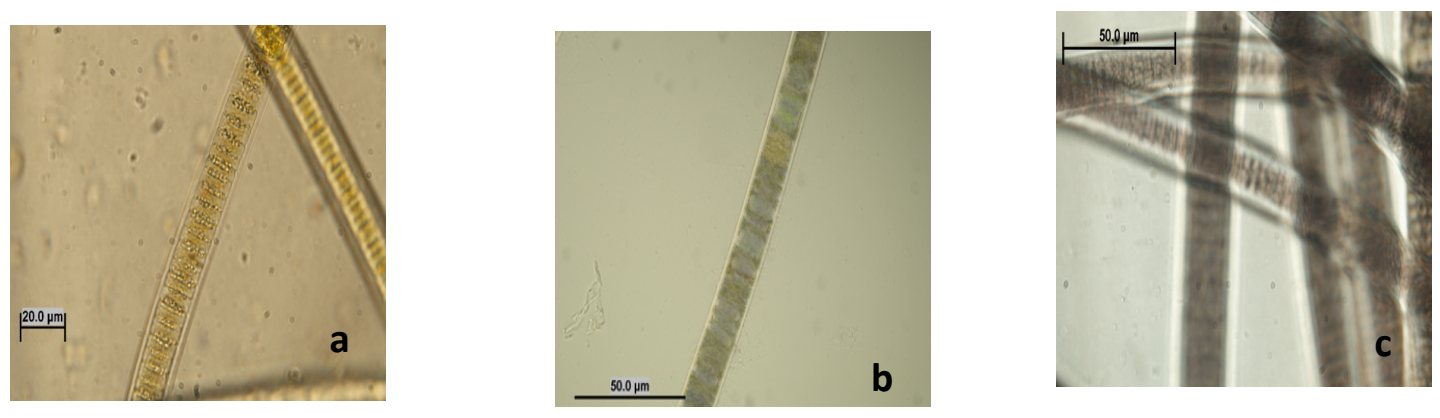

Figure 20: Lyngbya 1 sp., in BG 11 media: a) standard $\mathrm{ZnSO}_{4}$ b) Bulk $\mathrm{ZnO} 1$ ppm c) Nano $\mathrm{ZnO} 1 \mathrm{ppm}$. 
The Lyngbya 2 sp. had a morphology change in color. The control had a brownish green color, the bulk at $1 \mathrm{ppm} \mathrm{Zn}$ showed a brown purple hue, and the nano at 1 ppm underwent a change color to purple. In trial 2, Lyngbya $2 \mathrm{sp}$. had similar results as for the trial 1.
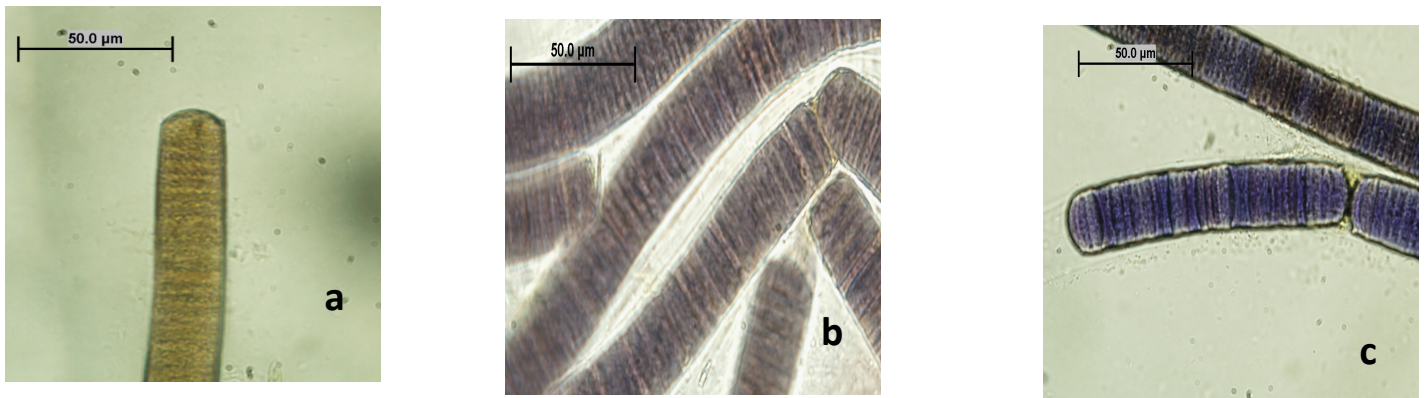

Figure 21: Lyngbya 1 sp.., in BG 11 media: a) standard $\mathrm{ZnSO}_{4}$ b) Bulk $\mathrm{ZnO} 1 \mathrm{ppm}$ c) Nano $\mathrm{ZnO} 1 \mathrm{ppm}$.

For the Porphoridium sp., there was also a morphology in terms of its color transition. The control had a pink color. The bulk at $1 \mathrm{ppm} \mathrm{Zn} \mathrm{had} \mathrm{some} \mathrm{microalgae}$ convert to a pink hue, but some turned green. The microalgae nano at $1 \mathrm{pm}$ experienced a turn to green (Figure 22). In trial 2, the Porphoridium sp. had similar results.
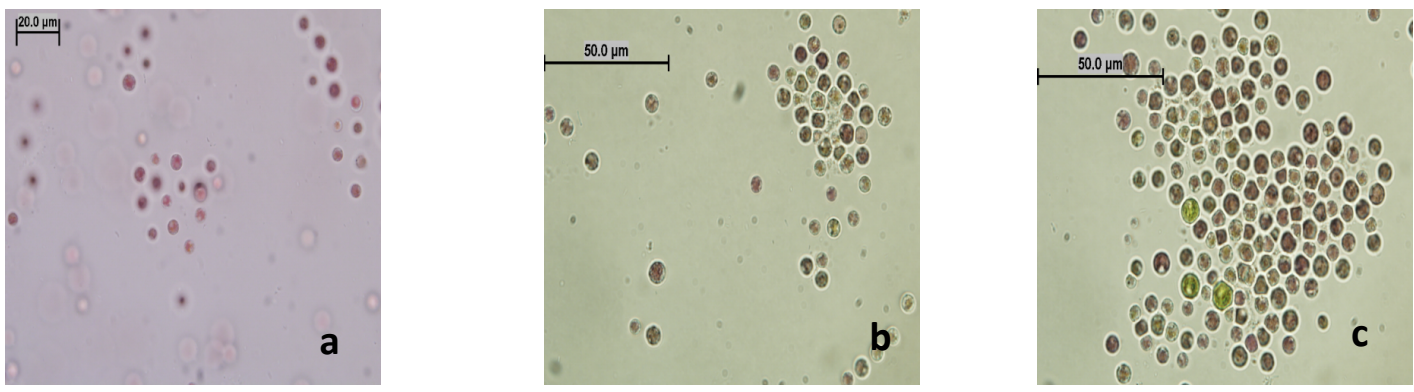

Figure 22: Porphoridium sp., in $\mathrm{BG} 11$ media: a) standard $\mathrm{ZnSO}_{4}$ b) Bulk $\mathrm{ZnO}$ $1 \mathrm{ppm}$ c) Nano ZnO 1 ppm. 
For the Roseofilum sp., there was also a morphology change in the coloration of the microalgae. The control yielded a pink color and a high concentration of filaments. The bulk at $1 \mathrm{ppm} \mathrm{Zn}$ showed some microalgae turn a light green, while the nano at 1 ppm turned vert light green which was almost transparent and with less concentration on filaments (Figure 23). The trial 2 of the Roseofilum sp. yielded similar results.
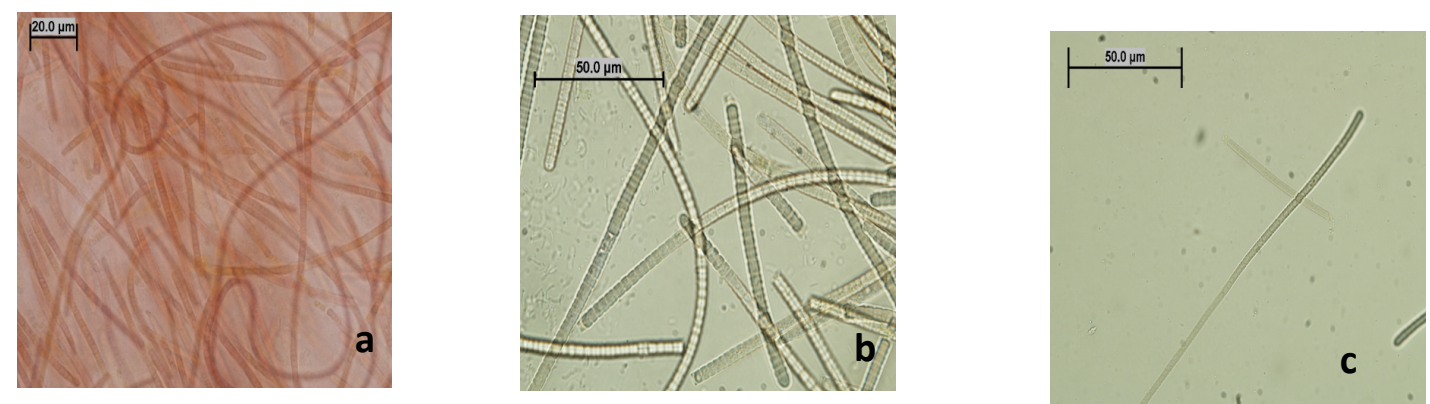

Figure 23: Roseofilum sp., in BG 11 media: a) standard $\mathrm{ZnSO}_{4}$ b) Bulk $\mathrm{ZnO} 1 \mathrm{ppm}$ c) Nano $\mathrm{ZnO} 1$ ppm.

For the Apistonema sp., a morphology change from the control was noted. The control displayed round shapes. The bulk at $1 \mathrm{ppm} \mathrm{Zn}$ showed a round shape however larger than the control and also an agglomeration occurred. The nano at $1 \mathrm{ppm}$ yielded a very similar result to the bulk in terms of its agglomeration (Figure 24). In trial 2, Apistonema sp. had similar results.
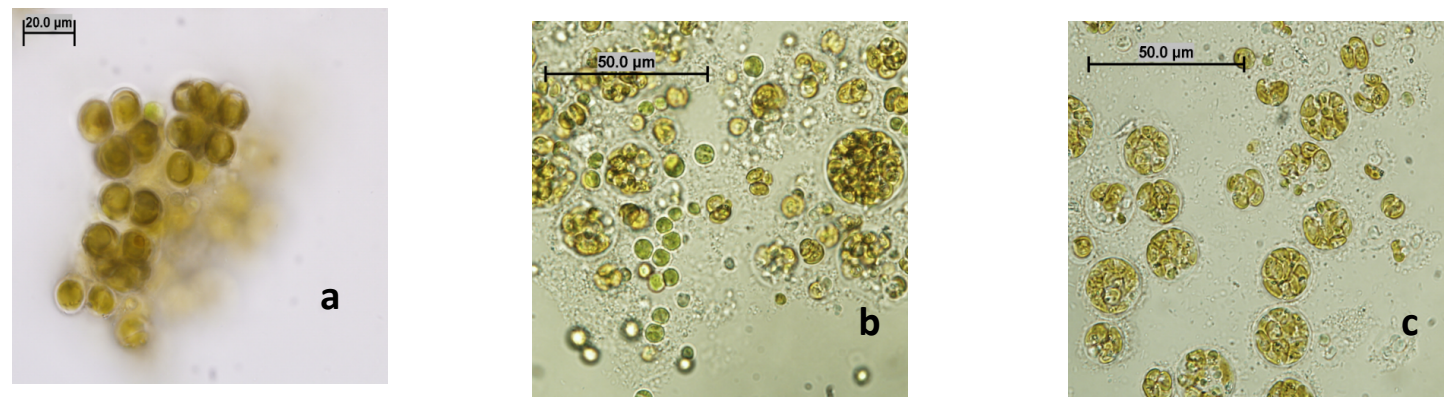

Figure 24: Apistonema sp., in BG 11 media: a) standard $\mathrm{ZnSO}_{4}$ b) Bulk $\mathrm{ZnO} 1 \mathrm{ppm}$ c) Nano $\mathrm{ZnO} 1$ ppm. 


\subsubsection{Growth response}

The results for the two-way mixed (ANOVA) Lower dosage experiments with: Cyno 1: Limnothrix sp., Cyno 2: Leptolyngbya sp., Cyno 3: Lyngbya 1 sp., Cyno 4: Lyngbya 2 sp. Cyno5: Porphoridium sp., Cyno 6: Roseofilum sp. Cyno 7: Apistonemas. The codification for dosages was as follow: B1: 0.125ppm Bulk ZnO, B2: 0.25 ppm Bulk ZnO, B3 0.5 ppm: Bulk ZnO, B4: 1 ppm Bulk ZnO, N1: 0.125ppm NPs ZnO, N2: 0.25 ppm NPs ZnO, N3: 0.5 ppm NPs ZnO and N4: 1 ppm NPs ZnO.

After the assumptions were met the ANOVA was conducted. The Test of between-subjects' effects was done to a statistically significant difference in absorbance concentration between intervention of treatments. There was a statistically significant difference in absorbance concentration between intervention of treatments $F(8,15.762)=$ 6.521, $\mathrm{p}=.000$, partial $\eta^{2}=.592$ for Limnothrix sp. $; \mathrm{F}(8,32)=6.521, \mathrm{p}=.000$, partial $\eta^{2}$ $=.704$ for Leptolyngbya sp. $; \mathrm{F}(8,3.449)=48.911, \mathrm{p}=.000$, partial $\eta 2=.431$ for Lyngbya sp. ;F( 8, 31)=13.116, p=0.000 $\eta 2=1.736$ for Lyngbya $\mathrm{sp} ; \mathrm{F}(8,35)=1.208$, $\mathrm{p}=.000 \eta 2=.014$ for Porphoridium sp. $; \mathrm{F}(8,37)=10.814, \mathrm{p}=.000 \eta 2=.138$ for Roseofilum sp. and F $(8,34)=7.588, \mathrm{p}=.000 \eta 2=.499$ for Apistonema sp.

Multiple Comparisons was used to know the sadistically significantly between treatments. For Limnothrix sp.: Absorbance concentration was statistically significantly greater in the control compare all of the other treatments $(0.125 \mathrm{ppm}, 0.25 \mathrm{ppm}, 0.5 \mathrm{ppm}$, 1 ppm, bulk and nano $\mathrm{ZnO})$ For example: Control and b1( 0.125ppm ZnO bulk) $(\mathrm{M}=.935510, S E=.1738216 \mathrm{~nm}, p=.000)$. The absorbance concentration in all the treatments excluding control was not statistically significantly lower than. For example: the control group b1 and n4 $(M=.194290, S E=.1738216 \mathrm{~nm}, p=.968)$. 
For Leptolyngbya sp.: For the results in these microalgae had many variety results absorbance concentrations were statistically significantly greater: Control with all the treatments (b1-n4); All bulk (b1-b4) with all nano (n1-n4). For example: Control with $\mathrm{b} 1(\mathrm{M}=.204250, \mathrm{SE}=.0371248, \mathrm{p}=0)$. The absorbance concentration in all bulk with all bulk treatments (b1-b4) and all nano with nano treatments (n1-n4) were not statistically significantly greater. For example, b1 with b3 $(\mathrm{M}=.001100, \mathrm{SE}=.0350016$, $\mathrm{p}=1.00)$.

For Lyngbya 1 sp.: Absorbance concentration was statistically significantly greater in the control compare all of the other treatments (b1-n4). For example: Control and $\mathrm{b} 1(\mathrm{M}=.528250, \mathrm{SE}=.0331947 \mathrm{~nm}, \mathrm{p}=.000)$. The absorbance concentration in all the treatments excluding control was not statistically significantly lower than. For example: the control group b1 and $\mathrm{n} 4(\mathrm{M}=.053313, \mathrm{SE}=.0314912, \mathrm{p}=.746)$.

For Lyngbya 2 sp: Absorbance concentration was statistically significantly greater in the control compare all of the other treatments (b1-n4) and for all bulk with N4. For example: $\mathrm{B} 1$ and $\mathrm{N} 4(\mathrm{M}=.078875, \mathrm{SE}=.0087693, \mathrm{p}=.004)$. The absorbance concentration in most treatments excluding control was not statistically significantly lower than. For example: $\mathrm{n} 1$ and $\mathrm{n} 4(\mathrm{M}=.020400, \mathrm{SE}=.0355980, \mathrm{p}=.999)$.

For Porphoridium sp.: The absorbance concentration for all the treatments was not statistically significantly lower than. There is no significance difference between the treatments.

For Roseofilum sp.: Absorbance concentration was statistically significantly greater in the control with b4 and N4; B1 with N4; B2 with N2 and N4; B3 with N2 and 
$\mathrm{N} 4$; $\mathrm{N} 1$ and N4. For example, control group and $\mathrm{b} 4 \mathrm{M}=.113563, \mathrm{SE}=.0339681, \mathrm{p}=$ 0.004); The absorbance concentration in some treatments was not statistically significantly lower. For example: control and b1 $(\mathrm{M}=.035375, \mathrm{SE}=.0339681, \mathrm{p}=.979)$.

For Apistonema sp.: Absorbance concentration was statistically significantly greater in the control with all bulks (b1-b4); B4 with B1. For example, control group and $\mathrm{b} 4(\mathrm{M}=.118787, \mathrm{SE}=.0268076, \mathrm{p}=0.002)$. The absorbance concentration most treatments was not statistically significantly lower than for control with all nano (n1-n4), Nano with bulk. For example: $\mathrm{B} 1$ and b2 $(\mathrm{M}=.014750, \mathrm{SE}=.0330920, \mathrm{p}=1.00)$.

The two-way interaction is statistically significant for all the cyanobacteria but Lyndya $1 \mathrm{sp}$. did not pass the Levene's test of equality of error variance meaning there was no variance of growth was equally distributed across groups for each of the comparison days. Also, the Apistonema sp. there was no homogeneity of variances because it fails the Box's test of equality of covariance matrices there was no other variants.

For Limnothrix sp., there were no significant outliers, as assessed by boxplot. The data was normally distributed, as assessed by Shapiro-Wilk's test of normality $(p>.05)$. There was homogeneity of variances $(p>.05)$ and covariance $(p>.05)$, as assessed by Levene's test of homogeneity of variances with the exception of days 5 and 7 for cyanobacteria 1 and Box's M test, respectively. "Mauchly's test of sphericity was used to examine the assumption of sphericity. The Huynh-Feldt epsilon was used to interpret the two-way interactions. Test of Within-subjects' effects: There was a statistically significant interaction between the intervention and days on absorbance, $\mathrm{F}(3,108)=$ $67.223, \mathrm{p}=0.00$, partial $\eta 2=.651$. Absorbance concentration was statistically 
significantly greater in the control compare all of the other treatments (b1-n4). For example: Control and $\mathrm{b} 1(\mathrm{M}=.935510, \mathrm{SE}=.1738216 \mathrm{~nm}, \mathrm{p}=.000)$. The absorbance concentration in all the treatments excluding control was not statistically significantly lower than. For example: the control group b1 and n $4(\mathrm{M}=.194290, \mathrm{SE}=.1738216 \mathrm{~nm}$, $\mathrm{p}=.968)$

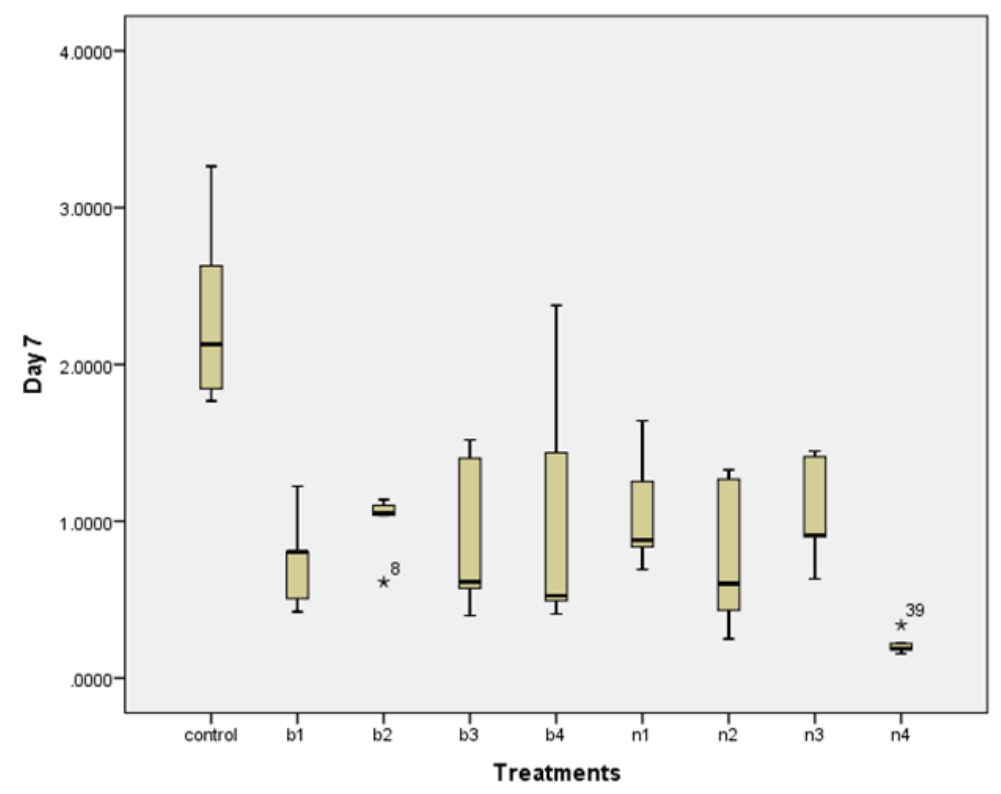

Figure 25: Box plot's shows the effects of $\mathrm{ZnO}$ Nano and bulk particles on Limnothrix sp., growth at day 7.

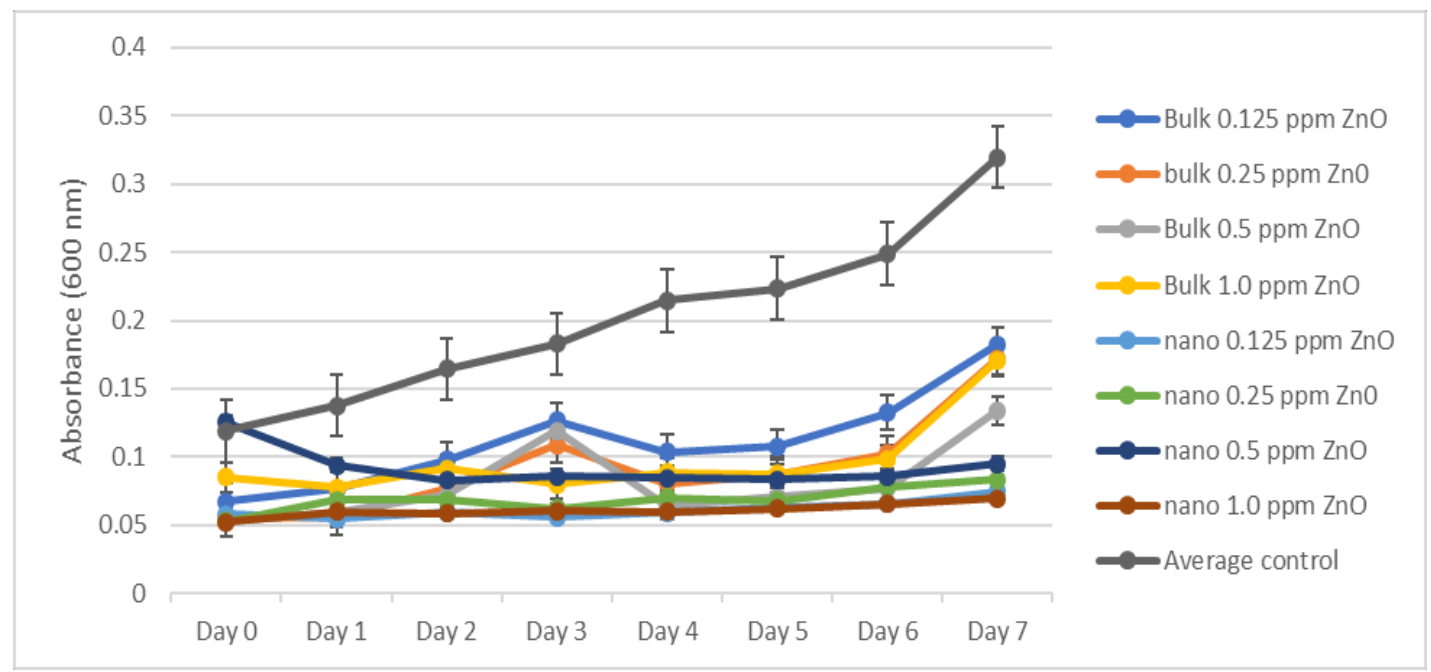

Figure 26: The effects of $\mathrm{ZnO}$ Nano and bulk particles on Limnothrix sp., growth. 
For Leptolyngbya sp, there were no outliers, as assessed by boxplot. The data was normally distributed, as assessed by Shapiro-Wilk's test of normality $(\mathrm{p}>.05)$. There was homogeneity of variances $(p>.05)$ and covariance $(p>.05)$, as assessed by Levene's test of homogeneity of variances with the exception of days 5 and 7 for cyanobacteria 1 and Box's M test, respectively. "Mauchly's test of sphericity was used to examine the assumption of sphericity. The Huynh-Feldt epsilon was used to interpret the two-way interactions. Test of Within-subjects' effects: There was a statistically significant interaction between the intervention and days on absorbance $F(1,96)=26.758 ; p=.000$, partial $\eta 2=6.362$. For the results in this microalgae had many variety results. Absorbance concentration was statistically significantly greater: Control with all the treatments (b1-n4); B1 with all nano (n1-n4); B2 with all nano (N1-n4); B3 all nano (N1n4); B4 with all nano (N1-n4). For example: Control with b1 $(\mathrm{M}=.204250, \mathrm{SE}=$ $.0371248, \mathrm{p}=0$ ). The absorbance concentration in all bulk with bulk treatments (B1 with $\mathrm{b} 2, \mathrm{~b} 3, \mathrm{~b} 4)$ and all nano with nano treatments (N1 with $\mathrm{n} 2, \mathrm{n} 3, \mathrm{n} 4)$. For example, b1 with b3 $(\mathrm{M}=.001100, \mathrm{SE}=.0350016, \mathrm{p}=1)$. 


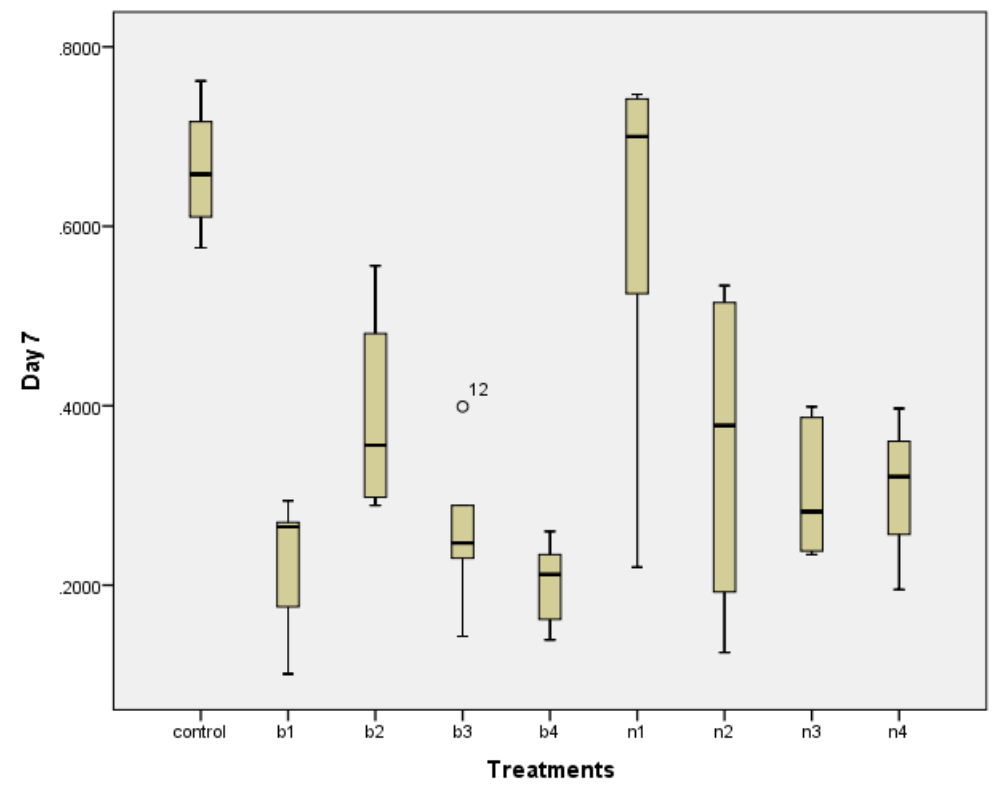

Figure 27: Box plot's shows the effects of $\mathrm{ZnO}$ Nano and bulk particles on Leptolyngbya sp., growth at day 7.

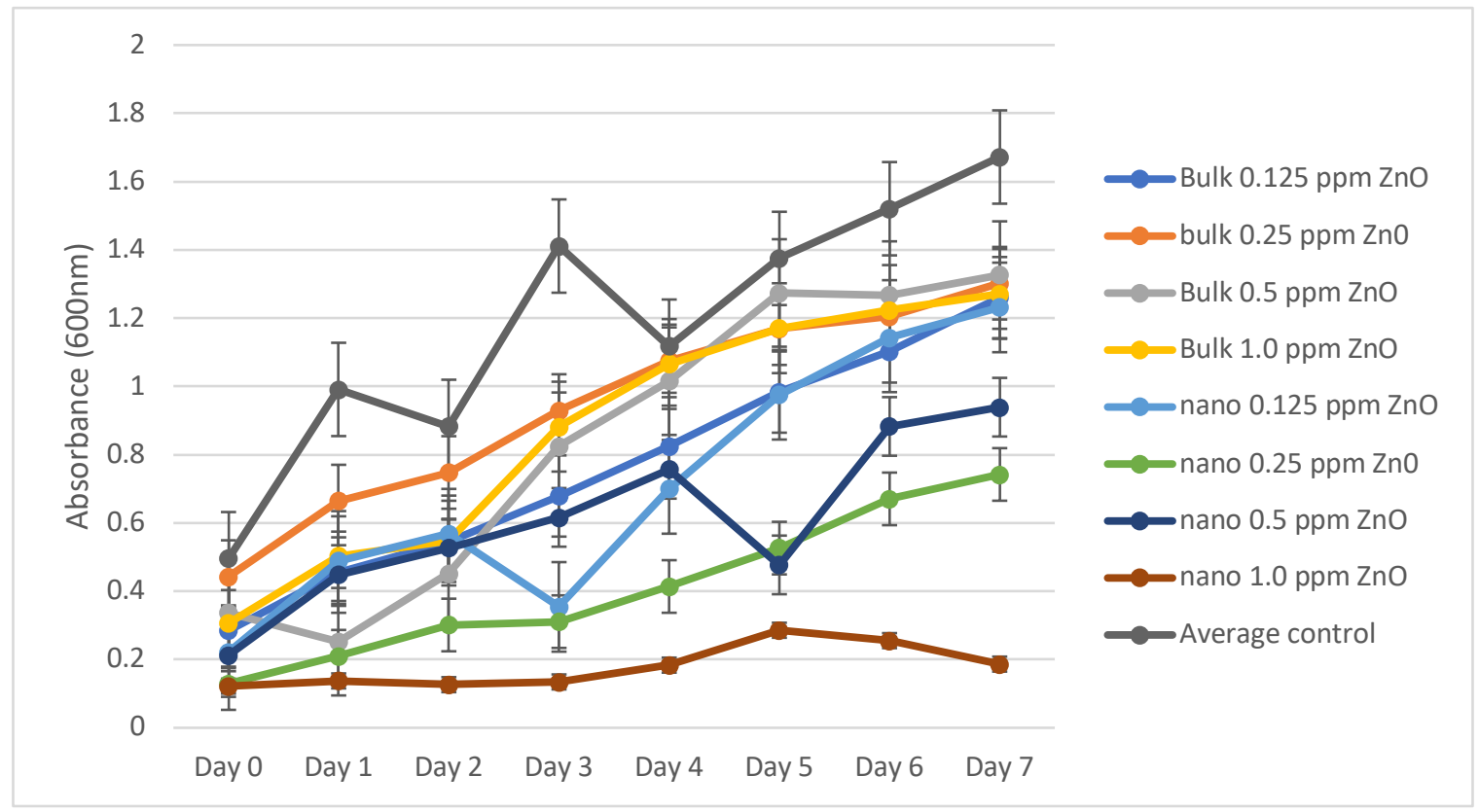

Figure 28: The effects of $\mathrm{ZnO}$ Nano and bulk particles on Leptolyngbya sp., growth. 
For Lyngbya $1 \mathrm{sp}$., there were no outliers, as assessed by boxplot. The data was normally distributed, as assessed by Shapiro-Wilk's test of normality $(\mathrm{p}>.05)$. There was no homogeneity of variances $(\mathrm{p}>.05)$ and covariance $(\mathrm{p}>.05)$, as assessed by Levene's test of homogeneity of variances but the Box's M test did pass. Unfortunately, transformations were not successful and there are no robust mixed ANOVA methods available in SPSS Statistics because the Leven's was violated but the analysis and testing continued regardless. Mauchly's test of sphericity was used to examine the assumption of sphericity. The Huynh-Feldt epsilon was used to interpret the two-way interactions. Test of Within-subjects' effects: There was a statistically significant interaction between the intervention and days on absorbance $(3,90)=11.959 \mathrm{p}=.000$, partial $\eta 2=.056$. Absorbance concentration was statistically significantly greater in the control compare all of the other treatments (b1-n4). For example: Control and b1 $(\mathrm{M}=.528250, \mathrm{SE}=$ $.0331947 \mathrm{~nm}, \mathrm{p}=.000)$. The absorbance concentration in all the treatments excluding control was not statistically significantly lower than. For example: the control group b1 and $\mathrm{n} 4(\mathrm{M}=.053313, \mathrm{SE}=.0314912, \mathrm{p}=.746)$. 


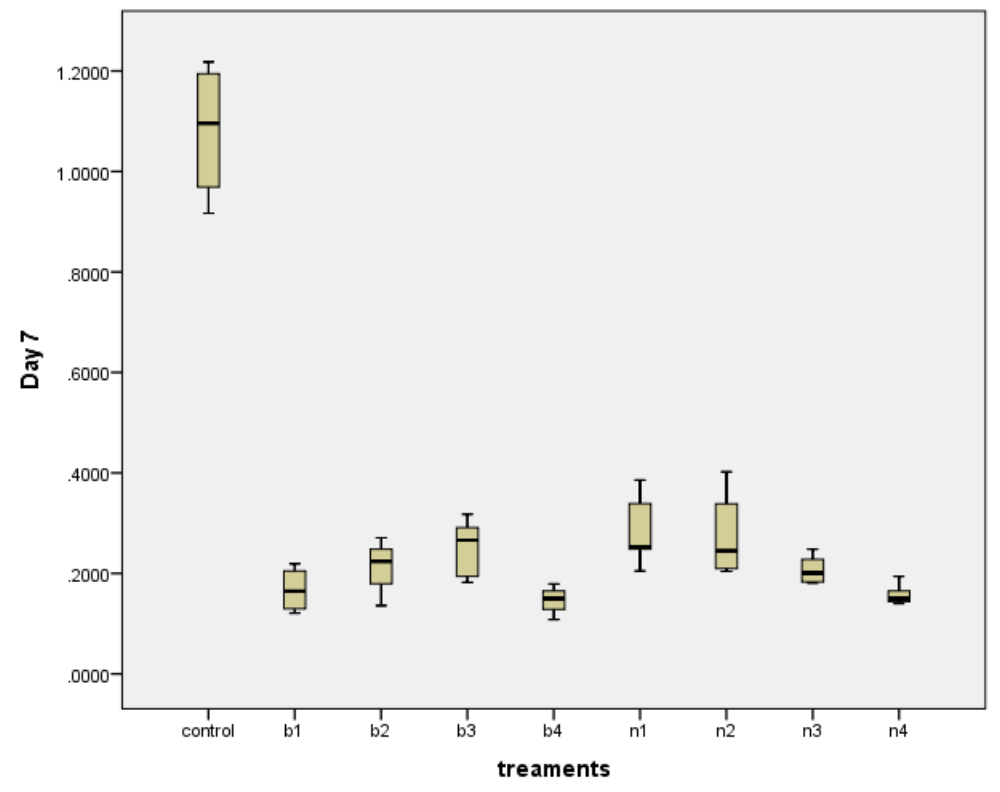

Figure 29: Box plot's shows the effects of $\mathrm{ZnO}$ Nano and bulk particles on Lyngbya 1 sp., growth at day 7.

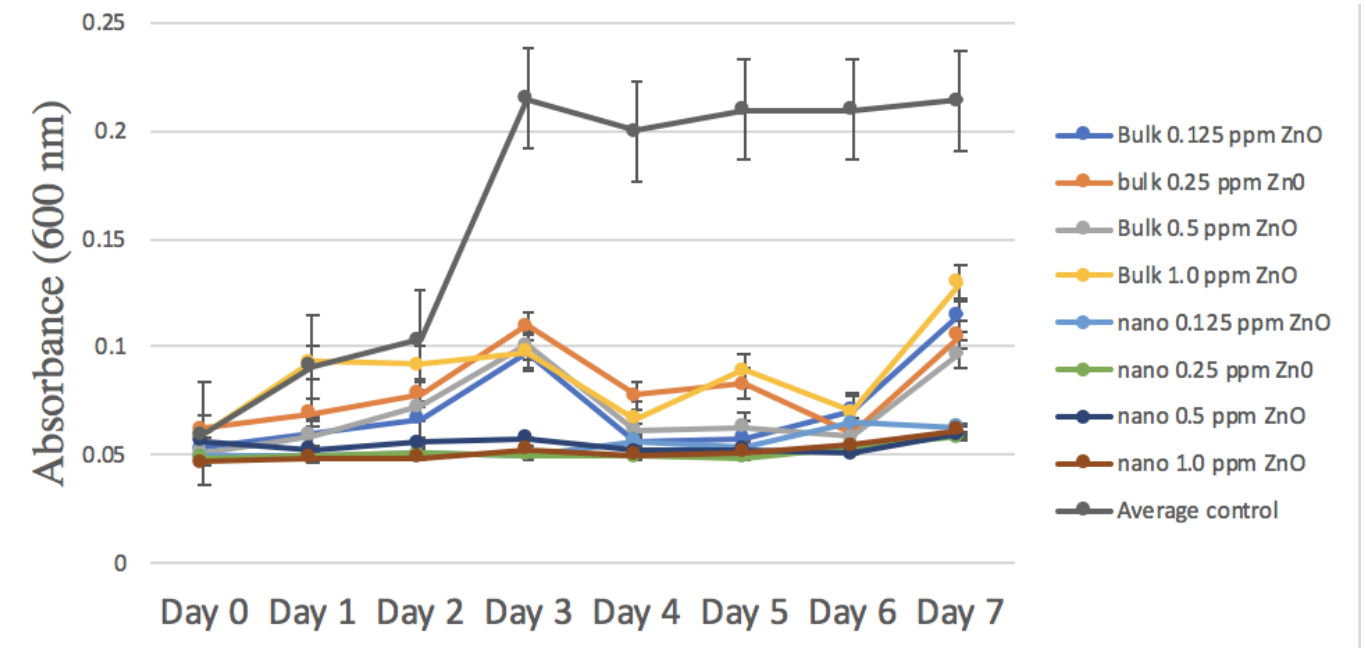

Figure 30: The effects of $\mathrm{ZnO}$ Nano and bulk particles on Lyngbya $1 \mathrm{sp}$., growth at day 7. 
For Lyngbya $2 \mathrm{sp}$., there were no outliers, as assessed by boxplot. The data was normally distributed, as assessed by Shapiro-Wilk's test of normality $(\mathrm{p}>.05)$. There was homogeneity of variances $(\mathrm{p}>.05)$ and covariance $(\mathrm{p}>.05)$, as assessed by Levene's test of homogeneity of variances with the exception of days 5 and 7 for cyanobacteria 1 and Box's M test, respectively. "Mauchly's test of sphericity was used to examine the assumption of sphericity. The Huynh-Feldt epsilon was used to interpret the two-way interactions. Test of Within-subjects' effects: There was a statistically significant interaction between the intervention and days on absorbance $F(3,93)=8.248 \mathrm{p}=.000$, partial $\eta 2=.027$. Absorbance concentration was statistically significantly greater in the control compare all of the other treatments (b1-n4); b3 with $\mathrm{n} 3(\mathrm{M}=.078875$, $\mathrm{SE}=.0087693, \mathrm{p}=.004)$. The absorbance concentration in most treatments excluding control was not statistically significantly lower. For example: the control group b1 and $\mathrm{n} 4(\mathrm{M}=.020400, \mathrm{SE}=.0355980, \mathrm{p}=.999)$.

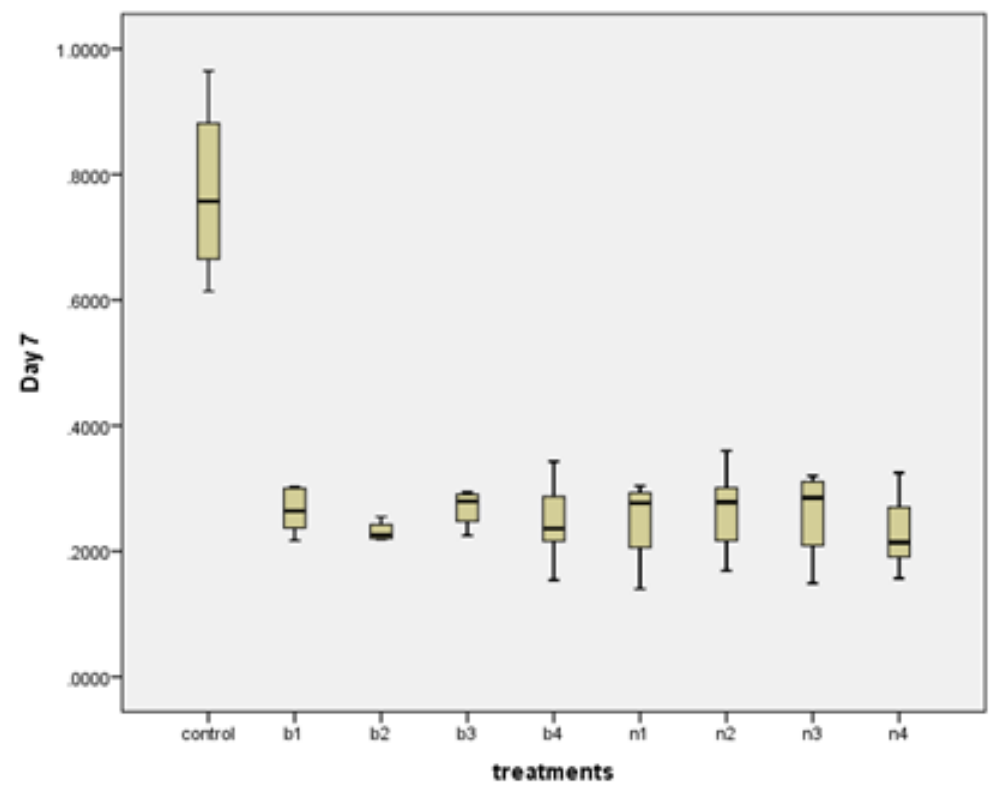

Figure 31: Box plot's shows the effects of $\mathrm{ZnO}$ Nano and bulk particles on Lyngbya 2 sp., growth at day 7 . 


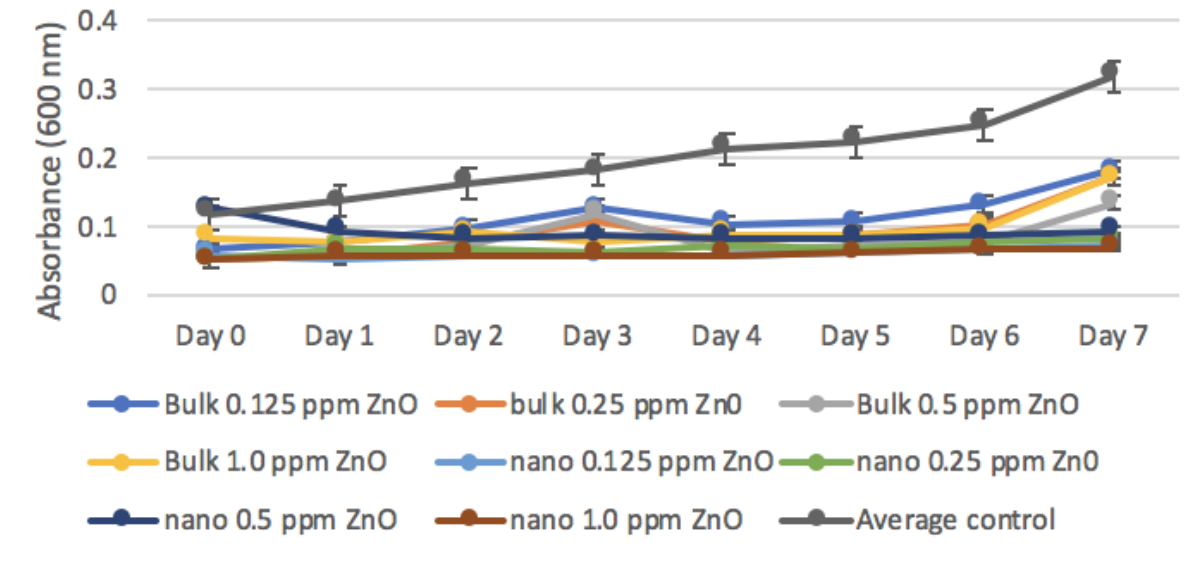

Figure 32: The effects of $\mathrm{ZnO}$ Nano and bulk particles on Lyngbya 2 sp., growth.

For Porphoridium sp., there were no significant outliers, as assessed by boxplot. The data was normally distributed, as assessed by Shapiro-Wilk's test of normality ( $\mathrm{p}>$ $.05)$. There was homogeneity of variances $(p>.05)$ and covariance $(p>.05)$, as assessed by Levene's test of homogeneity of variances with the exception of days 5 and 7 for cyanobacteria 1 and Box's M test, respectively. "Mauchly's test of sphericity was used to examine the assumption of sphericity. The Huynh-Feldt epsilon was used to interpret the two-way interactions. Test of within-subjects' effects: There was a statistically significant interaction between the intervention and days on absorbance $\mathrm{F}(3,105)=$ $55.043, p=.00 \eta 2=.261$. The absorbance concentration for all the treatments was not statistically significantly lower than. There is no significance difference between the treatments. 


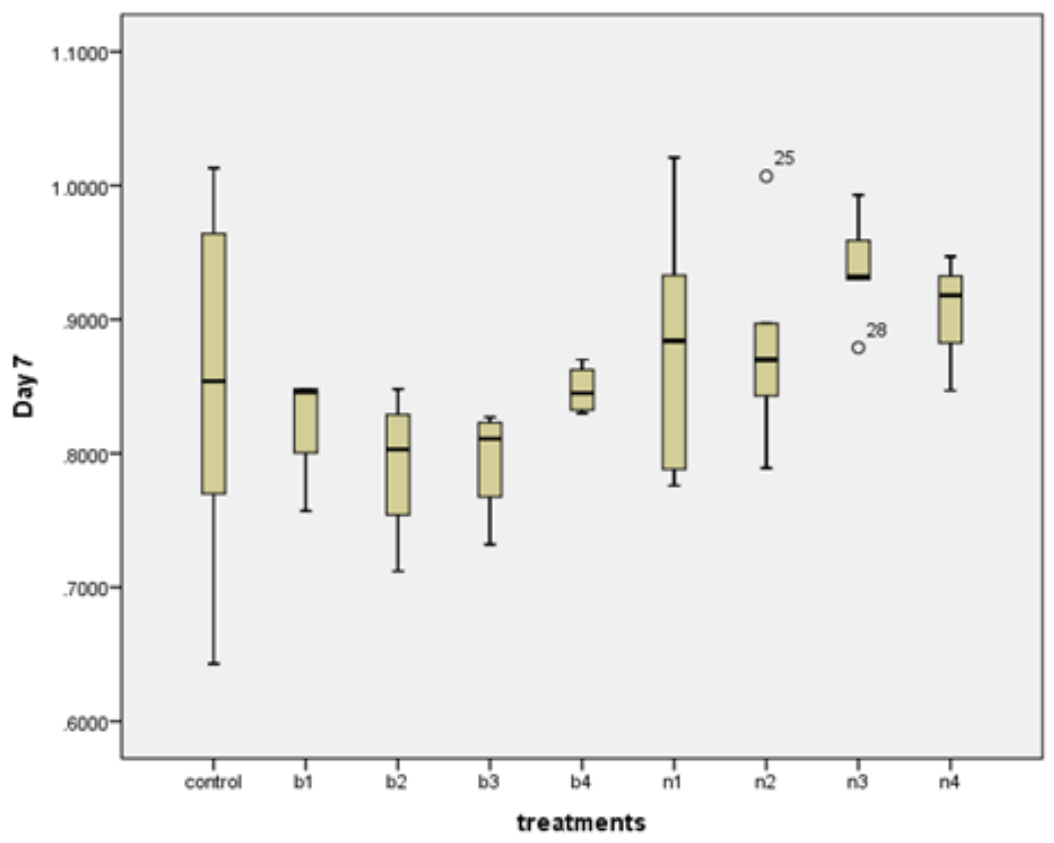

Figure 33: Box's plot of effects of $\mathrm{ZnO}$ Nano and bulk particles on Porphoridium sp., growth at day 7 .

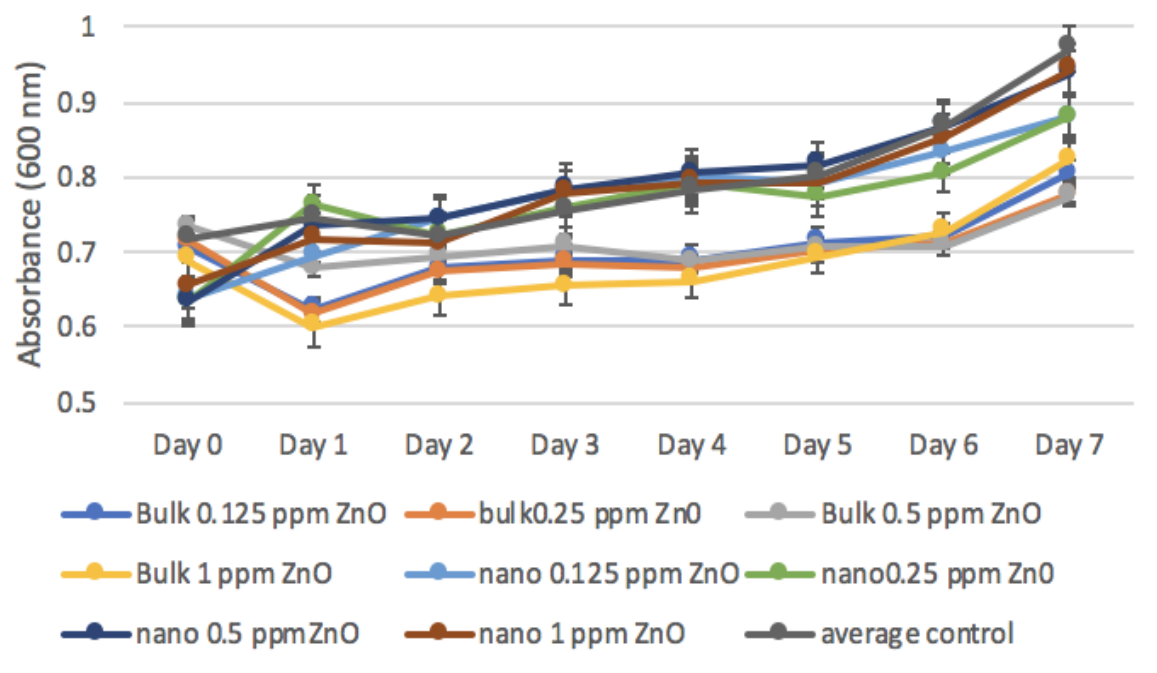

Figure 34: The effects of $\mathrm{ZnO}$ Nano and bulk particles on Porphoridium sp., growth. 
For Roseofilum sp., there were no outliers, as assessed by boxplot. The data was normally distributed, as assessed by Shapiro-Wilk's test of normality $(\mathrm{p}>.05)$. There was homogeneity of variances $(p>.05)$ and covariance $(p>.05)$, as assessed by Levene's test of homogeneity of variances with the exception of days 5 and 7 for cyanobacteria 1 and Box's M test, respectively. "Mauchly's test of sphericity was used to examine the assumption of sphericity. The Huynh-Feldt epsilon was used to interpret the two-way interactions. Test of within-subjects' effects: There was a statistically significant interaction between the intervention and days on absorbance $F(3,111)=51.799, p=.00 \eta 2$ $=1.209$. Absorbance concentration was statistically significantly greater in the control with b4 and N4; B1 with N4; B2 with N2 and N4; B3 with N2 and N4; N1 and N4. For example, control group and $\mathrm{b} 4(\mathrm{M}=.113563, \mathrm{SE}=.0339681, \mathrm{p}=0.004)$. The absorbance concentration in some treatments was not statistically significantly lower. For example: control and b1 $(\mathrm{M}=.035375, \mathrm{SE}=.0339681, \mathrm{p}=.979)$.

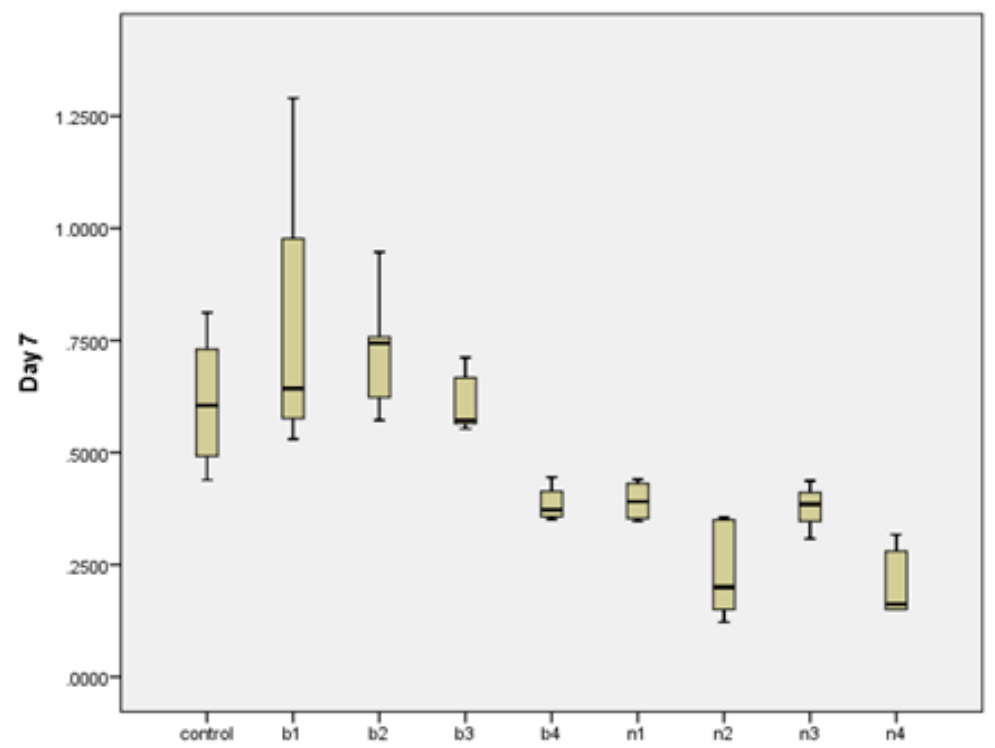

Figure 35: Box's plot of effetestogftzonO Nano and bulk particles on Roseofilum sp., growth at day 7. 


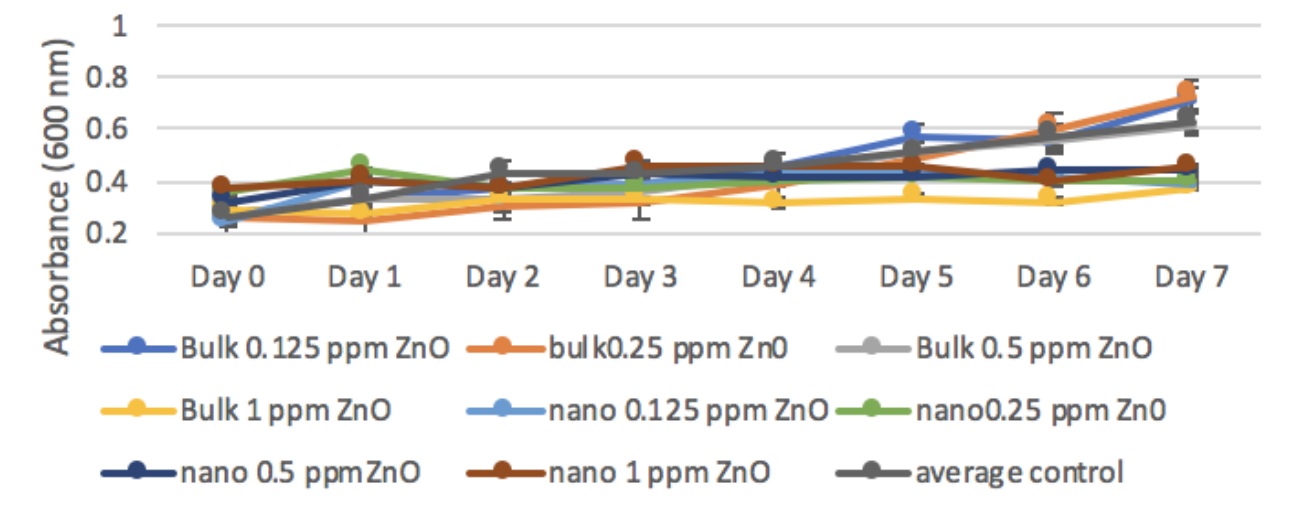

Figure 36: The effects of $\mathrm{ZnO}$ Nano and bulk particles on Roseofilum sp.., growth.

\subsection{Cyanobacteria -Exposure to Low Zn Concentrations with Additional Zn Source}

The results of the multi-well plate-based experiment with four cyanobacteria:

Limnothrix sp. (173-10-1), Leptolyngbya (146-5-2), Neolyngbya sp. (EK17-3A), and Oscillatoria sp. (Bpm 173F) Observation following the incubation of multi-well plates, growth inhibition due to nano $\mathrm{Zn}$ was clearly indicated by visible total loss of pigmentation (in row two, Figure 37).

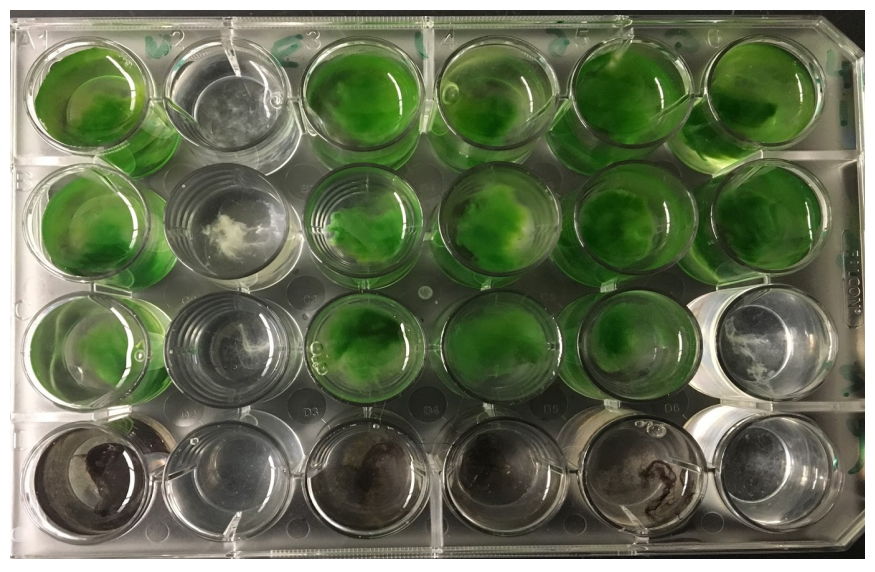

Figure 37: 24 well plates with different concentration of nano zinc and cyanobacteria.

\subsubsection{Optical microscope}


After seven days, the four cyanobacteria were observed in 100x magnification. For the Limnothrix sp., there was a significant morphology change between control and high concentration of zinc. The control had a bright green color while those exposed to the high concentrations of zinc were transparent and showed almost no filaments (Figure $38)$.
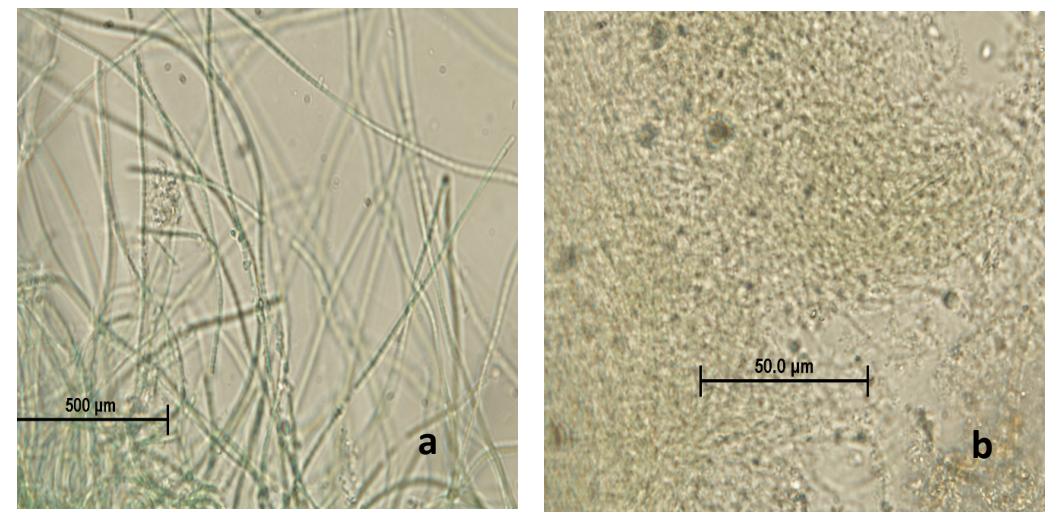

Figure 38: Limnothrix sp., in BG 11 media with a) standard $\mathrm{ZnSO}_{4}$ b) High concentration of $\mathrm{ZnSO}_{4}$.

For the Leptolyngbya sp., there was a prominent morphology change between control and high concentration of zinc. The control had a bright green color while those exposed to the high concentrations of zinc were transparent and showed small size filaments (Figure 39).
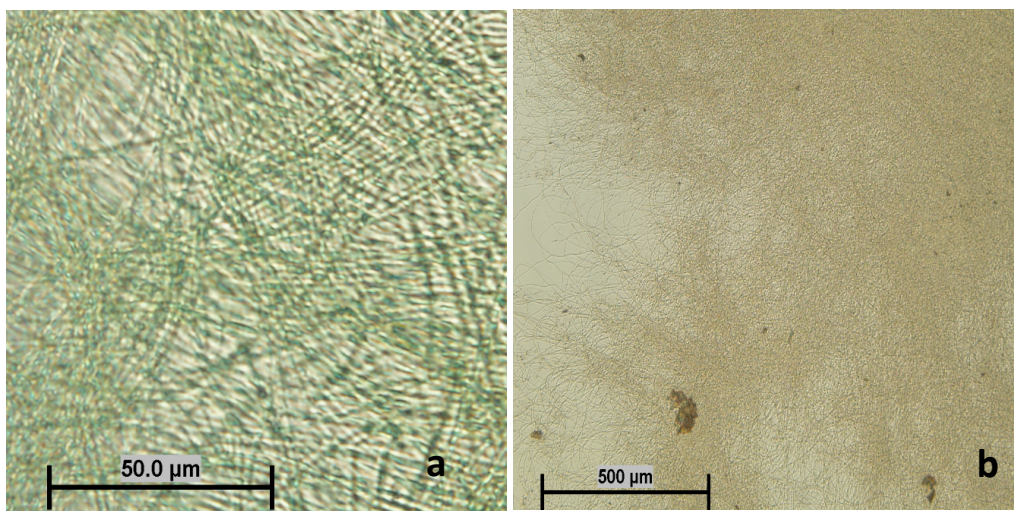

Figure 39: Leptolyngbya sp. in BG 11 media with a) standard $\mathrm{ZnSO}_{4}$ b) High concentration of $\mathrm{ZnSO}_{4}$. 
For the Lyngbya $1 \mathrm{sp}$, there was a distinguished morphology change between control and those with high zinc concentration exposure. The control had a bright green color while the high concentration of zinc was transparent and there was a size reduction (Figure 32).
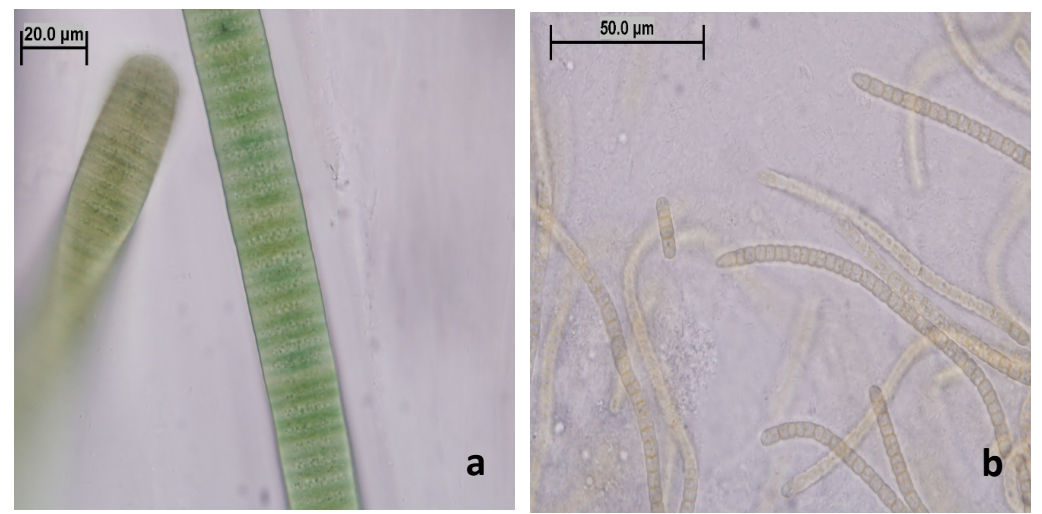

Figure 40: Lyngbya 1 sp. in BG 11 media with a) standard $\mathrm{ZnSO}_{4}$ b) High concentration of $\mathrm{ZnSO}_{4}$.

For the Lyngbya $2 \mathrm{sp}$, , there was a noted morphology change between control and high concentration of zinc. The control had a bright green color while those with high concentration of zinc were transparent and experienced a size reduction (Figure 33). 

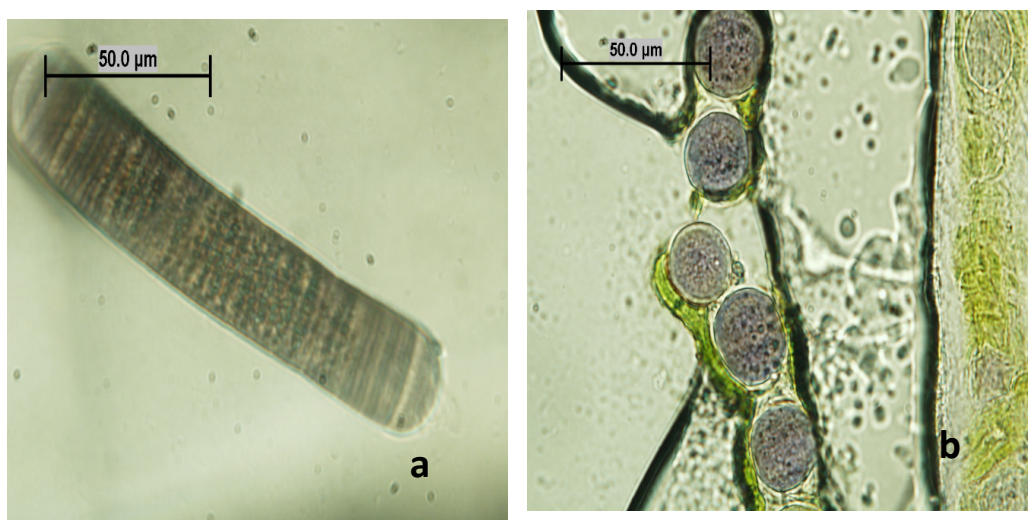

Figure 41: Lyngbya 2 sp. in BG 11 media with a) standard $\mathrm{ZnSO}_{4}$ b) High concentration of $\mathrm{ZnSO}_{4}$.

\subsubsection{Statistical Analysis}

The results for the two-way mixed (ANOVA) with higher dosage of Zinc experiments with: Limnothrix sp., Leptolyngbya sp., Lyngbya 1sp. and Lyngbya $2 \mathrm{sp}$. The codification for dosages was as follow: Extra: High concentration of ZnSO4, B1: 0.125ppm Bulk ZnO, B2: 0.25 ppm Bulk ZnO, B3 0.5 ppm: Bulk ZnO, B4: 1 ppm Bulk ZnO, N1: $0.125 p p m$ NPs ZnO, N2: 0.25 ppm NPs ZnO, N3: 0.5 ppm NPs ZnO and N4: 1 ppm NPs ZnO.

After most the assumption was met the results were reported. There was a statistically significant difference in absorbance concentration between intervention of treatments $\mathrm{F}(9,23)=4.139, \mathrm{p}=.003$, partia $\eta 2=.387$ for Limnothrix sp.; $\mathrm{F}(9,22)=$ $31.527, \mathrm{p}=.000$, partial $\eta 2=2.419$ for Leptolyngbya sp; $\mathrm{F}(9,28)=5.423, \mathrm{p}=.000$ partial $\eta 2=.104$ for Lyngbya $1 \mathrm{sp}$. and $\mathrm{F}(9,28)=14.984, \mathrm{p}=0.000 \eta 2=.042$ for Lyngbya $2 \mathrm{sp.}$ 
The multiple Comparisons table was analyzed to determine which treatments were significantly different. For Limnothrix sp., the absorbance concentration was statistically significantly greater in the control treatments with all the treatments. For example, Extra and control $(\mathrm{M}=.531222 \mathrm{SE}=.1140085 \mathrm{~nm}, \mathrm{p}=.004)$. The absorbance concentration in all the treatments excluding control was not statistically significantly lower than. For example: extra and $b 1(\mathrm{M}=.024611, \mathrm{SE}=.1248900 \mathrm{~nm}, \mathrm{p}=1.00)$.

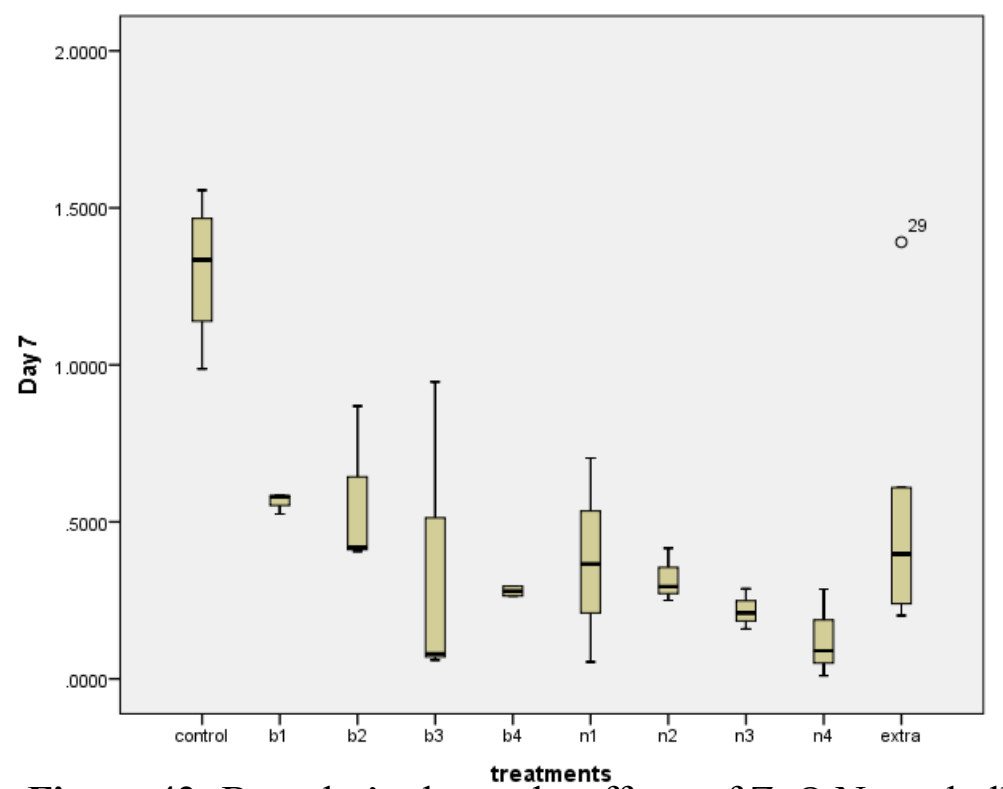

Figure 42: Box plot's shows the effects of $\mathrm{ZnO}$ Nano, bulk particles and extra zinc on Limnothrix sp., growth at day 7. 


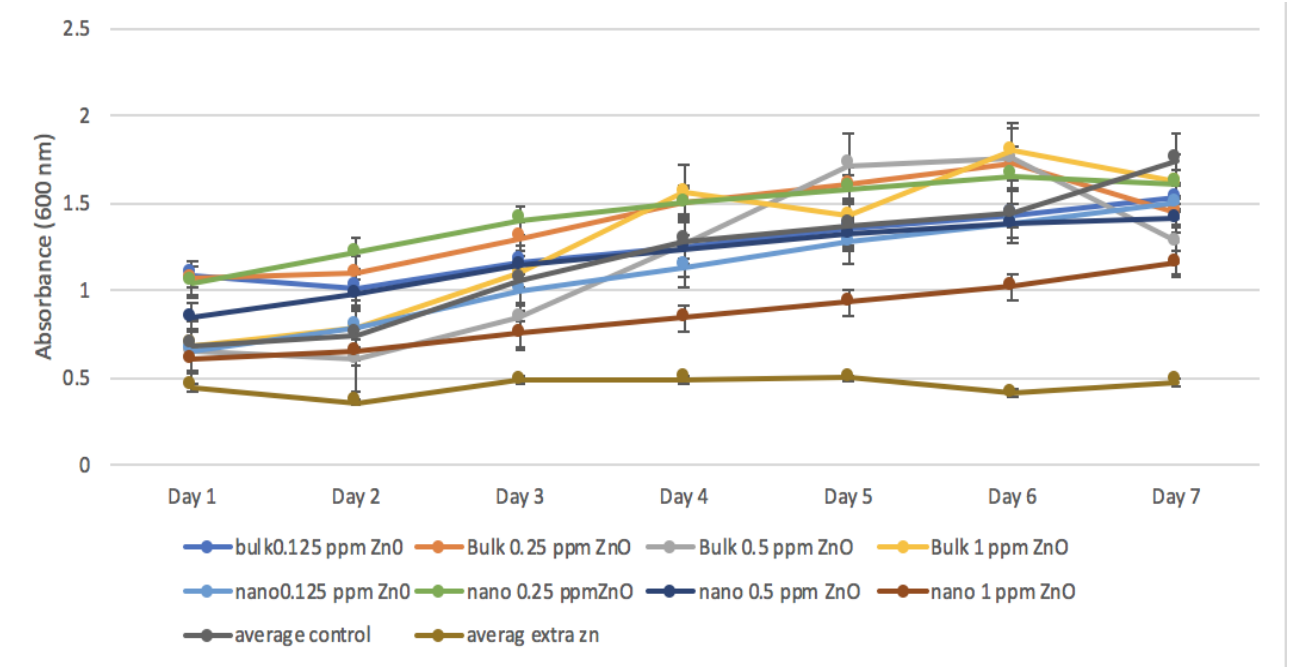

Figure 43: The effects of $\mathrm{ZnO}$ Nano, bulk particles and extra zinc on Limnothrix sp.

For Leptolyngbya sp. the absorbance concentration was statistically significantly greater in the control treatments with all the treatments. For example, extra and control $(\mathrm{M}=.908417 \mathrm{SE}=.1130879 \mathrm{~nm}, \mathrm{p}=.000)$. The absorbance concentration in all the treatments excluding control was not statistically significantly lower than. For example: extra and b1 $(\mathrm{M}=.006694, \mathrm{SE}=.1221489 \mathrm{~nm}, \mathrm{p}=1.00)$. 


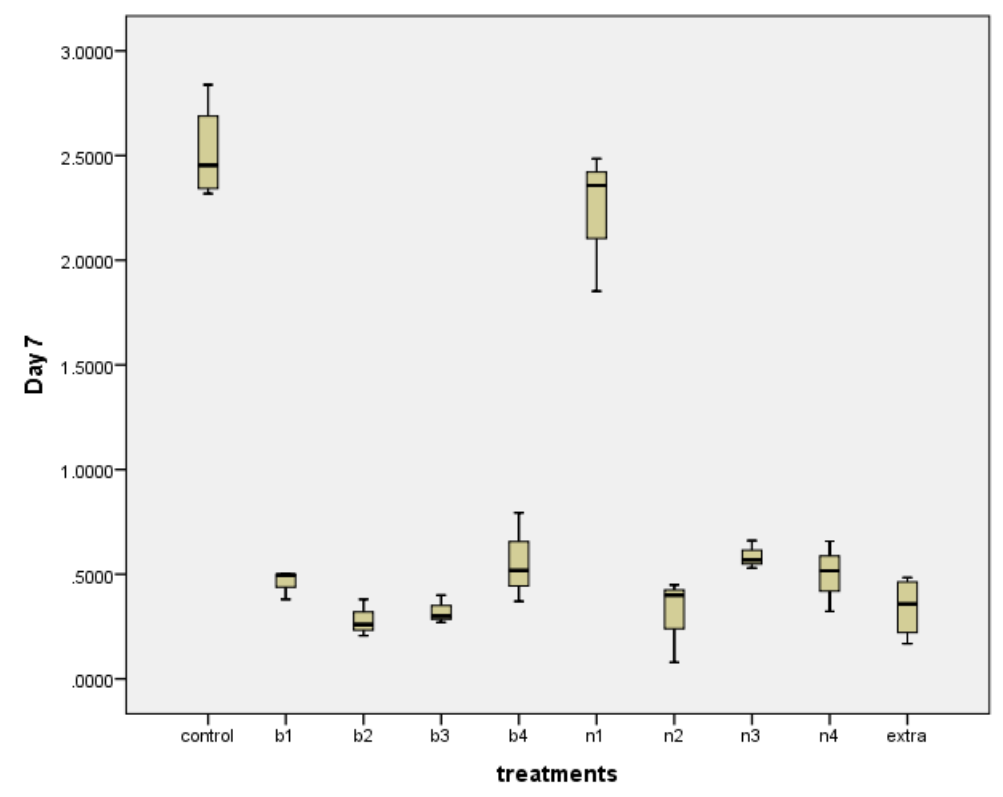

Figure 44: Box plot's shows the effects of $\mathrm{ZnO}$ Nano, bulk particles and extra zinc on Leptolyngbya sp. growth at day 7.

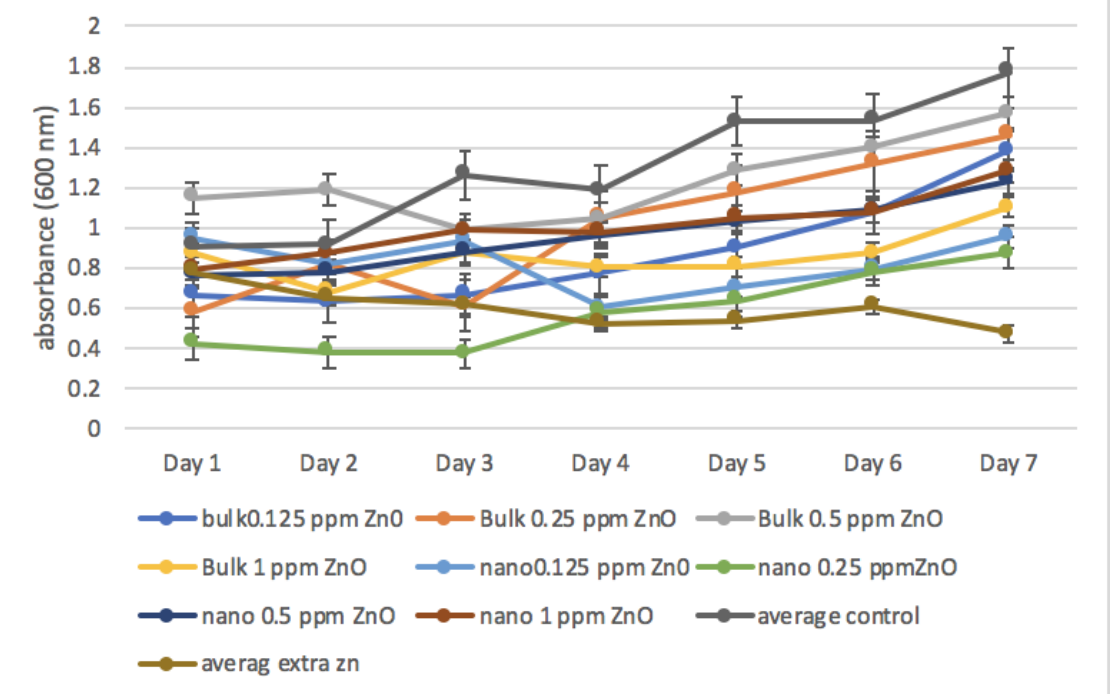

Figure 45: The effects of $\mathrm{ZnO}$ Nano, bulk particles and extra zinc on Leptolyngbya sp. 
For Lyngbya $1 \mathrm{sp}$. the absorbance concentration was statistically significantly greater in the control compare to some treatments but not all. For example: Control and b1 $(\mathrm{M}=.287300, \mathrm{SE}=.0541944 \mathrm{~nm}, \mathrm{p}=.000)$. The absorbance concentration in extra zinc with all bulk and nano was not statistically significantly lower. For example, the control group extra and $\mathrm{n} 4(\mathrm{M}=.053313, \mathrm{SE}=.0314912, \mathrm{p}=.746)$.

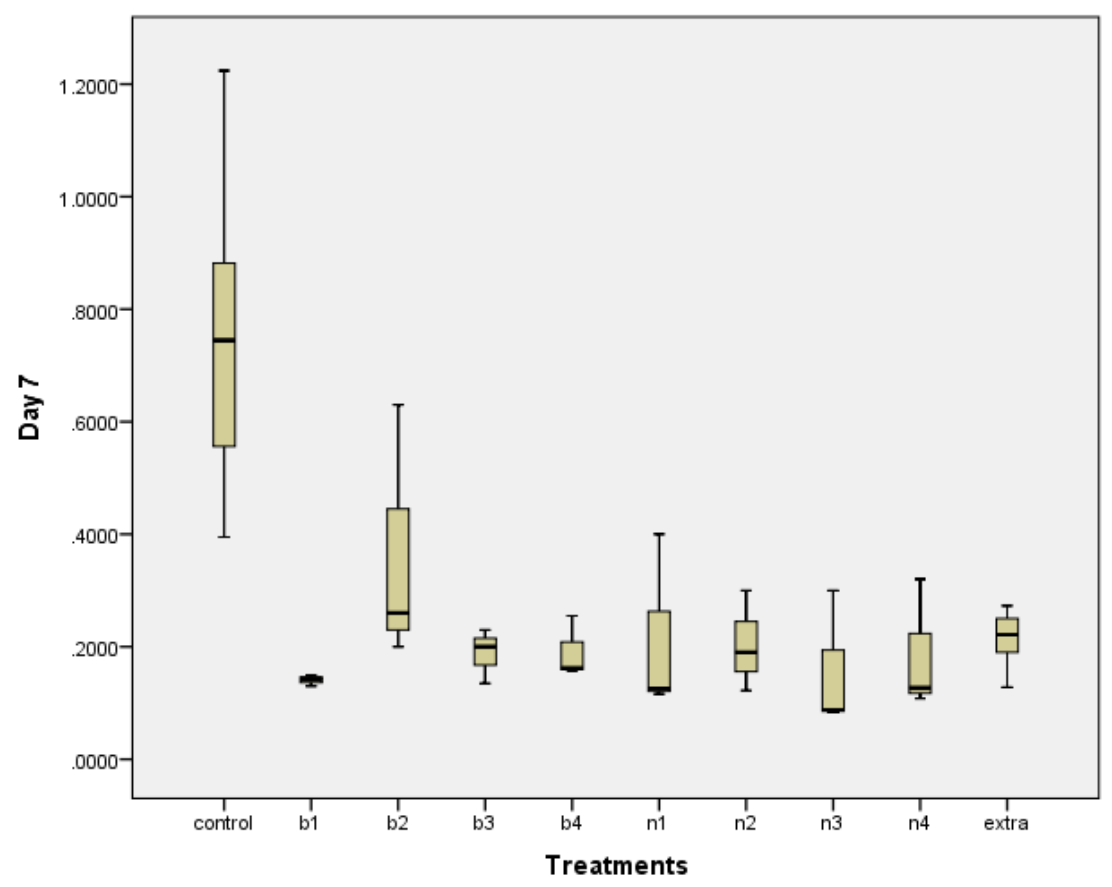

Figure 46: Box plot's shows the effects of $\mathrm{ZnO}$ Nano, bulk particles and extra zinc on Lyngbya 1 sp. growth at day 7. 


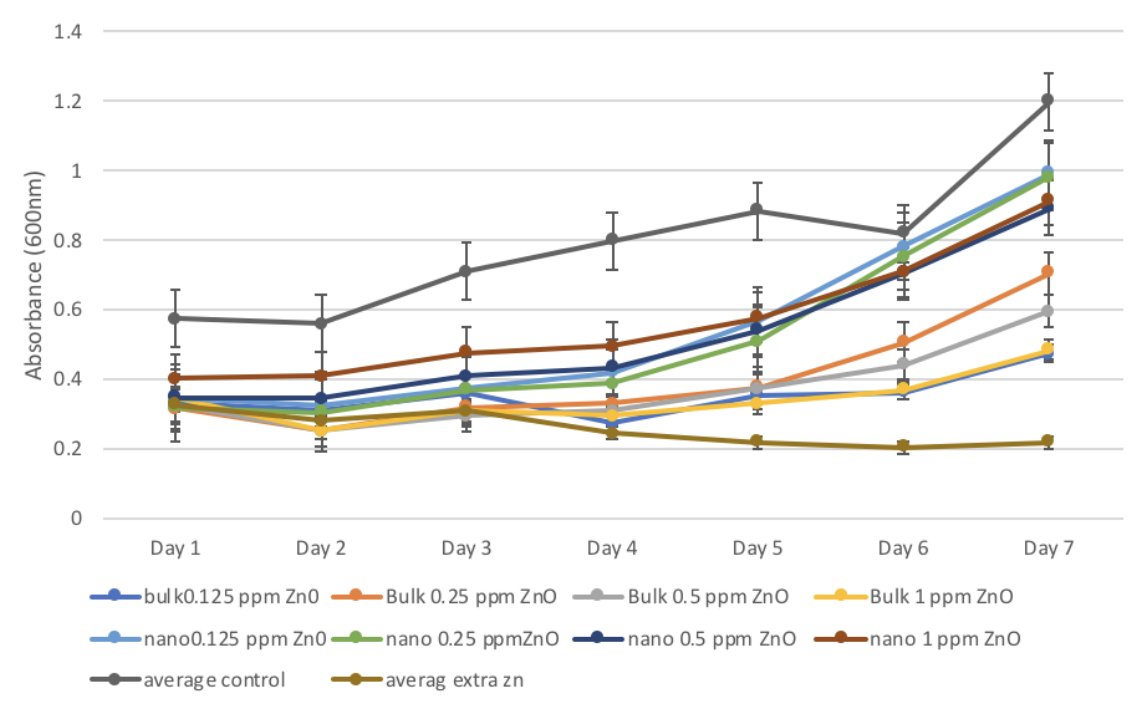

Figure 47: The effects of $\mathrm{ZnO}$ Nano, bulk particles and extra zinc on Lyngbya 1 sp.

For Lyngbya $2 \mathrm{sp}$, the absorbance concentration was statistically significantly greater in the control treatments with all the treatments. For example, extra and control $(\mathrm{M}=.155931 \mathrm{SE}=.0164524 \mathrm{~nm}, \mathrm{p}=.000)$. The absorbance concentration in all the treatments excluding control was not statistically significantly lower than. For example, extra and $\mathrm{b} 1(\mathrm{M}=.002833, \mathrm{SE}=.0215413 \mathrm{~nm}, \mathrm{p}=1.00)$. 


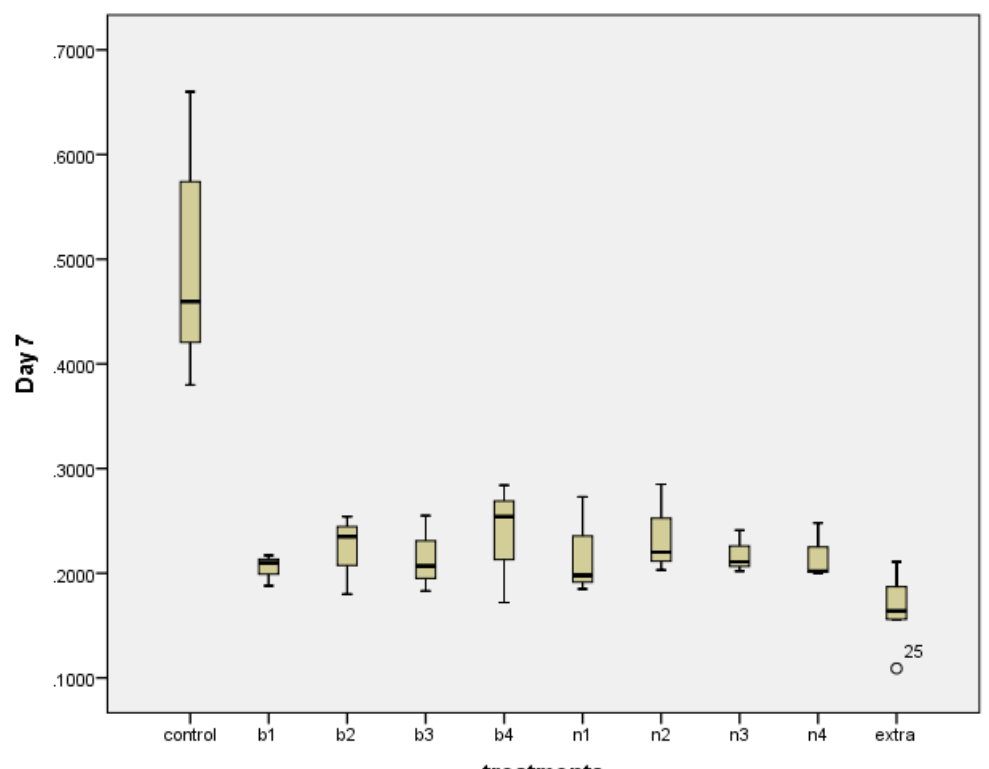

Figure 48: Box plot's shows the effects of $\mathrm{ZnO}$ Nano, bulk particles and extra zinc on Lyngbya $2 \mathrm{sp}$. growth at day 7.

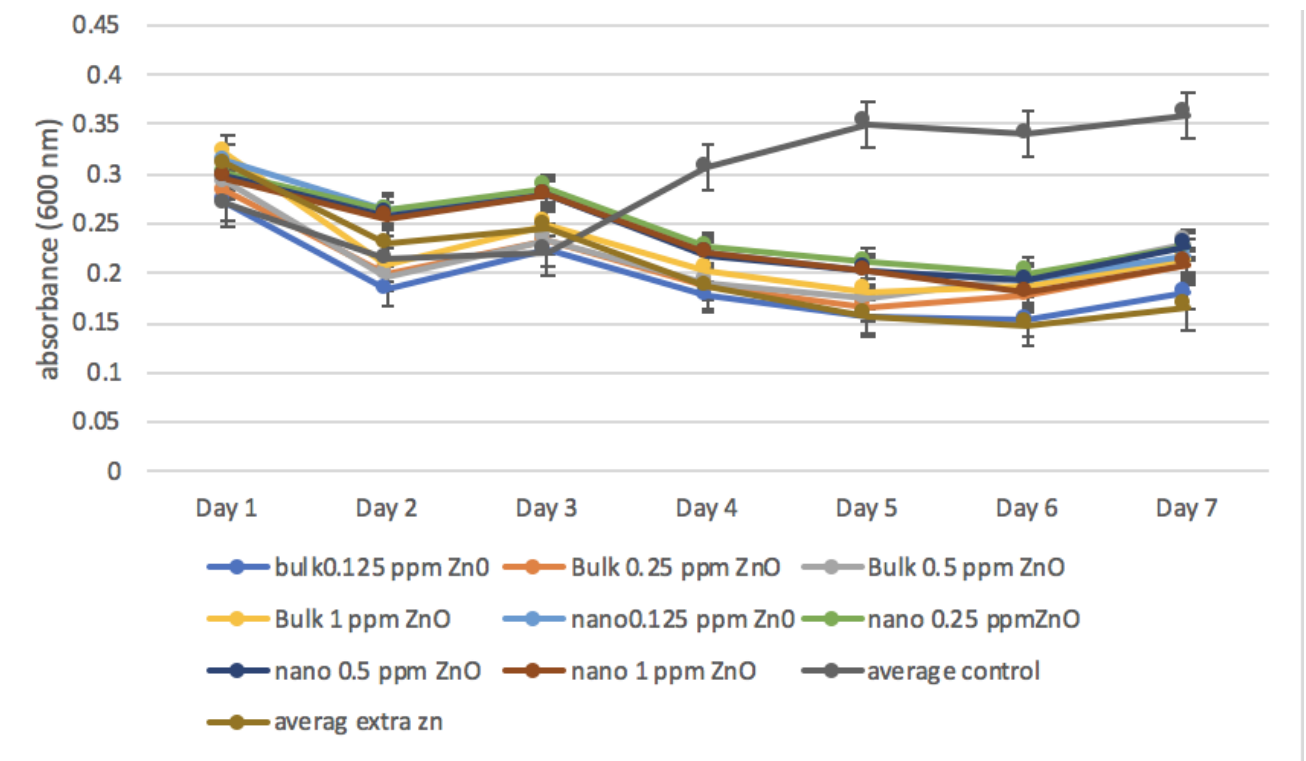

Figure 49: The effects of $\mathrm{ZnO}$ Nano, bulk particles and extra zinc on Lyngbya $2 \mathrm{sp}$. 
There was a statistically significant interaction between the intervention and days on absorbance, for Limnothrix sp.: $\mathrm{F}(2,46)=6.630, \mathrm{p}=0.03$, partial $\eta 2=.285$ and for Leptolyngbya sp.: $\mathrm{F}(2,44)=8.241, \mathrm{p}=0.03$, partial $\eta 2=.458$. There was no significant statistically significant interaction between the intervention and days on absorbance, for Lyngbya 1 sp.: $F(2,56)=3.919, \mathrm{p}=0.026$, partial $\eta 2=.123$, and for Lyngbya $2 \mathrm{sp} .: \mathrm{F}(2$, 56) $=34.023, \mathrm{p}=0.03$, partial $\eta 2=.055$.

Pairwise comparison was analysis to know the statistically significant between days. For all cyanobacteria, the absorbance concentration was not statistically significantly difference for all of the days. For Leptolyngbya sp.: The absorbance concentration was not statistically significantly different between day $0-4(\mathrm{M}=.100$, $\mathrm{SE}=.075, \mathrm{p}=.529)$; day $4-7(\mathrm{M}=.140, \mathrm{SE}=.060, \mathrm{p}=.088)$ but the absorbance concentration was statistically significantly difference at day $0-7(\mathrm{M}=.119, \mathrm{SE}=.017, \mathrm{p}=.000)$. For the Lyngbya $1 \mathrm{sp}$.: The absorbance concentration was not statistically significantly different between all days. For Lyngbya 2 sp.: The absorbance concentration was not statistically significantly different between day $4-7(\mathrm{M}=-.028, \mathrm{SE}=.011, \mathrm{p}=0.58)$; but the absorbance concentration was statistically significantly difference at day 0-4 $(\mathrm{M}=.079$, $\mathrm{SE}=.007, \mathrm{p}=.000)$, day $0-7(\mathrm{M}=.052, \mathrm{SE}=.011, \mathrm{p}=.000)$.

\subsection{Green Microalgae - Exposure to Low Zn Concentrations}

For the first experiment, green microalgae were exposed at low concentrations (0.125 ppm, $0.25 \mathrm{ppm}, 0.5 \mathrm{ppm}$, and $1 \mathrm{ppm})$. The results show that most of the green microalgae have some tolerance to bulk and nano $\mathrm{ZnO}$. The results will be divided by microscope and the absorbance. The trial conducted with three green microalgae used 
were: 146-2-6 Chlorococcum sp., 146-2-10 Chlamydomonas sp., and 146-2-16 Chlorella. Then, a second trial was performed which yielded similar results.

\subsubsection{Optical microscope}

After the seven days, the three microalgae were observed in 100x magnification.

For the Chlorococcum sp. (Figure 50), Chlamydomonas sp. (Figure 51) and Chlorella sp. (Figure 52), no morphology changes in all the concentration were observed. These microalgae kept their shape and color.
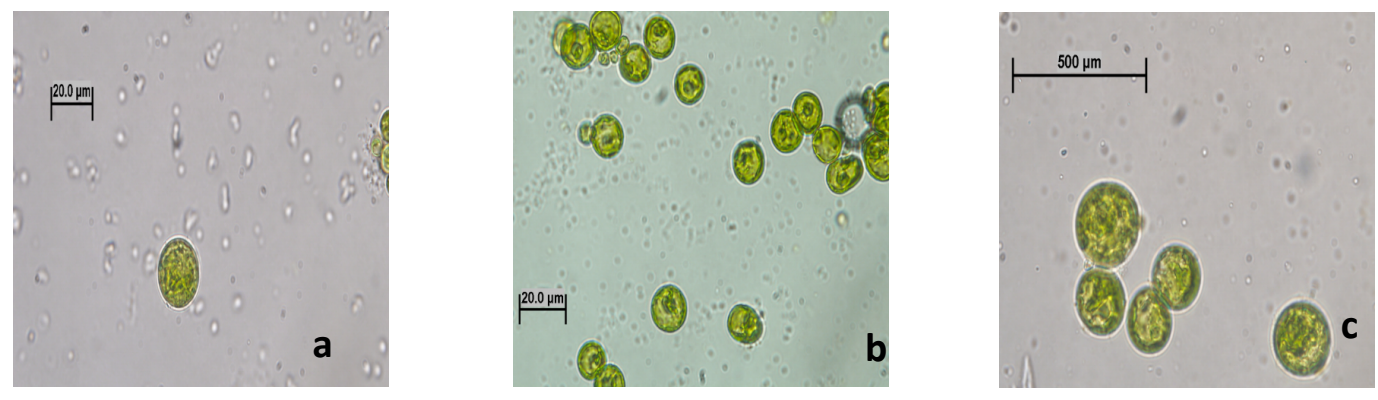

Figure 50: Chlorococcum sp., in BG 11 media: a) standard $\mathrm{ZnSO}_{4}$ b) Bulk $\mathrm{ZnO} 1$ ppm c) Nano ZnO 1 ppm.
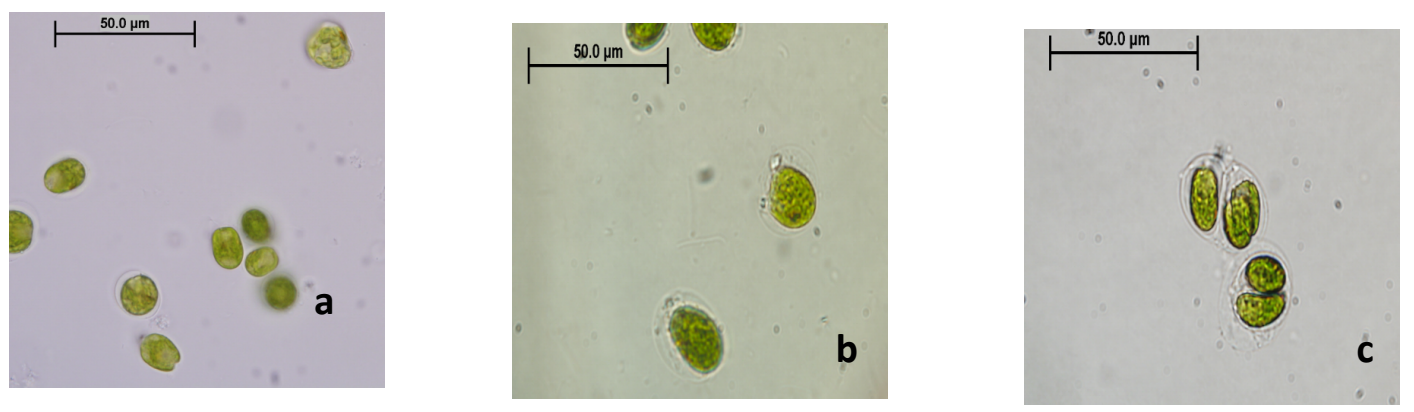

Figure 51: Chlamydomonas sp., in BG 11 media: a) standard $\mathrm{ZnSO}_{4}$ b) Bulk $\mathrm{ZnO}$ $1 \mathrm{ppm} \mathrm{c)} \mathrm{Nano} \mathrm{ZnO} 1$ ppm. 

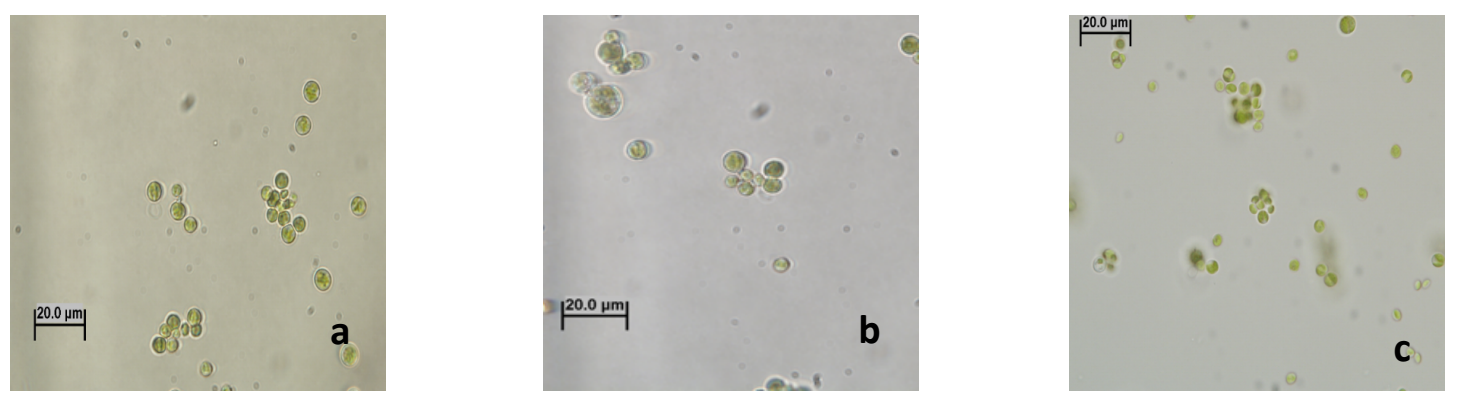

Figure 52: Chlorella sp., in BG 11 media: a) standard $\mathrm{ZnSO}_{4}$ b) Bulk $\mathrm{ZnO} 1$ ppm c) Nano $\mathrm{ZnO} 1$ ppm.

\subsubsection{Statistical Analysis}

The results for the two-way mixed (ANOVA) Lower dosage experiments with: Chlorococcum sp., Chlamydomonas sp., and Chlorella sp., dosages was as follow: B1: 0.125 ppm Bulk ZnO, B2: 0.25 ppm Bulk ZnO, B3 0.5 ppm: Bulk ZnO, B4: 1 ppm Bulk ZnO, N1: 0.125 ppm NPs ZnO, N2: 0.25 ppm NPs ZnO, N3: 0.5 ppm NPs ZnO and N4: 1 ppm NPs ZnO.

After all the assumption was met the results were reported. Test of betweensubjects effects was analysis to determine if there was a statistically significant difference in absorbance concentration between intervention of treatments $F(8,38)=6.521, p=$ $.000, \eta^{2}=.043$ for Chlorococcum sp. $; \mathrm{F}(8,34)=4.217, \mathrm{p}=.000$, partial $\eta^{2}=.193$ for Chlamydomonas sp. and $\mathrm{F}(8,34)=6.303, \mathrm{p}=.000, \eta 2=.088$ for Chlorella sp.

Multiple Comparisons was analyzed know if the absorbance concentration was or not statistically significantly for the treatments. For Chlorococcum sp., the absorbance concentration in all the treatments was not statistically significantly lower. For example, the control group and $\mathrm{n} 4(M=.035775, S E=.039786 \mathrm{~nm}, p=.992)$. For Chlamydomonas sp. the absorbance concentration was statistically significantly greater in the control compare with $n 3$ and $n 4$. For example, control and $n 4(M=.155350, S E=$ 
$.0322812, \mathrm{p}=.001)$. The absorbance concentration in most treatments was not statistically significantly different. For example: the control group b1 and $\mathrm{n} 4 \mathrm{M}=.041512 \mathrm{SE}=$ $.0395362, \mathrm{p}=.979)$. For Chlorella sp., the absorbance concentration in all the treatments was not statistically significantly lower. For example: the control group and $\mathrm{n} 4(\mathrm{M}=-.183887, \mathrm{SE}=.0629066 \mathrm{~nm}, \mathrm{p}=.119)$.

There was statistically significant interaction between the intervention and days on absorbance, $\mathrm{F}(3,114)=103.874, p=0.00, \eta^{2}=1.212$ for Chlorococcum sp.; $\mathrm{F}(3,34)$ $=684.391, \mathrm{p}=0.00, \eta 2=10.450$ for Chlamydomonas sp. and $\mathrm{F}(3,102)=270.412, \mathrm{p}$ $=0.00, \eta 2=1.876$ for Chlorella sp. .

The Pairwise comparison table was used to know if there was statistically significant between days of testing. The absorbance concentration was not statistically significantly different between day 0 and day $2(\mathrm{M}=-.032 \mathrm{SE}=.037, \mathrm{p}=.021)$, but the absorbance concentration was statistically significantly difference at for the rest of the days for Chlorococcum sp. For Chlamydomonas sp. and Chlorococcum sp., the absorbance concentration was statistically significantly difference for all days.

The results were reported, for Chlorococcum sp.: There were no outliers, as assessed by boxplot. The data was normally distributed, as assessed by Shapiro-Wilk's test of normality $(p>.05)$. There was homogeneity of variances $(p>.05)$ and covariance $(p>.05)$, as assessed by Levene's test of homogeneity of variances with the exception of day 0 for Chlorococcum sp. and Box's M test, respectively. "Mauchly's test of sphericity was used to examine the assumption of sphericity. The Huynh-Feldt epsilon was used to interpret the two-way interactions. Test of Within-subjects effects: There was a statistically significant interaction between the intervention and days on absorbance, $\operatorname{g~F}(3,114)=103.874$. The absorbance concentration in all the treatments 
was not statistically significantly lower. For example, the control group and n4 $(\mathrm{M}=$ $.035775, \mathrm{SE}=.039786 \mathrm{~nm}, \mathrm{p}=.992)$.

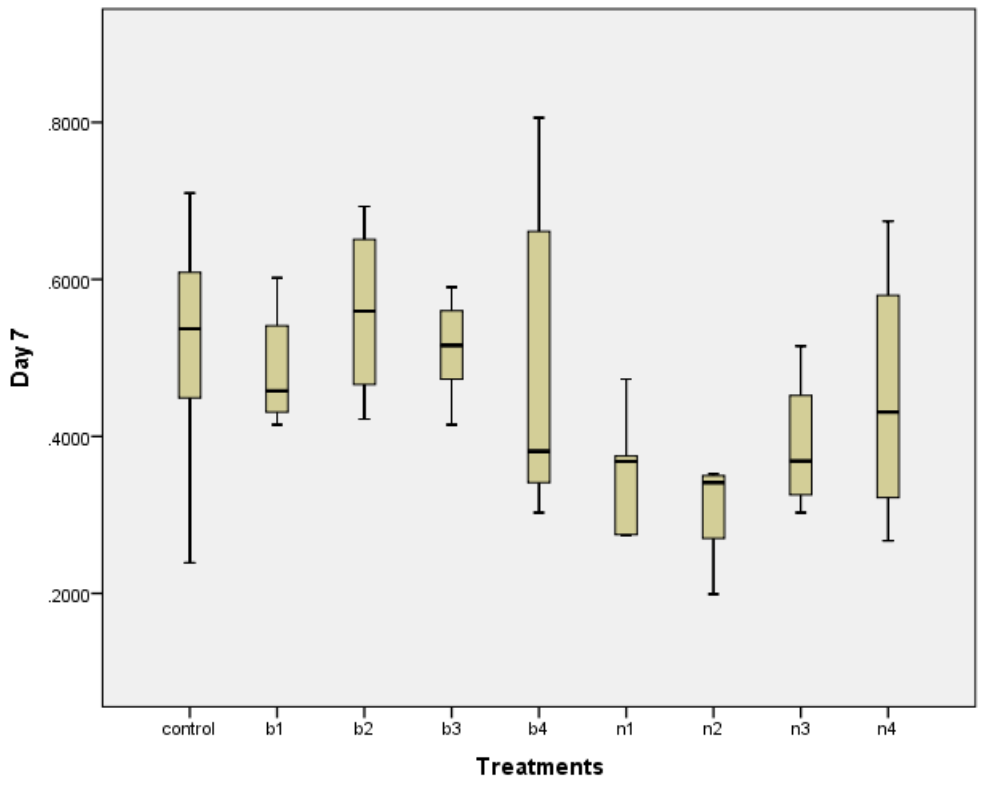

Figure 53: Box plot's shows the effects of ZnO Nano, bulk particles and extra zinc on Chlorococcum sp. growth at day 7.

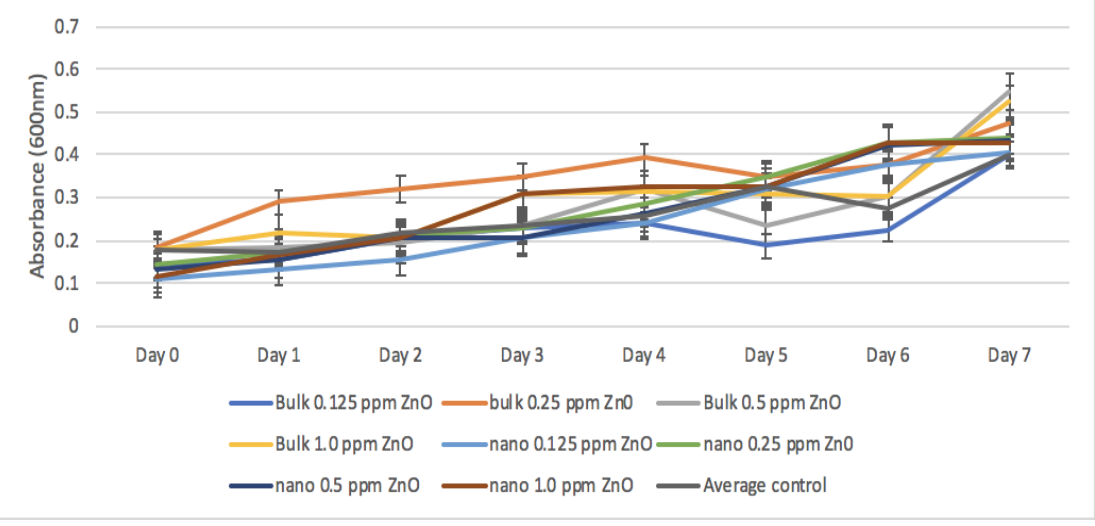

Figure 54: The effects of $\mathrm{ZnO}$ Nano, bulk particles and extra zinc on Chlorococcum sp. growth. 
For Chlamydomonas sp.: There were no outliers, as assessed by boxplot. The data was normally distributed, as assessed by Shapiro-Wilk's test of normality $(p>.05)$. There was homogeneity of variances $(p>.05)$ and covariance $(p>.05)$, as assessed by Levene's test of homogeneity of variances and Box's M test, respectively. "Mauchly's test of sphericity was used to examine the assumption of sphericity. The Huynh-Feldt epsilon was used to interpret the two-way interactions. Test of Within-subjects effects: There was a statistically significant interaction between the intervention and days on absorbance $F(3,102)=270.412, p=0.00, \eta 2=1.876$ : Absorbance concentration was statistically significantly greater in the control compare with $\mathrm{n} 3$ and $\mathrm{n} 4$. For example, the control and $\mathrm{n} 4$ yielded $\mathrm{M}=.155350, \mathrm{SE}=.0322812$, and $\mathrm{p}=.001$. The absorbance concentration in most treatments excluding control was not statistically significantly lower than it. For example, the control group b1 and $n 4(\mathrm{M}=.041512 \mathrm{SE}=.0395362, \mathrm{p}$ $=.979$ ). 


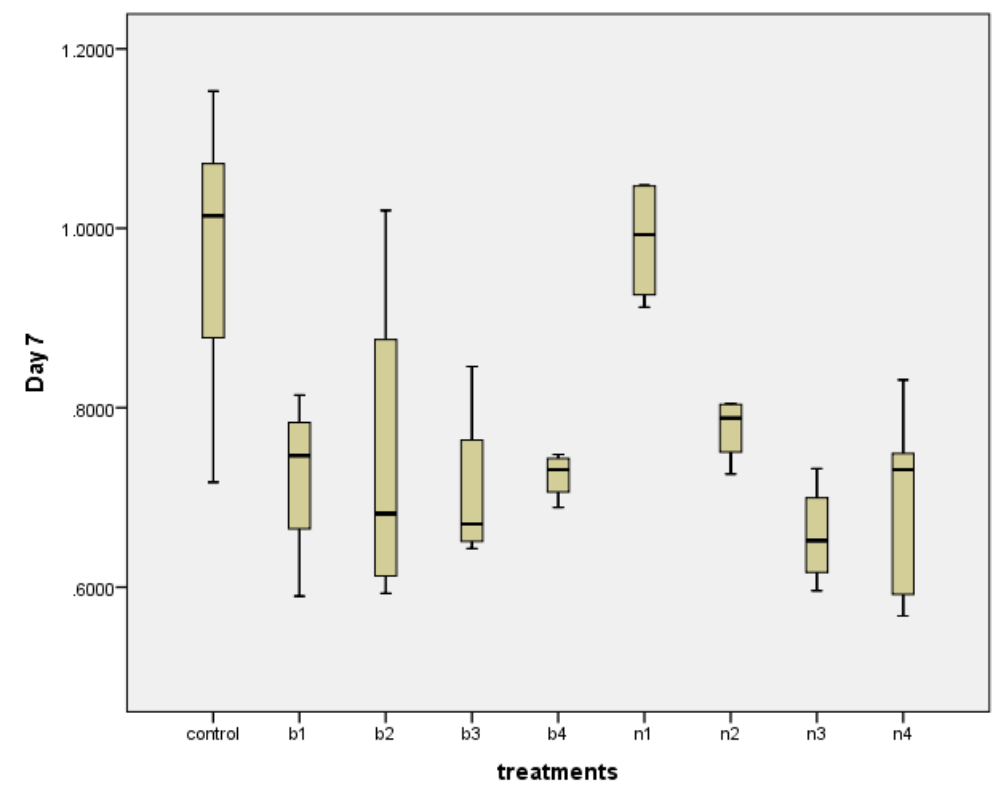

Figure 55: Box plot's shows the effects of $\mathrm{ZnO}$ Nano, bulk particles and extra zinc on Chlamydomonas sp. growth at day 7.

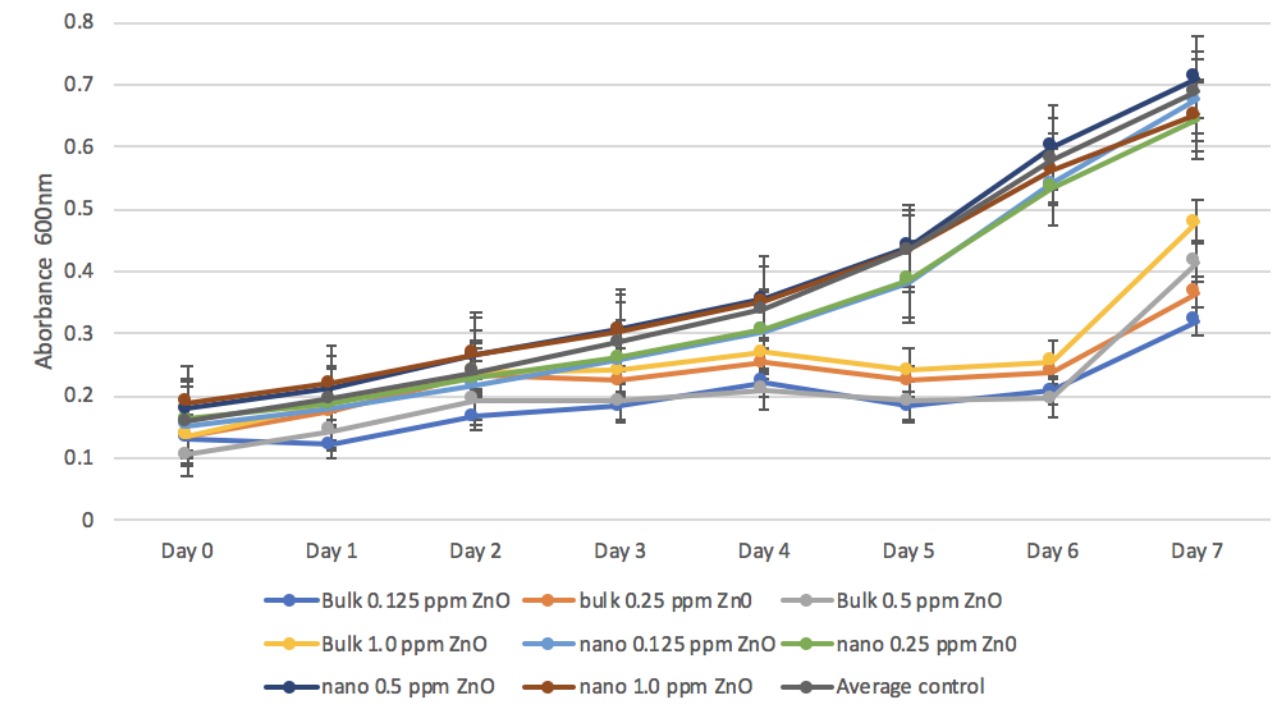

Figure 56: The effects of $\mathrm{ZnO}$ Nano, bulk particles and extra zinc on Chlamydomonas sp. growth.

For Chlorella sp.: There were no outliers, as assessed by boxplot. The data was normally distributed, as assessed by Shapiro-Wilk's test of normality ( $p>.05)$. There 
was homogeneity of variances $(p>.05)$ and covariance $(p>.05)$, as assessed by Levene's test of homogeneity of variances with the exception of days 7 and Box's M test, respectively. "Mauchly's test of sphericity was used to examine the assumption of sphericity. The Huynh-Feldt epsilon was used to interpret the two-way interactions. Test of Within-subjects effects: There was a statistically significant interaction between the intervention and days on absorbance $F(3,34)=684.391, p=0.00, \eta 2=10.450$. The absorbance concentration in all the treatments was not statistically significantly lower than. For example, the control group and $\mathrm{n} 4(\mathrm{M}=-.183887, \mathrm{SE}=.0629066 \mathrm{~nm}, \mathrm{p}=$ $.119)$.

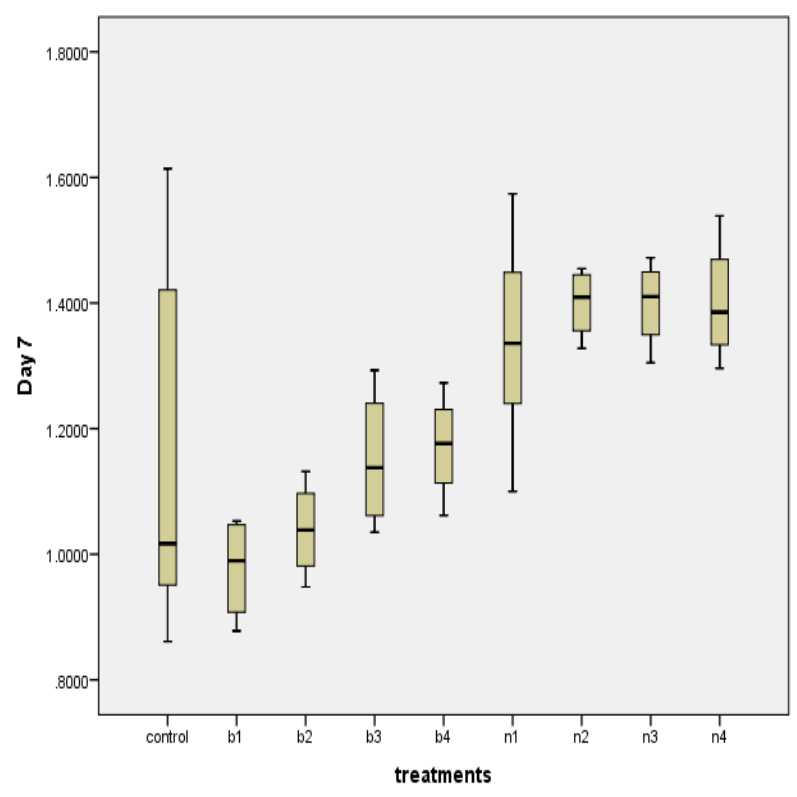

Figure 57: Box plot's shows the effects of $\mathrm{ZnO}$ Nano, bulk particles and extra zinc on Chlorella sp. growth at day 7. 


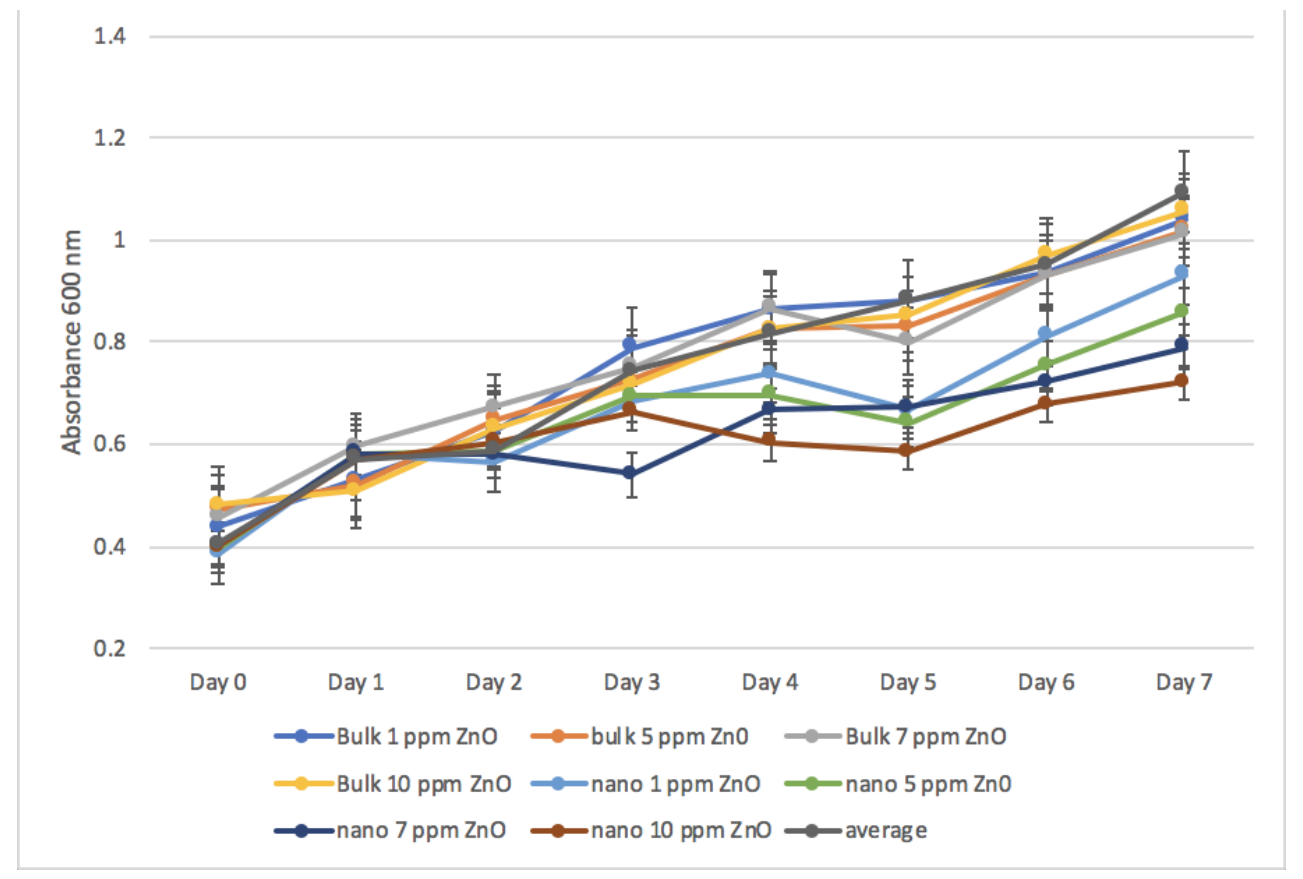

Figure 58: The effects of $\mathrm{ZnO}$ Nano, bulk particles and extra zinc on Chlorella sp. growth.

\subsection{Green Microalgae - Exposure to High Zn Concentrations}

For the second experiment, which was exposed to high concentration (2.5 ppm, 5 ppm, $7.5 \mathrm{ppm}, 10 \mathrm{ppm}$, and $20 \mathrm{ppm}$ ), showed some tolerance again. The results will be divided by microscope and the absorbance. This experiment was performed with four cyanobacteria again with the 24 wells: 146-2-6 Chlorococcum sp., 146-2-10 Chlamydomonas sp., and 146-2-16 Chlorella.

\subsubsection{Optical Microscope}

After seven days of testing, the three microalgae were observed in 100x magnification. For the Chlorococcum sp. (Figure 59), the Chlamydomonas sp. (Figure 60), and the Chlorella sp. (Figure 61) some morphology changes in high nano concentrations was observed. These microalgae retained their original shape and color. 
For the Chlorococcum sp. (Figure 59), from control to nano it retained the same color, however there was small noted morphology change for the 20 ppm nano.

Chlamydomonas sp. (Figure 60) for the nano 20 ppm appears to have some sensitivity as is indicated with the clear parches observed. The Chlorella sp. (Figure 61) also did not show any morphology change (i.e. tolerance).

Table 4: Potential Tolerance and Sensitivity of the Microalgae

\begin{tabular}{|l|l|}
\hline Microalgae & Tolerance or Sensitive \\
\hline Chlorococcum sp. & Tolerance \\
\hline Chlamydomonas $\mathrm{sp}$. & Sensitivity \\
\hline Chlorella sp. & Tolerance \\
\hline
\end{tabular}
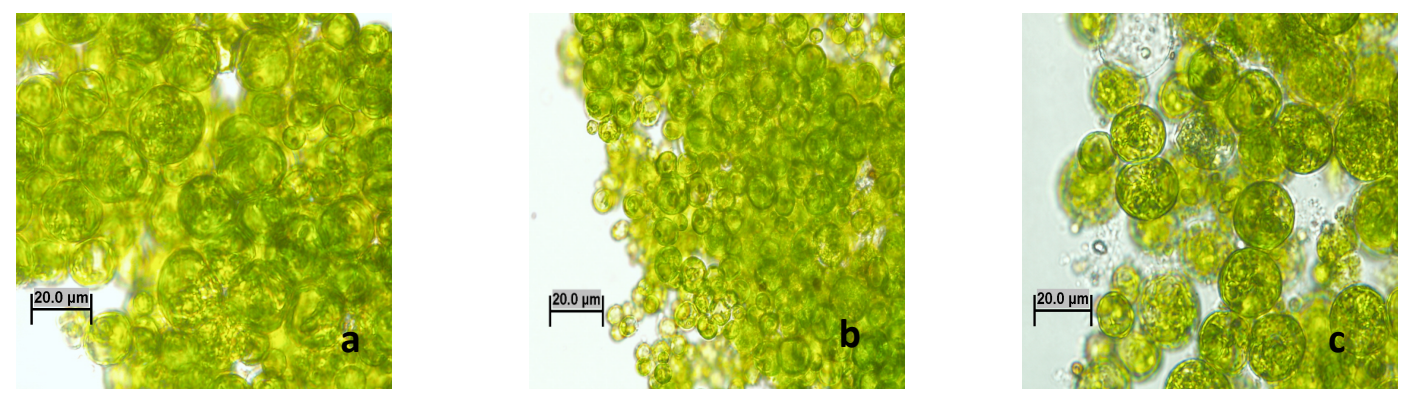

Figure 59: Chlorococcum sp., in BG 11 media: a) standard $\mathrm{ZnSO}_{4}$ b) Bulk $\mathrm{ZnO} 20$ ppm c) Nano ZnO 20 ppm.
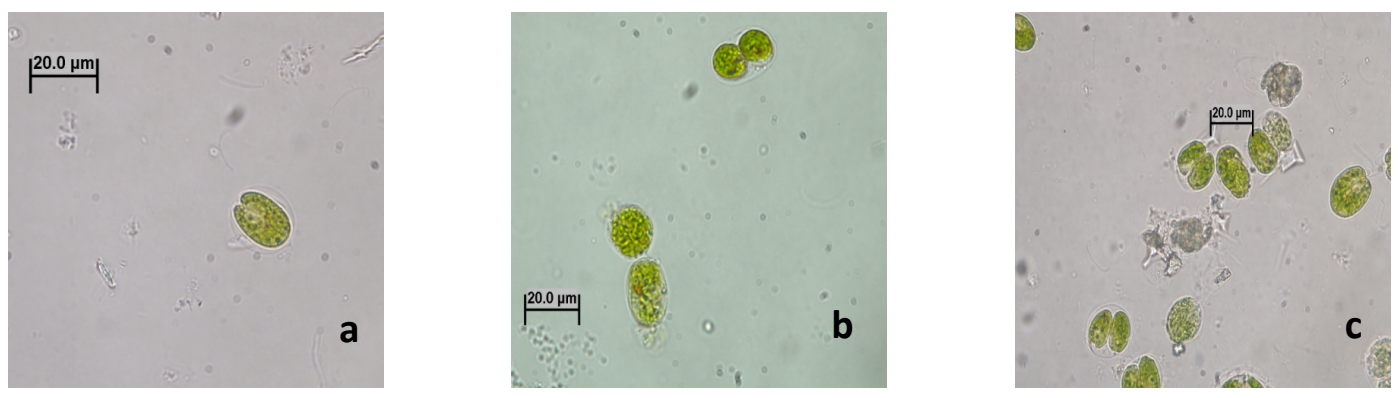
Figure 60: Chlamydomonas sp. in BG 11 media: a) standard $\mathrm{ZnSO}_{4}$ b) Bulk $\mathrm{ZnO}$ 20 ppm c) Nano ZnO 20 ppm.
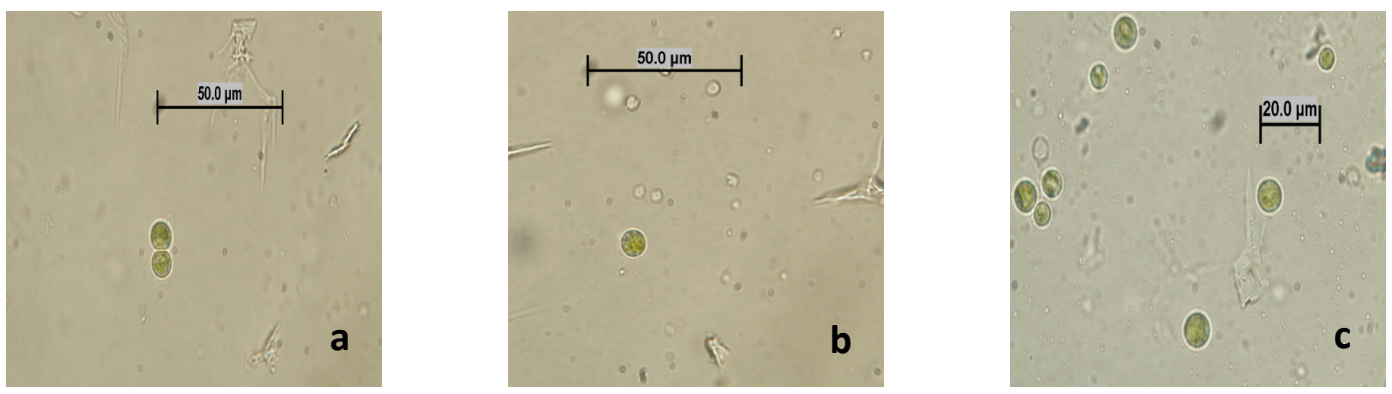

Figure 61: Chlorella sp. in BG 11 media with a) standard $\mathrm{ZnSO}_{4}$ b) Bulk $\mathrm{ZnO}$ 20 ppm c) Nano ZnO 20 ppm.

\subsubsection{Statistical Analysis}

The results for the two-way mixed (ANOVA) with higher dosage with Chlorococcum sp., Chlamydomonas sp. and Chlorella sp.; the dosage was coded as follows: B1: 2.5 ppm Bulk ZnO, B2: 5 ppm Bulk ZnO, B3: 7.5 ppm: Bulk ZnO, B4: 10 ppm Bulk ZnO, N1: 2.5 ppm NPs ZnO, N2: 5 ppm NPs ZnO, N3: 7.5 ppm: NPs ZnO and N4: 10 ppm NPs ZnO.

After all the assumption was met the results were reported. Test of betweensubjects' effects was analysis to determine if there was a statistically significant difference in absorbance concentration between intervention of treatments $\mathrm{F}(8,38)=$ 2.451, $\mathrm{p}=.000, \eta^{2}=.045$ for Chlorococcum sp.; $\mathrm{F}(8,33)=4.646, \mathrm{p}=.001, \eta^{2}=.199$ for Chlamydomonas sp. and $\mathrm{F}(8,34)=6.346, \mathrm{p}=.000, \eta 2=.090$ for Chlorella sp.

Multiple Comparisons was analyzed to see if the absorbance concentration was or was not statistically significant for the treatments. For Chlorococcum sp., the absorbance concentration in all the treatments was not statistically significantly different. For 
example: the control and n4 $(M=.039750, S E=.0399180 \mathrm{~nm}, p=.984)$. For

Chlamydomonas sp., the absorbance concentration was statistically significantly greater in the control to $\mathrm{n} 2, \mathrm{n} 3$ and $\mathrm{n} 4$. For example: Control and $\mathrm{n} 4(\mathrm{M}=.157857, \mathrm{SE}=$ $.0323052 \mathrm{~nm}, \mathrm{p}=.001)$. The absorbance concentration in was not statistically significantly for most of the treatments except control and n4/n3/n2. For example: the control group and b1 $(\mathrm{M}=.116345, \mathrm{SE}=.0348937 \mathrm{~nm}, \mathrm{p}=.047)$. For Chlorella sp., the absorbance concentration in all the treatments was not statistically significantly. For example: the control and $\mathrm{n} 4(\mathrm{M}=.198951, \mathrm{SE}=. .0621882 \mathrm{~nm}, \mathrm{p}=.065)$.

There was a statistically significant interaction between the intervention and days on absorbance, for Chlorococcum sp.: $F(3,114)=105.894, p=0.00$, partial $\eta^{2}=.399$; for Chlamydomonas sp.: F $(3,99)=491.399, \mathrm{p}=.000, \eta 2=4.91$ and for Chlorella sp.: $\mathrm{F}$ $(3,102)=267.584 p=.000$, partial $\eta 2=1.875$.

The Pairwise comparison table was used to know if there was statistically sig. between days. The absorbance concentration was not statistically significantly different between day 0 and day $2(\mathrm{M}=.030, \mathrm{SE}=.010, \mathrm{p}=.019)$, but the absorbance concentration was statistically significantly difference at for the rest of the days for Chlorococcum sp. For Chlamydomonas sp. and Chlorococcum sp., the absorbance concentration was statistically significantly difference for all days.

The results were reported, for Chlorococcum sp.: There were no outliers, as assessed by boxplot. The data was normally distributed, as assessed by Shapiro-Wilk's test of normality $(p>.05)$. There was homogeneity of variances $(p>.05)$ and covariance $(p>.05)$, as assessed by Levene's test of homogeneity of variances and Box's M test, respectively. "Mauchly's test of sphericity was used to examine the assumption of sphericity. The Huynh-Feldt epsilon was used to interpret the two-way interactions. Test 
of Within-subjects' effects: There was a statistically significant interaction between the intervention and days on absorbance: $F(3,114)=105.894, p=0.00, \eta 2=.399$. The absorbance concentration in all the treatments was not statistically significantly. For example: the control and $\mathrm{n} 4(\mathrm{M}=.039750, \mathrm{SE}=.0399180 \mathrm{~nm}, \mathrm{p}=.984)$.

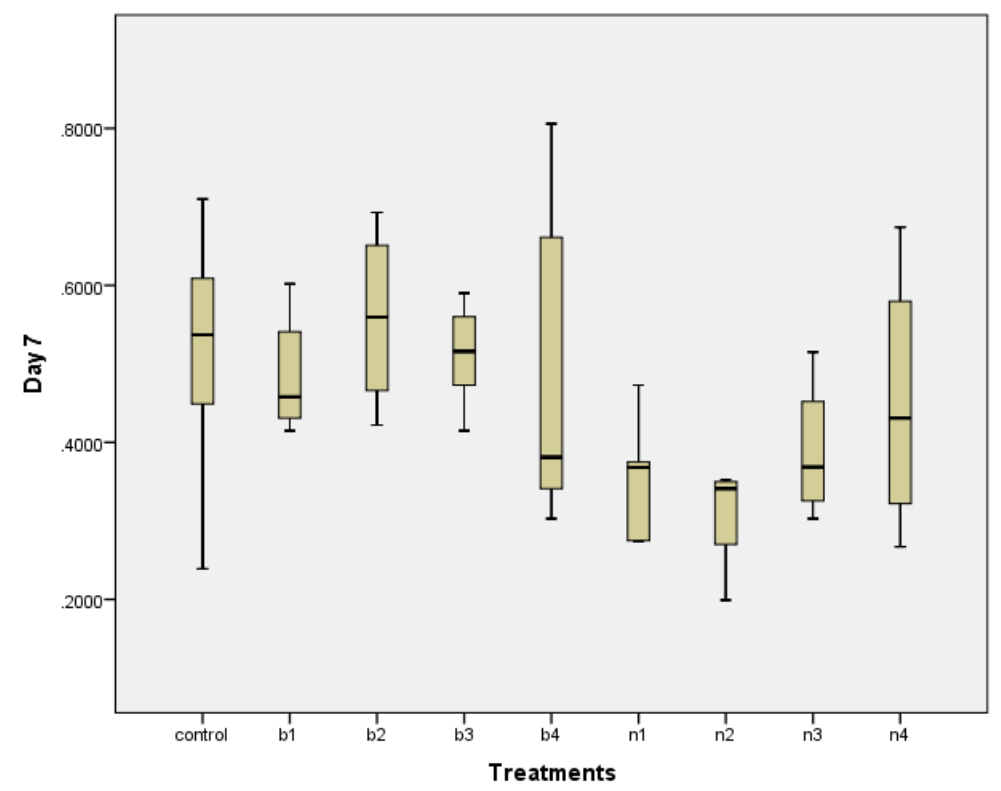

Figure 62: Box plot's shows the effects of $\mathrm{ZnO}$ Nano, bulk particles and extra zinc on Chlorococcum sp. growth at day 7. 


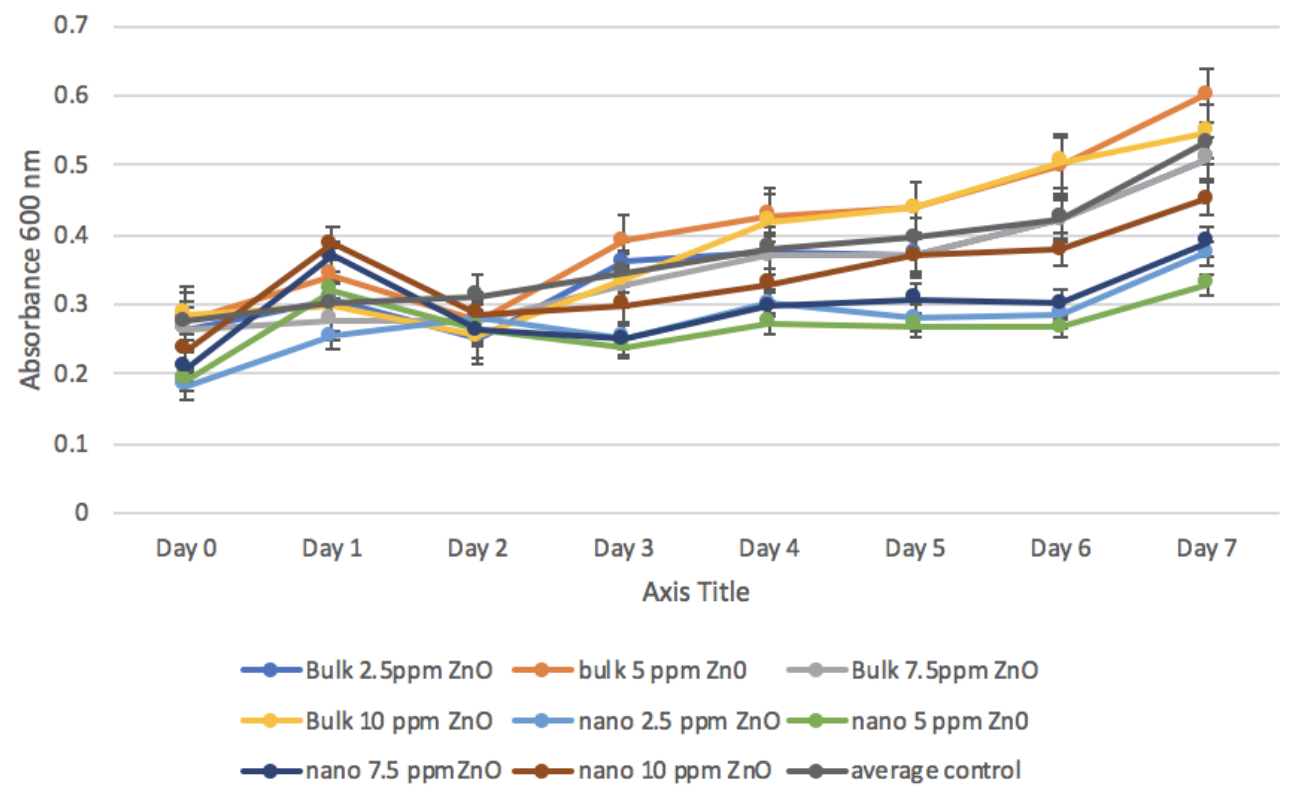

Figure 63: The effects of $\mathrm{ZnO}$ Nano, bulk particles and extra zinc on Chlorococcum sp. growth.

For Chlamydomonas sp.: There were no outliers, as assessed by boxplot. The data was normally distributed, as assessed by Shapiro-Wilk's test of normality $(\mathrm{p}>.05)$. There was homogeneity of variances $(p>.05)$ and covariance $(p>.05)$, as assessed by Levene's test of homogeneity of variances and Box's M test, respectively. "Mauchly’s test of sphericity was used to examine the assumption of sphericity. The Huynh-Feldt epsilon was used to interpret the two-way interactions. Test of Within-subjects effects: There was a statistically significant interaction between the intervention and days on absorbance $\mathrm{F}(3,99)=491.399 ; \mathrm{p}=.000, \eta 2=4.911$. Absorbance concentration was statistically significantly greater in the control to $\mathrm{n} 1, \mathrm{n} 3$, and $\mathrm{n} 4$. For example: Control and $\mathrm{n} 4 \mathrm{M}=$ $.157857, \mathrm{SE}=.0323052 \mathrm{~nm}, \mathrm{p}=.001)$. The absorbance concentration in was not statistically significantly for most of the treatments except control and $n 1 / n 4 / n 3$. For example: the control group and b1 $(\mathrm{M}=.116345, \mathrm{SE}=.0348937 \mathrm{~nm}, \mathrm{p}=.047)$. 


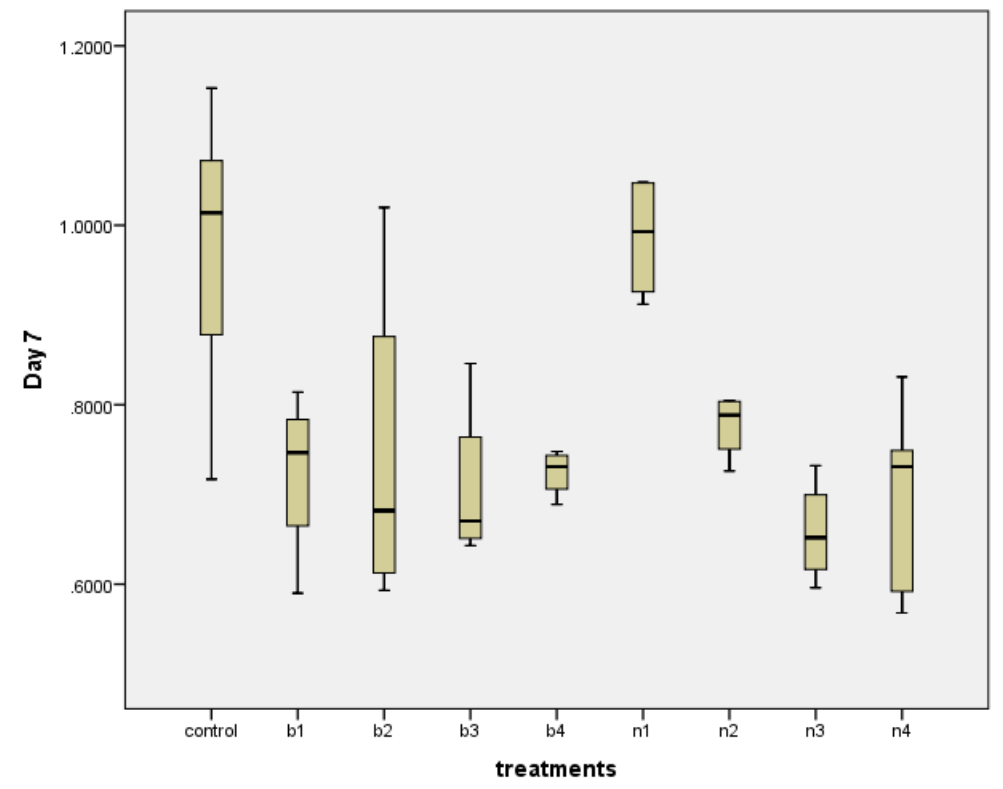

Figure 64: Box plot's shows the effects of $\mathrm{ZnO}$ Nano, bulk particles and extra zinc on Chlamydomonas sp. growth at day 7 .

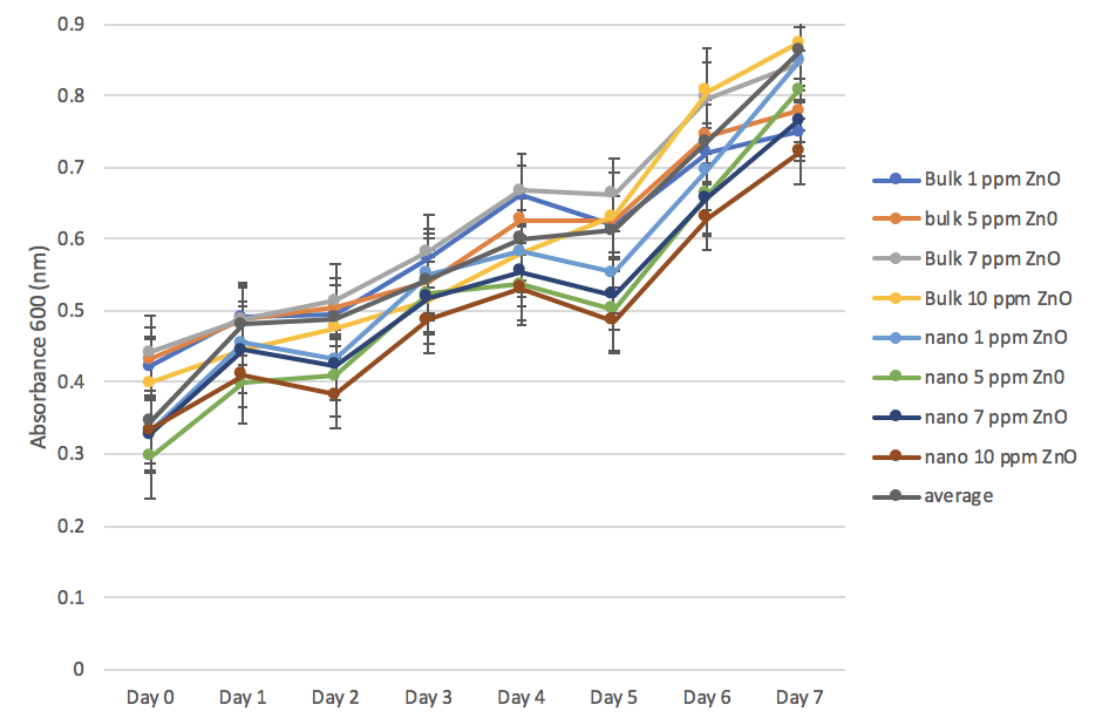

Figure 65: The effects of $\mathrm{ZnO}$ Nano, bulk particles and extra zinc on Chlamydomonas sp. 
For Chlorella sp.: There were no outliers, as assessed by boxplot. The data was normally distributed, as assessed by Shapiro-Wilk's test of normality $(\mathrm{p}>.05)$. There was homogeneity of variances $(p>.05)$ and covariance $(p>.05)$, as assessed by Levene's test of homogeneity of variances with the exception of days 0 and Box's M test, respectively. "Mauchly's test of sphericity was used to examine the assumption of sphericity. The Huynh-Feldt epsilon was used to interpret the two-way interactions. Test of Within-subjects' effects: There was a statistically significant interaction between the intervention and days on absorbance: $\mathrm{F}(3,102)=267.584$. $\mathrm{p}=.000$, partial $\eta 2=1.875$. The absorbance concentration in all the treatments was not statistically significantly. For example: the control and $\mathrm{n} 4(\mathrm{M}=.198951, \mathrm{SE}=.0621882 .0399180 \mathrm{~nm}, \mathrm{p}=.065)$.

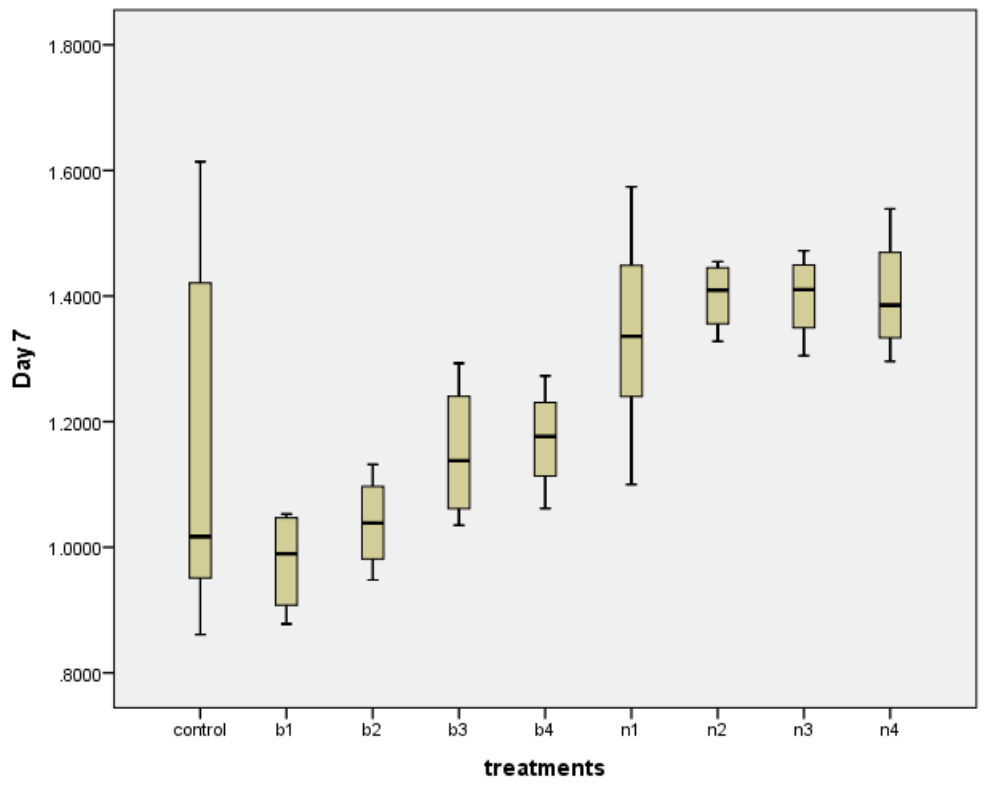

Figure 66: Box plot's shows the effects of $\mathrm{ZnO}$ Nano, bulk particles and extra zinc on Chlorella sp. growth at day 7. 


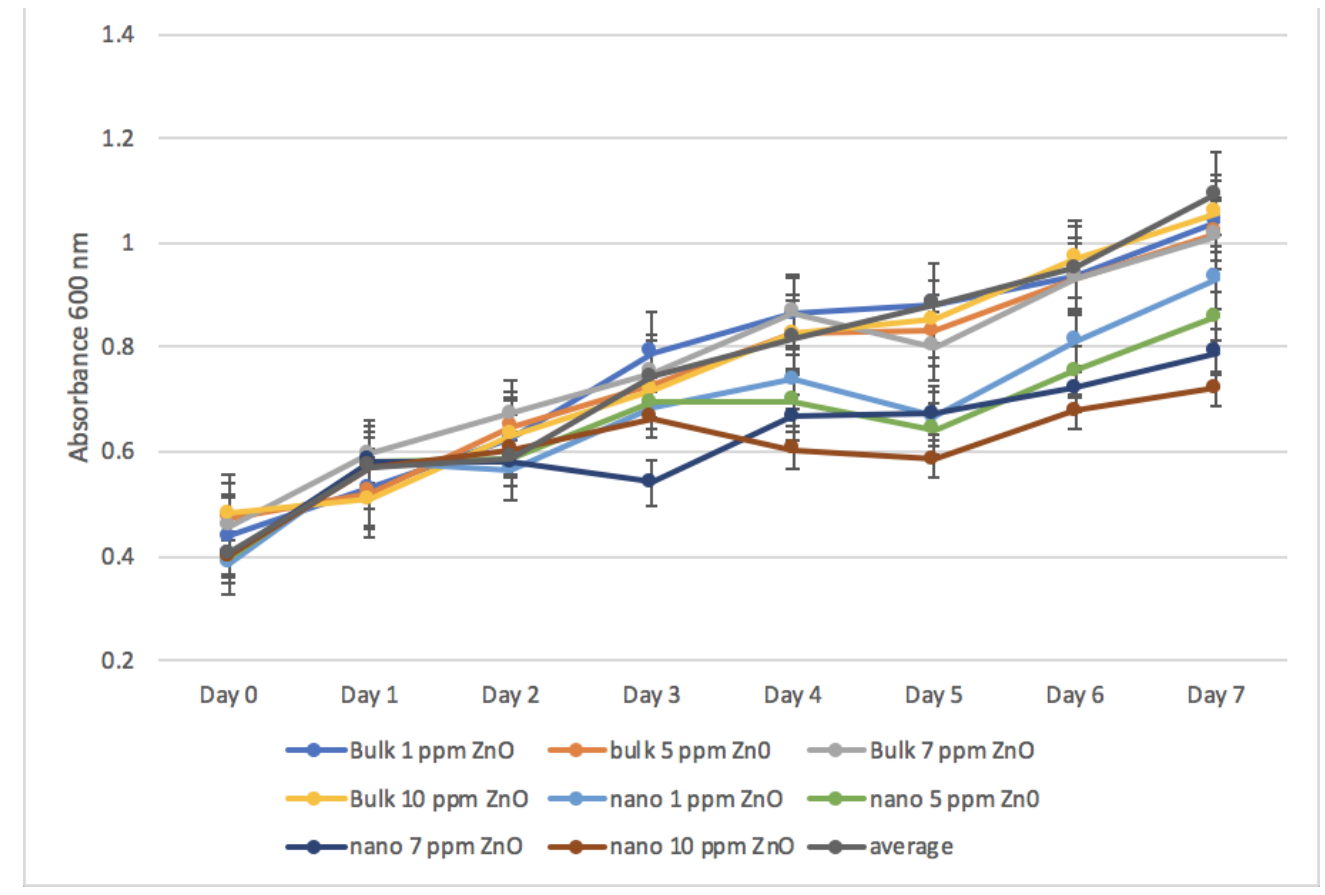

Figure 67: The effects of $\mathrm{ZnO}$ Nano, bulk particles and extra zinc on Chlorella sp.

\subsection{Flask Experiment}

Two trials were conducted for the flask experiment. The first trial was performed with Chlorococcum sp., Chlamydomonas sp., and Chlorococcum sp. however this specimen was found to have been contaminated. For the Chlamydomonas sp., the bulk grew more than control and nano (Figure 68) as observed visually. Trial two was performed with Chlorococcum sp. and Chlorella sp. This time the Chlorococcum sp. was not contaminated, and there was no color change visually between control, bulk and nano. There was measurement done with a microscope. The Chlorella sp. showed some 
sensitivity in the control and bulk as they can be seen to have the same green color, while the nano has a lighter color.

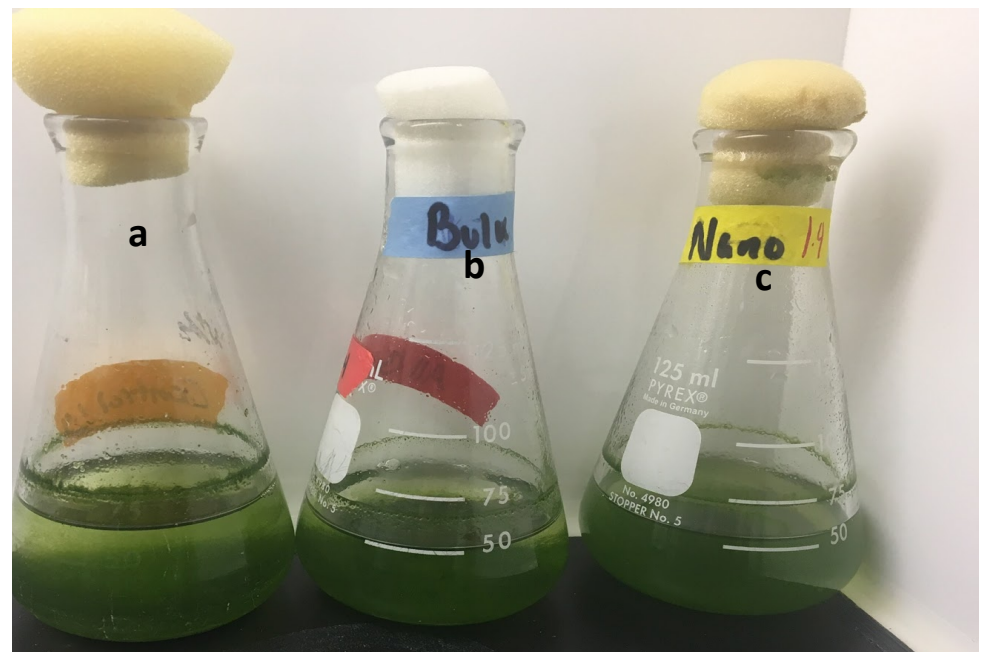

Figure 68: Chlorococcum sp. in flask experiment BG 11 media: a) standard $\mathrm{ZnSO}_{4}$ b) Bulk ZnO 20 ppm c) Nano $\mathrm{ZnO} 20$ ppm.

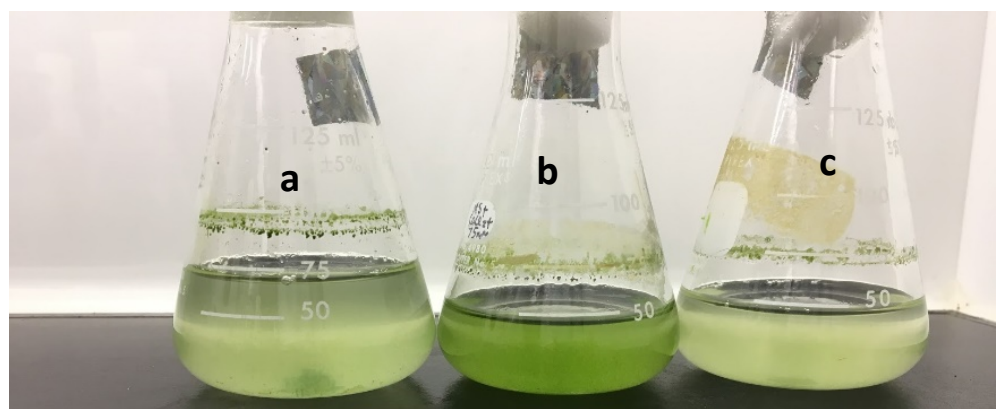

Figure 69: Chlamydomonas sp. in flask experiment BG 11 media: a) standard $\mathrm{ZnSO}_{4}$ b) Bulk ZnO 20 ppm c) Nano ZnO 20 ppm. 


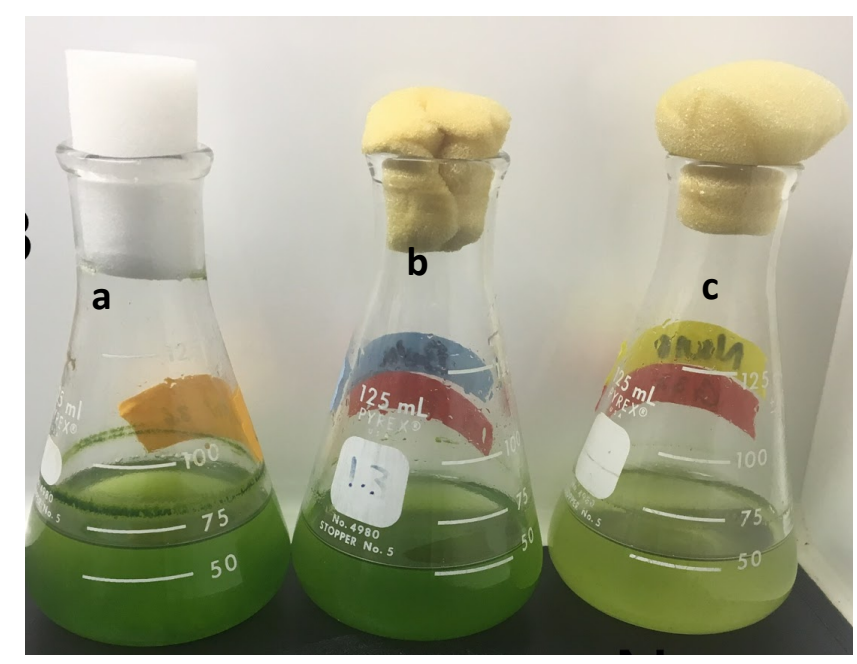

Figure 70: Chlorella sp. in flask experiment BG 11 media with a) standard $\mathrm{ZnSO}_{4}$ b) Bulk $\mathrm{ZnO} 20$ ppm c) Nano $\mathrm{ZnO} 20$ ppm.

\subsubsection{Optical Microscope}

The results for Chlorococcum sp. were unexpected. The Chlorococcum sp. was unanticipatedly contaminated with a type of filamentous microalgae, however the nano flask NPs were not contaminated (Figure 71). For the Chlamydomonas sp. (Figure 72), the control and bulk had similar morphology and color. However, the 20 ppm nano experienced some discoloration and disruption of the cells. The Chlorella sp. (Figure 73) exhibited some discoloration from control to nano. The Chlamydomonas sp. (Figure 74) was not contained such as in trial 1 . There was no visual morphology change. However, when seen through the microscopes, there is a notable difference from control and nano. The $20 \mathrm{ppm} \mathrm{ZnO}$ NPs can be observed starting to lose their green discoloration. 

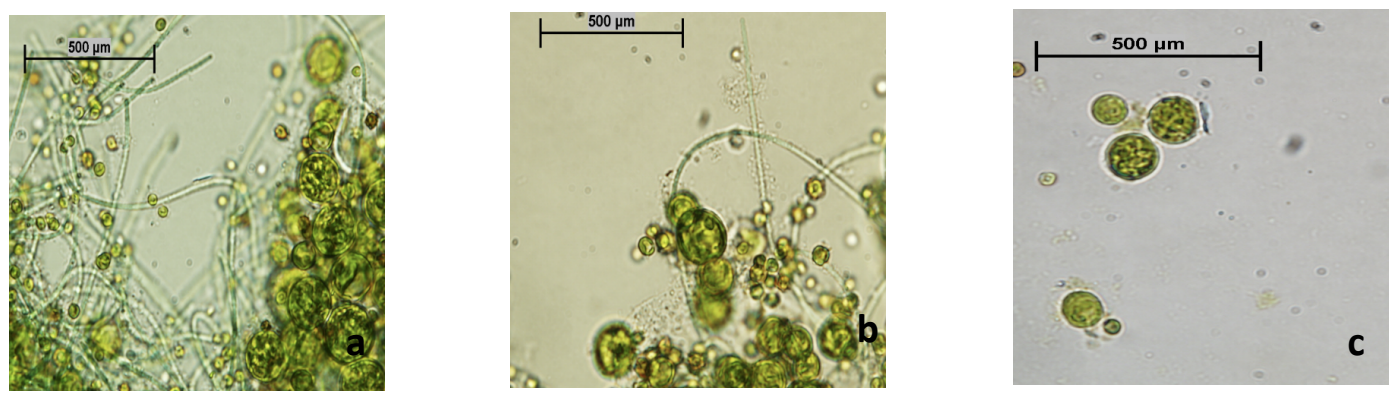

Figure 71: Chlorococcum sp. in BG 11 media: a) standard $\mathrm{ZnSO}_{4}$ b) Bulk $\mathrm{ZnO} 20$ ppm c) Nano ZnO 20 ppm.
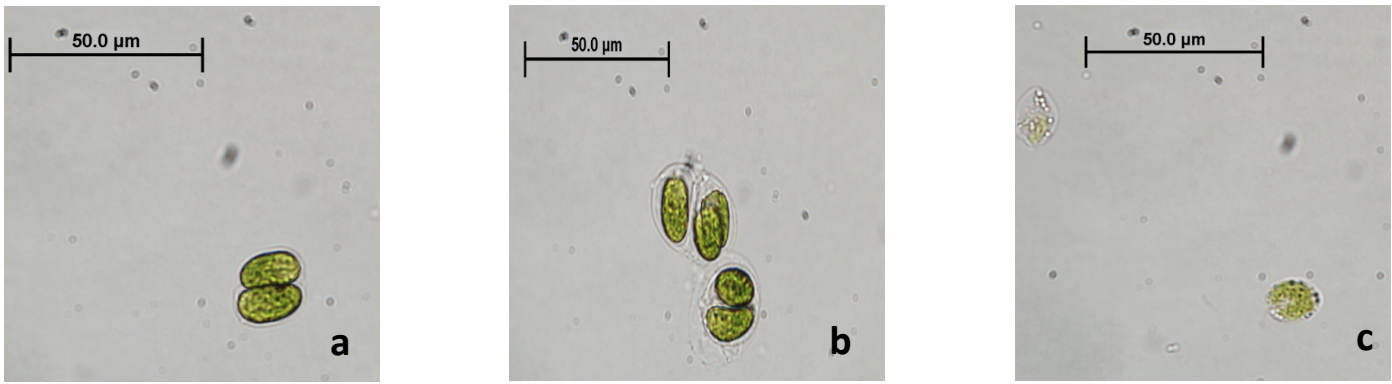

Figure 72: Chlamydomonas sp. in $\mathrm{BG} 11$ media: a) standard $\mathrm{ZnSO}_{4}$ b) Bulk $\mathrm{ZnO}$ 20 ppm c) Nano ZnO 20 ppm.
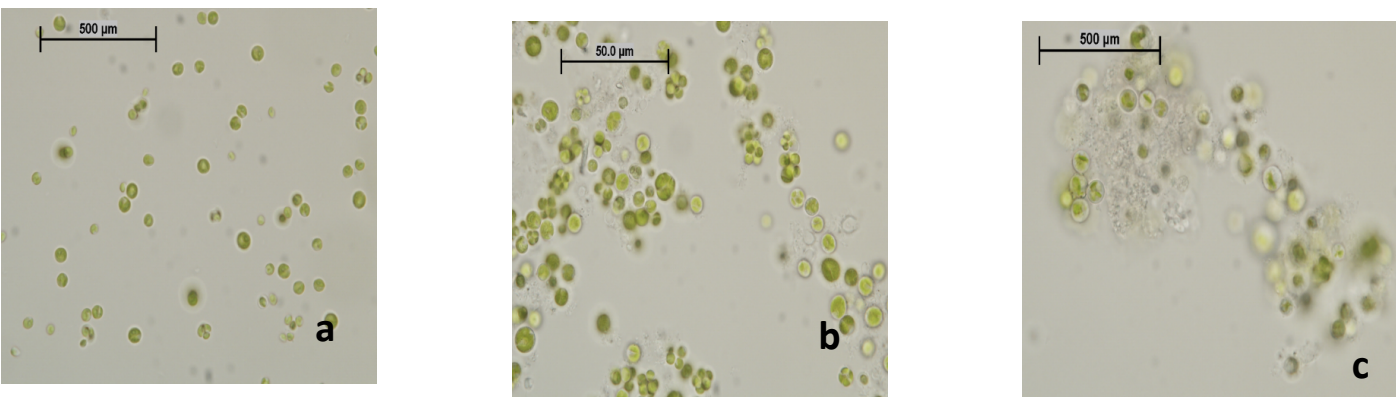

Figure 73: Chlorella sp. in flask in BG 11 media: a) standard $\mathrm{ZnSO}_{4}$ b) Bulk $\mathrm{ZnO}$ 20 ppm c) Nano ZnO 20 ppm.
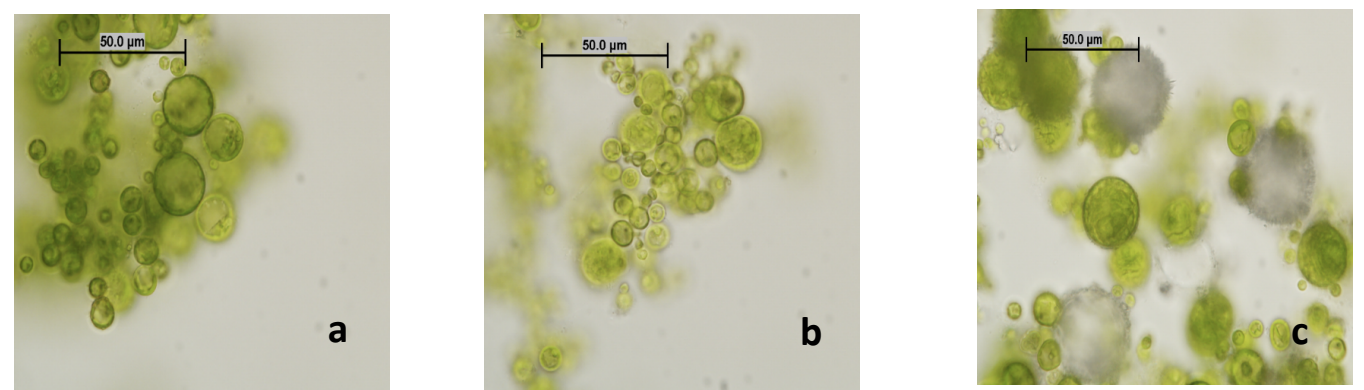

Figure 74: Chlorococcum sp. in flask in BG 11 media: a) standard $\mathrm{ZnSO}_{4}$ b) Bulk ZnO 20 ppm c) Nano ZnO 20 ppm. 


\subsubsection{Cell Counts}

The cell was counted for day 0 and day 7 on trial 1 and 2 . In trial 1 , Chlamydomonas sp. (Figure 76) exhibited an increase of cell amount for bulk and control, but for the nano there was a noted decrease. Chlorella sp. showed an increase for all three treatments, but the nano had less cells comparably (Figure 77).

Chlorococcum sp. had an increased number of cells (Figure 75).

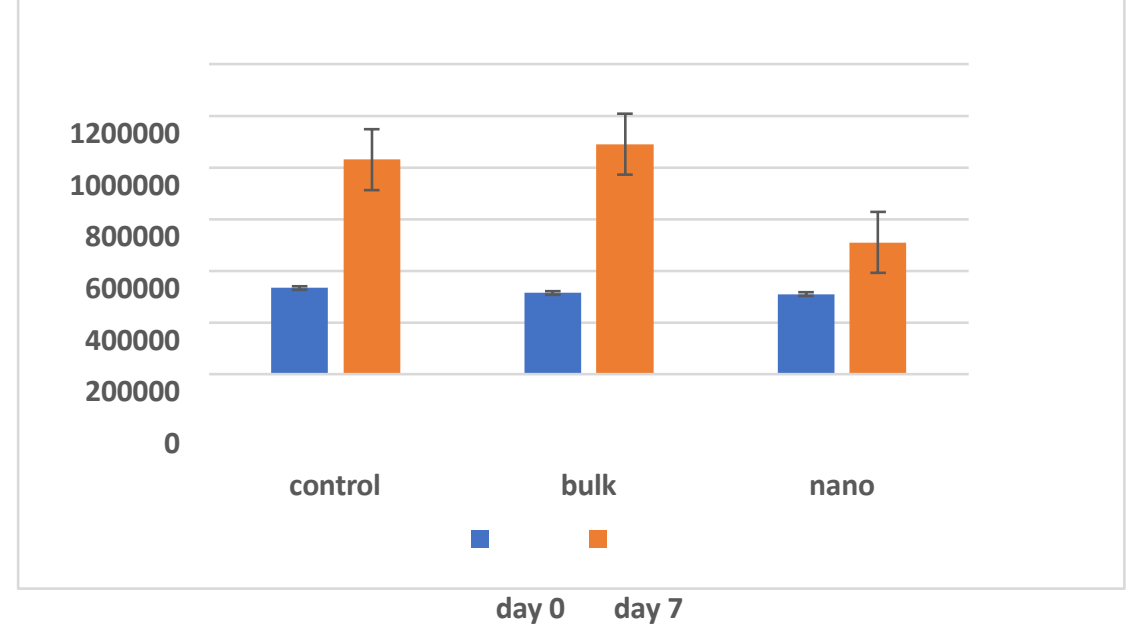

Figure 75: Chlorococcum sp. cells counted for day 0 and day 7.

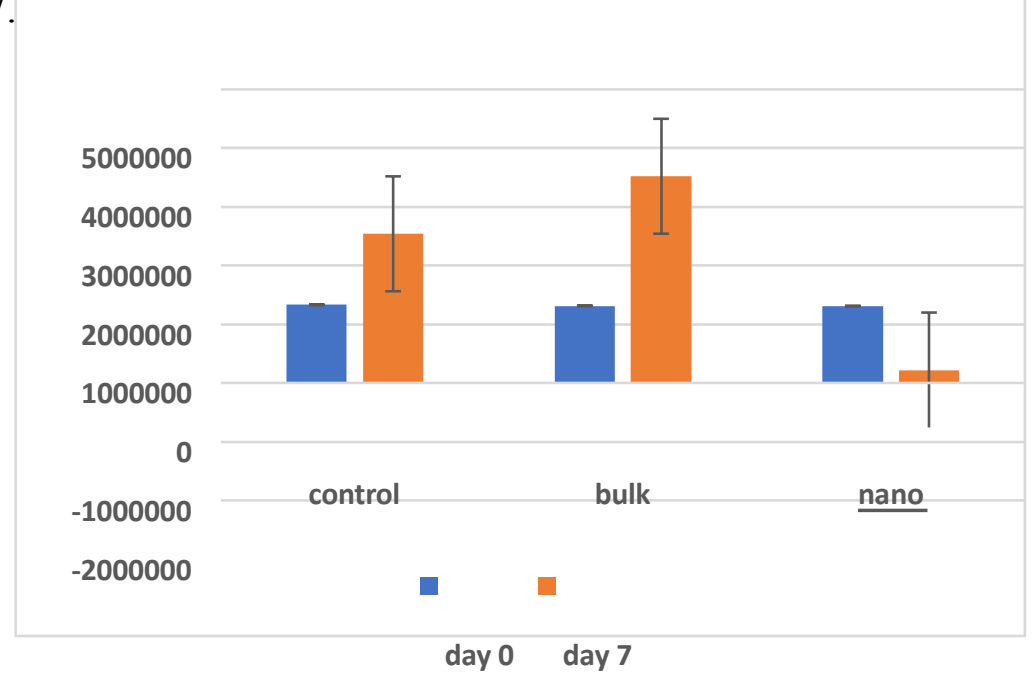

Figure 76: Chlamydomonas sp. cells counted for day 0 and day 7. 


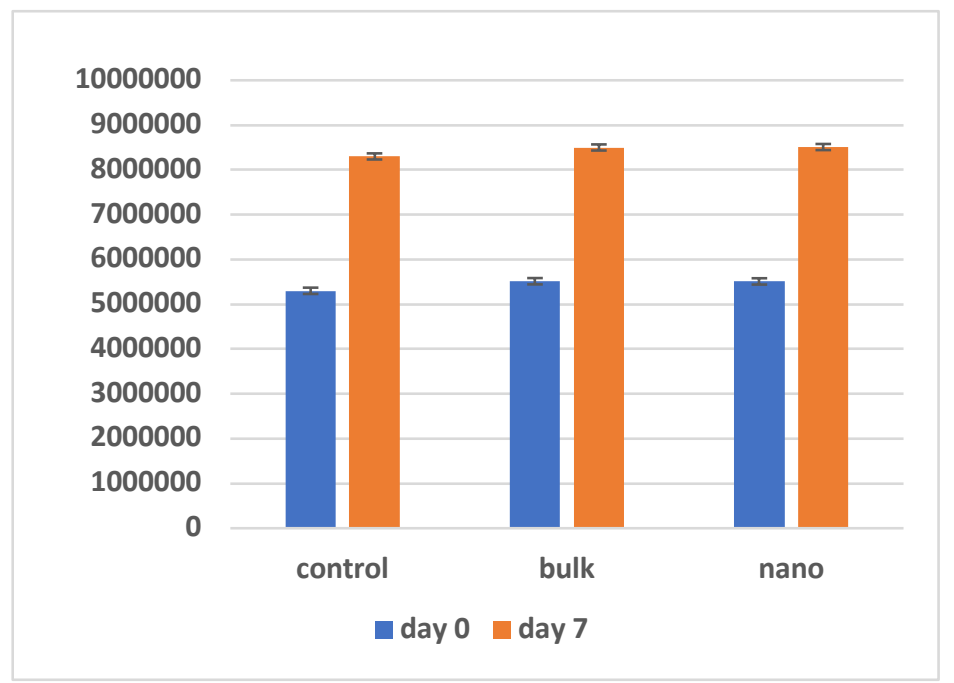

Figure 77: Chlorella sp. cells counted for day 0 and day 7.

\subsubsection{SEM and EDS}

The SEM and EDS were used to analyze Chlorococcum sp. (Figure 78). In three treatment trials, the microalgae retained their round morphology, and the nano had small particles attached were possible NPs can be noted. For the EDS (Figure 79), a spot test was conducted in order to determine the $\mathrm{Zn}$ concentration. The control $\mathrm{Zn}$ concentration was at $2.652 \mathrm{wt} . \%$, following with bulk having the lowest concentration of $\mathrm{Zn}$ at 1.189 wt.\%, and finally the nano which had the highest $\mathrm{Zn}$ concentrations $5.032 \mathrm{wt} . \%$.
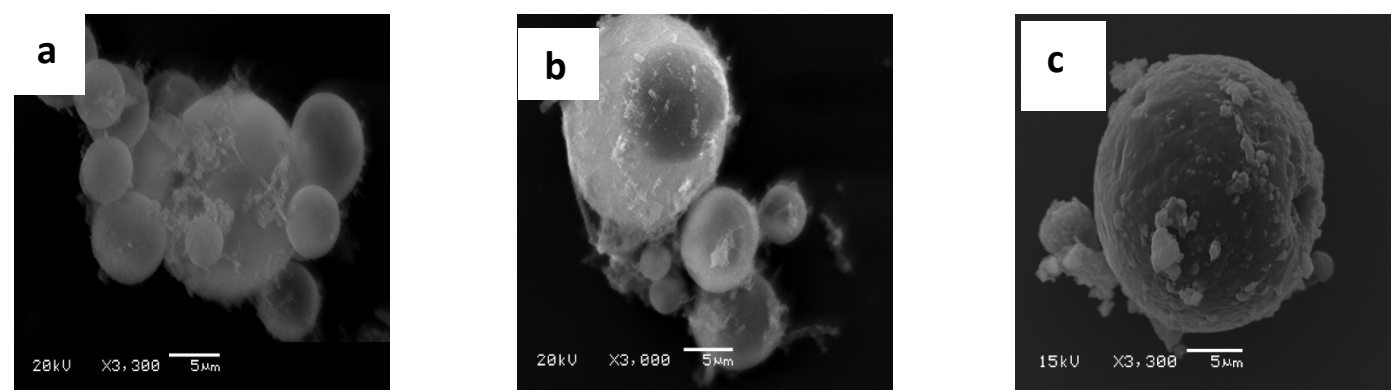

Figure 78: Chlorococcum sp. in BG 11 media: a) standard $\mathrm{ZnSO}_{4}$ b) Bulk $\mathrm{ZnO} 20$ ppm c) Nano ZnO 20 ppm. 


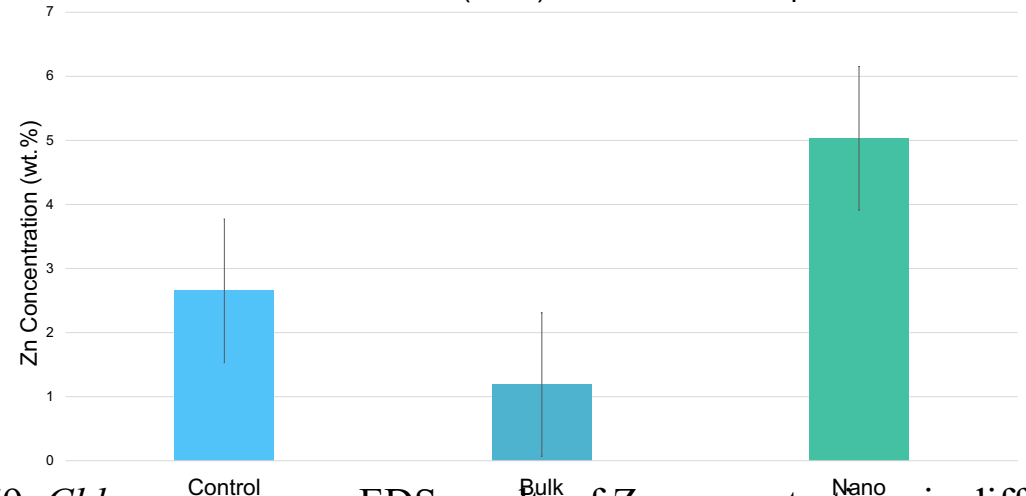

Figure 79: Chlorococccum sp. EDS results of Zn concentrations in different treatments

The SEM and EDS were used to analyze Chlamydomonas sp. It is important to note that the drying portion of the experiment was not done properly because the tank $\mathrm{CO}_{2}$ inadvertently ran out. This maybe the reason why the Chlamydomonas sp. morphology got disturbed (Figure 80). For the results, the flagella were found in most of the microalgae in the control, however in the bulk and the nano the flagella no longer appeared. For the EDS (Figure 79), spot testing was performed to determine the $\mathrm{Zn}$ concentration. The control $\mathrm{Zn}$ concentration was the lowest at $4.377 \mathrm{wt}$ \%, following with bulk at 9.695 wt. \%, and finally nano had the highest $\mathrm{Zn}$ concentrations at 11.274 wt. $\%$.
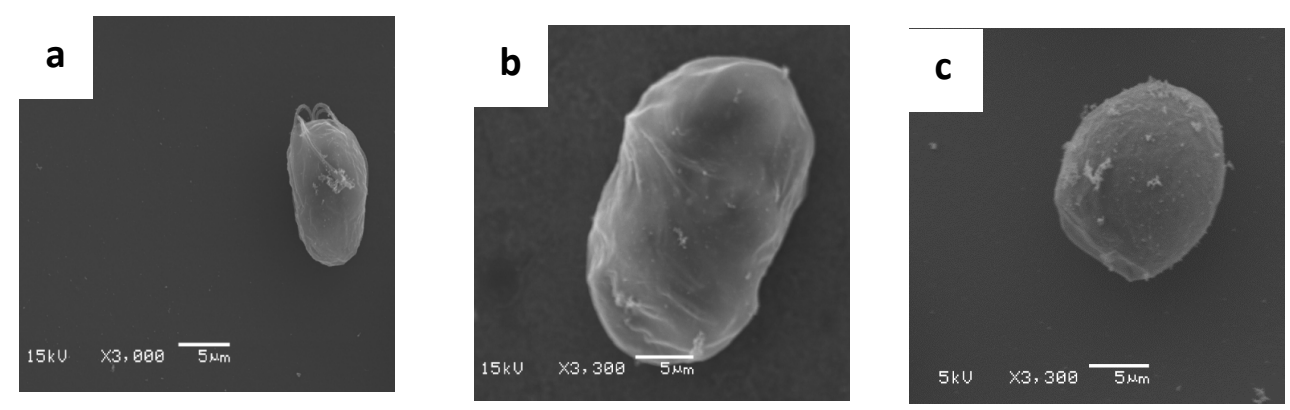

Figure 80: Chlamydomonas sp. in $\mathrm{BG} 11$ media with a) standard $\mathrm{ZnSO}_{4}$ b) Bulk ZnO 20 ppm c) Nano ZnO 20 ppm. 


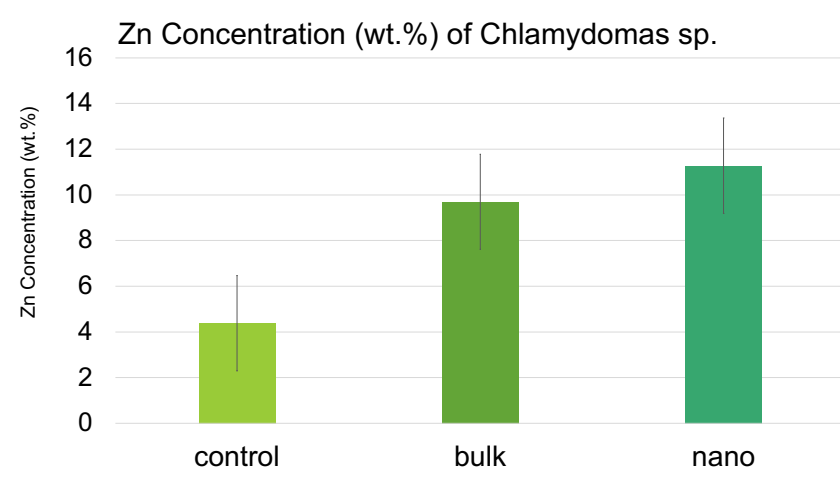

Figure 79: Chlamydomonas sp. EDS results of Zn concentrations in different treatments.

The SEM and EDS were used to analyze: Chlorella sp. (Figure 82). In the three treatment trails, the microalgae retained their small round morphology, even though the nano and bulk were observed to have small particles and filamentous structures. The EDS (Figure 83) spot test was conducted to determine the Zn concentration. As can be seen, the control $\mathrm{Zn}$ concentration had the lowest concentration at $4.204 \mathrm{wt} . \%$, following with bulk at $6.706 \mathrm{wt} . \%$, and finally the nano having the highest $\mathrm{Zn}$ concentrations at 8.239 wt. $\%$.
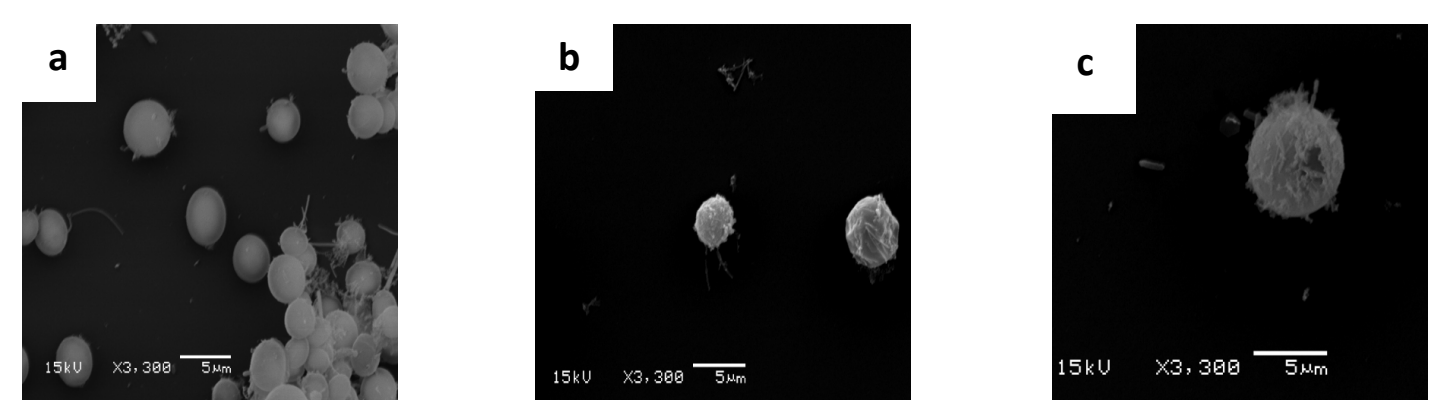

Figure 82: Chlorella sp. in BG 11 media with a) standard $\mathrm{ZnSO}_{4}$ b) Bulk $\mathrm{ZnO} 20$ ppm c) Nano ZnO 20 ppm. 
Zn Concentration (wt.\%) of Chlorella sp.

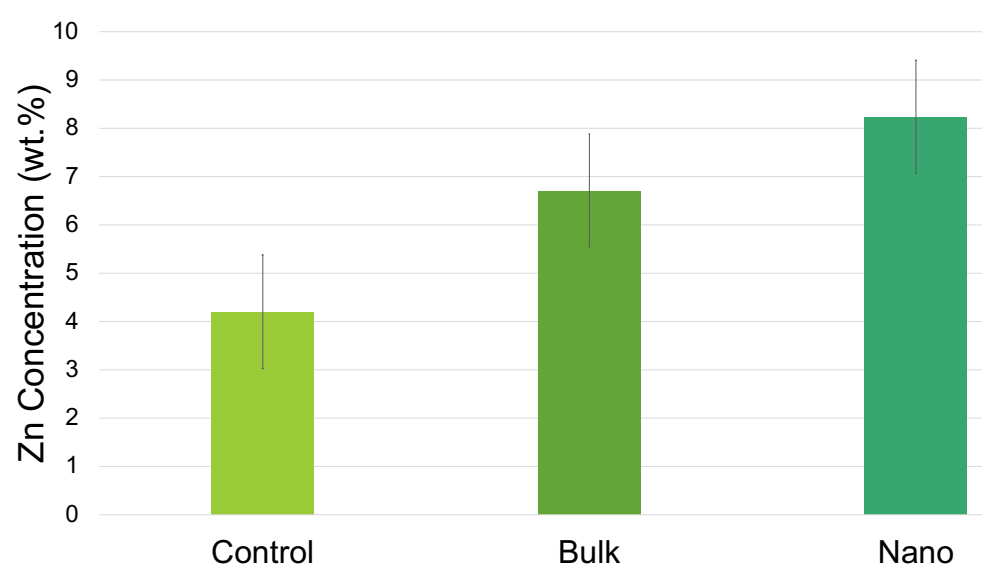

\subsubsection{Statistical Analysis}

The results for the two-way mixed (ANOVA) with $20 \mathrm{ppm} \mathrm{ZnO}$ with Chlorococcum sp., Chlorococcum sp. And Chlorella sp.; the dosage was coded has follow B 20: 20 ppm Bulk ZnO; N 20: 20 ppm NPs ZnO.

After all the assumption was met the results were reported. Test of betweensubjects' effects was analysis to determine if there was a statistically significant difference in absorbance concentration between intervention of treatments: $F(2,15)=$ $.532 \mathrm{p}=.000, \eta 2=.110$ for Chlorococcum sp. ; F $(2,13)=23.601 \mathrm{p}=.000, \eta 2=.020$ for Chlamydomonas sp.; F $(2,15)=11.985 \mathrm{p}=.000, \eta 2=1.074$ for Chlorella sp. .

Multiple Comparisons was analyzed know if the absorbance concentration was or was not statistically significantly for the treatments. For Chlorococcum sp., the absorbance concentration in all the treatments was not statistically significantly different. For example: the control and $\mathrm{n} 20(\mathrm{M}=.004750 \mathrm{SE}=.0124869, \mathrm{p}=.924)$. For Chlamydomonas sp., the absorbance concentration was statistically significantly greater in the control and nano; bulk and nano. For example: Control and nano $(\mathrm{M}=.078600, \mathrm{SE}$ 
$=.0124255 \mathrm{~nm}, \mathrm{p}=.000)$. The absorbance concentration in was not statistically significantly for control and bulk. For example: the control group and bulk $(\mathrm{M}=.013200$, $\mathrm{SE}=.0129780 \mathrm{~nm}, \mathrm{p}=.580$ ). For Chlorella sp.; Absorbance concentration was statistically significantly greater in the control and nano. For example: Control and nano $(\mathrm{M}=.597333, \mathrm{SE}=.1221930 \mathrm{~nm}, \mathrm{p}=.001)$. The absorbance concentration in was not statistically significantly for control and bulk; bulk and nano. For example: the control group and bulk $(\mathrm{M}=.270167, \mathrm{SE}=.1221930 \mathrm{~nm}, \mathrm{p}=.102)$.

There was a statistically significant interaction between the intervention and days on absorbance, for Chlorococcum sp.: $F(1,15)=149.527, p=0.00$, partial $\eta^{2}=23.704$; for green2: $\mathrm{F}(1,13)=34.375, \mathrm{p}=0.00$, partial $\eta 2=.035$. For Chlorella $\mathrm{sp} .: \mathrm{F}(1,15)=$ 72.307, $p=0.00$, partial $\eta^{2}=9.011$.

The Pairwise comparison table was used to know if there was statistically significant between days. For all the green microalgae the absorbance concentration was statistically significantly different for all days.

The results were reported, for Chlorococcum sp.: There were no significant outliers, as assessed by boxplot. The data was normally distributed, as assessed by Shapiro-Wilk's test of normality $(\mathrm{p}>.05)$. There was homogeneity of variances $(\mathrm{p}>.05)$ and covariance $(\mathrm{p}>.05)$, as assessed by Levene's test of homogeneity of variances and Box's M test, respectively. "Mauchly's test of sphericity was used to examine the assumption of sphericity. The Huynh-Feldt epsilon was used to interpret the two-way interactions. Test of Within-subjects effects: There was a statistically significant interaction between the intervention and days on absorbance $\mathrm{F}(1,15)=149.527, \mathrm{p}$ $=0.00$, partial $\eta 2=23.704$. The absorbance concentration in all the treatments was not 
statistically significantly. For example: the control and n20 $(\mathrm{M}=.004750 \mathrm{SE}=$ $.0124869, \mathrm{p}=.924)$.

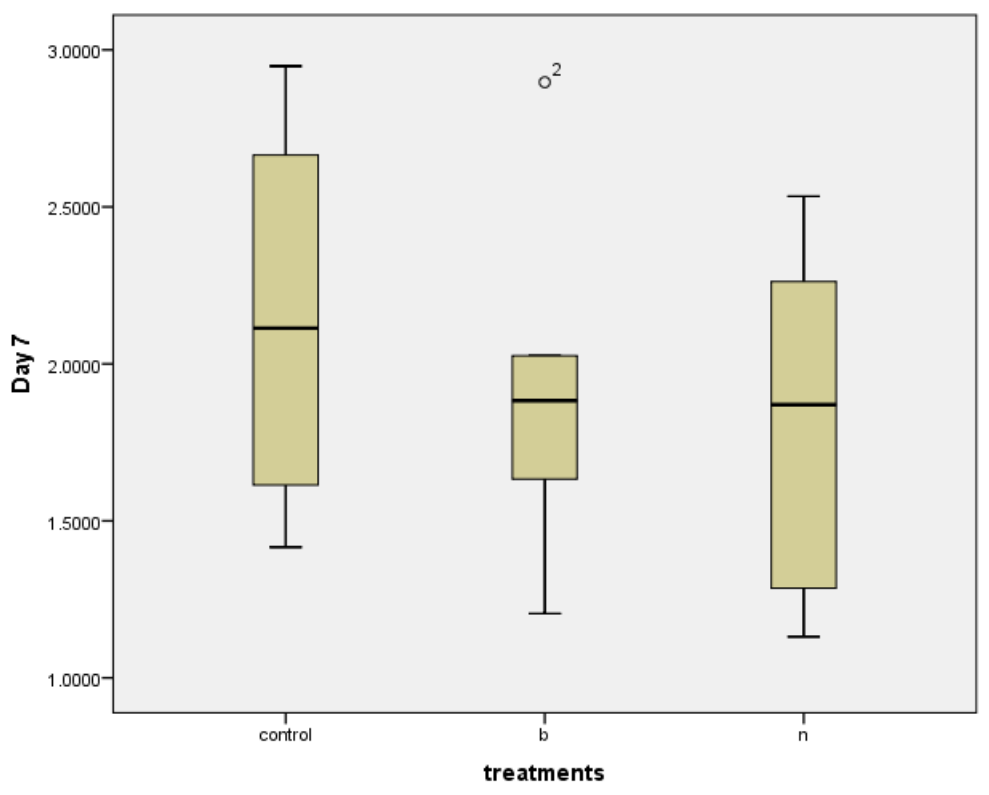

Figure 84: Box plot's shows the effects of $\mathrm{ZnO}$ Nano, bulk particles and extra zinc on Chlorococcum sp. growth at day 7.

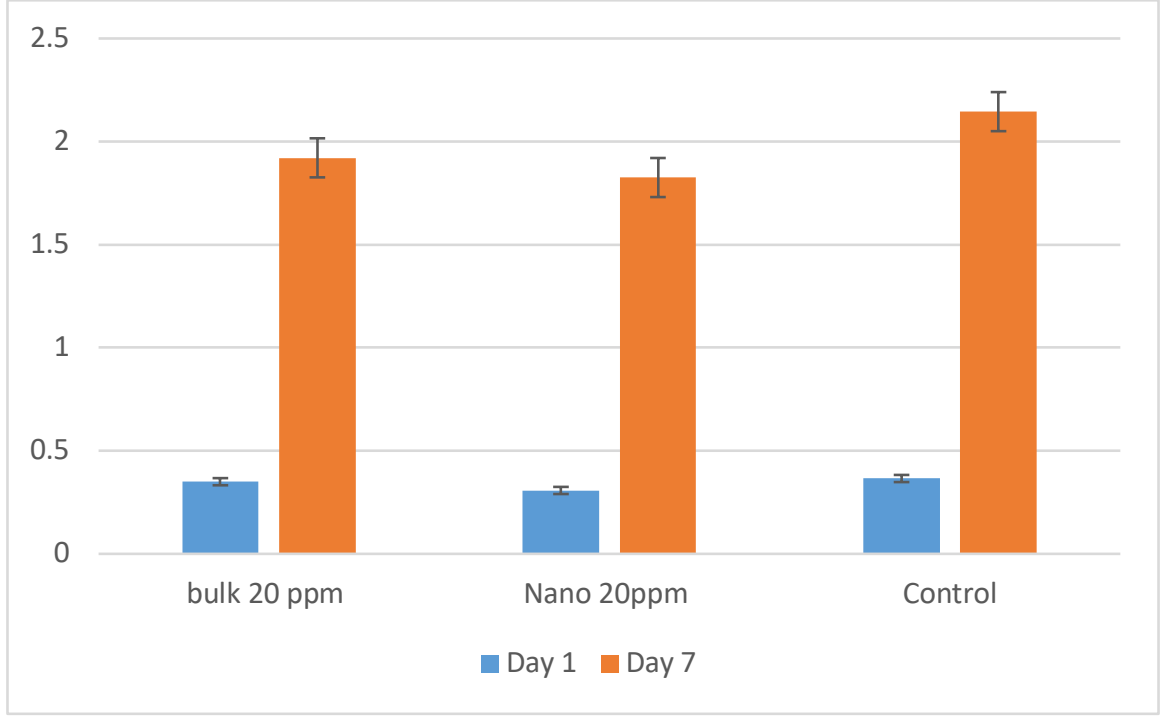

Figure 85: The effects of $\mathrm{ZnO} N a n o$, bulk particles and extra zinc on Chlorococcum sp. growth. 
For Chlamydomonas sp.: There were no outliers, as assessed by boxplot. The data was normally distributed, as assessed by Shapiro-Wilk's test of normality $(\mathrm{p}>.05)$. There was homogeneity of variances $(p>.05)$ and covariance $(p>.05)$, as assessed by Levene's test of homogeneity of variances and Box's M test, respectively. "Mauchly's test of sphericity was used to examine the assumption of sphericity. The Huynh-Feldt epsilon was used to interpret the two-way interactions. Test of Within-subjects effects: There was a statistically significant interaction between the intervention and days on absorbance $\mathrm{F}(1,13)=34.375, \mathrm{p}=0.00$, partial $\eta 2=.035$. Absorbance concentration was statistically significantly greater in the control and nano. For example: Control and nano $(\mathrm{M}=.078600, \mathrm{SE}=.0124255 \mathrm{~nm}, \mathrm{p}=.000)$. The absorbance concentration in was not statistically significantly for control and bulk. For example: the control group and bulk $(\mathrm{M}=.013200, \mathrm{SE}=.0129780 \mathrm{~nm}, \mathrm{p}=.580)$.

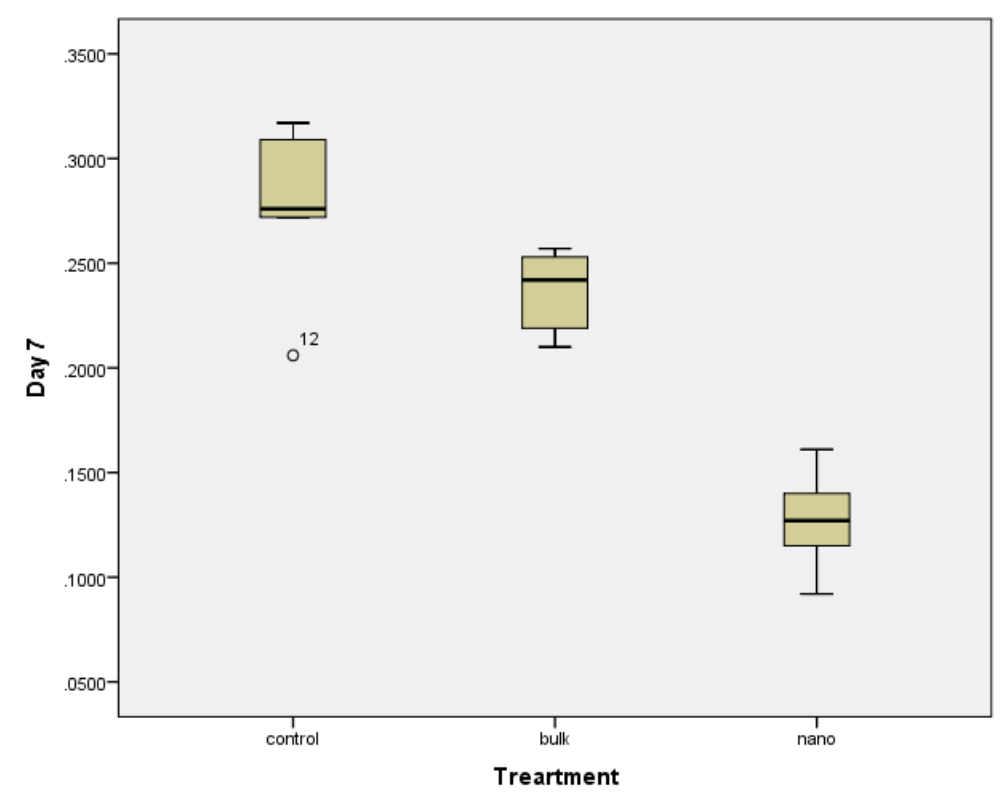

Figure 86: Box plot's shows the effects of $\mathrm{ZnO}$ Nano, bulk particles and extra zinc on Chlamydomonas sp. growth at day 7. 


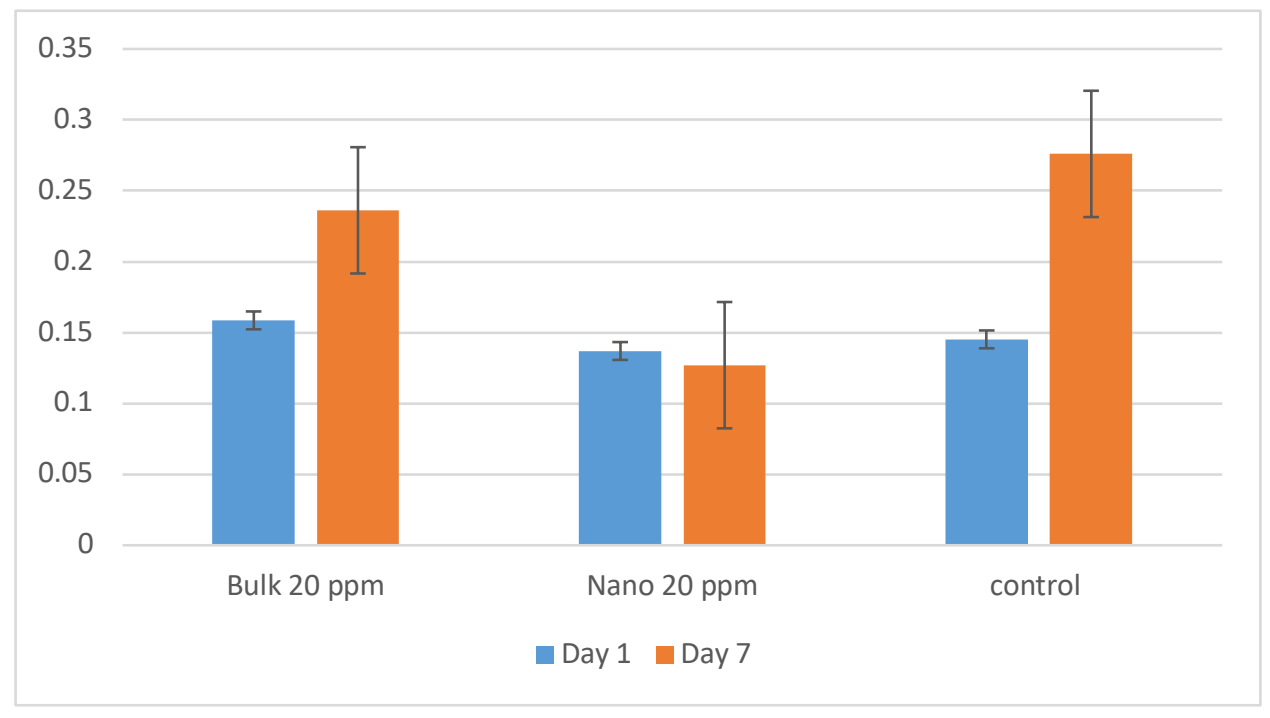

Figure 87: The effects of $\mathrm{ZnO}$ Nano, bulk particles and extra zinc on Chlamydomonas sp. growth.

For Chlorella sp.: There were no outliers, as assessed by boxplot. The data was normally distributed, as assessed by Shapiro-Wilk's test of normality $(\mathrm{p}>.05)$. There was homogeneity of variances $(p>.05)$ and covariance $(p>.05)$, as assessed by Levene's test of homogeneity of variances with the exception of days 0 and Box's M test, respectively. "Mauchly's test of sphericity was used to examine the assumption of sphericity. The Huynh-Feldt epsilon was used to interpret the two-way interactions. Test of Withinsubjects effects: There was a statistically significant interaction between the intervention and days on absorbance $F(1,15)=72.307, p=0.00$, partial $\eta 2=9.011$. The Absorbance concentration was statistically significantly greater in the control and nano. For example, Control and nano $(\mathrm{M}=.597333, \mathrm{SE}=.1221930 \mathrm{~nm}, \mathrm{p}=.001)$. The absorbance concentration in was not statistically significantly for control and bulk. For example, the control group and bulk $(\mathrm{M}=.270167, \mathrm{SE}=.1221930 \mathrm{~nm}, \mathrm{p}=.102)$. 


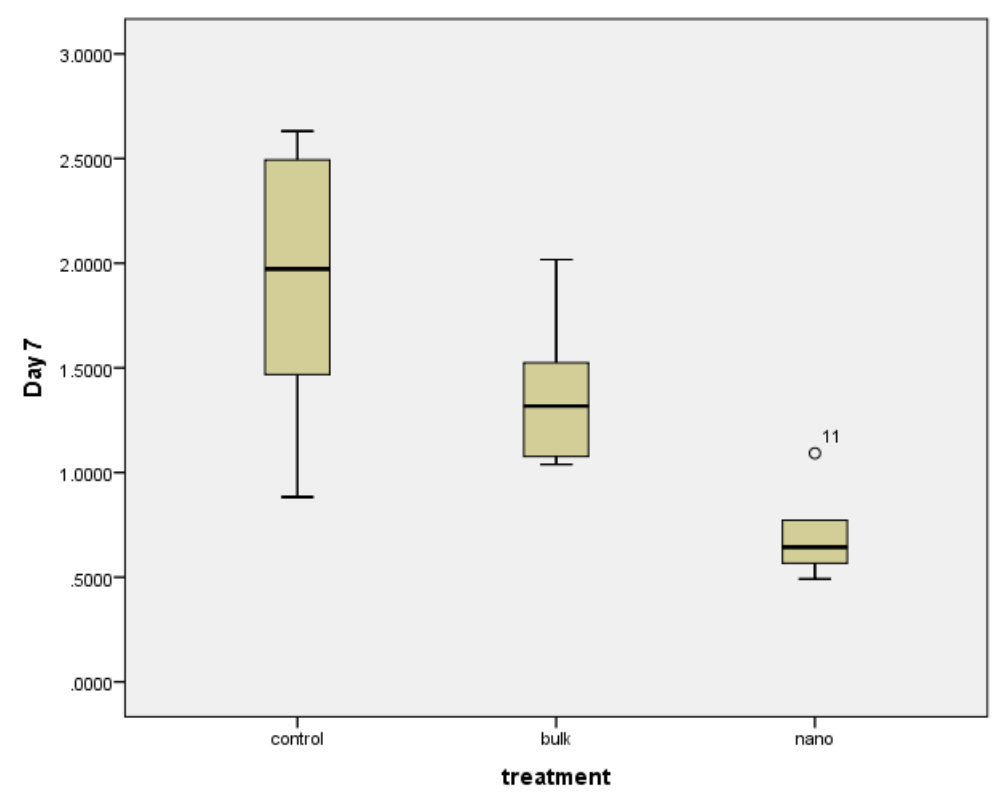

Figure 88: Box plot's shows the effects of $\mathrm{ZnO}$ Nano, bulk particles and extra zinc on Chlorella sp. growth at day 7 .

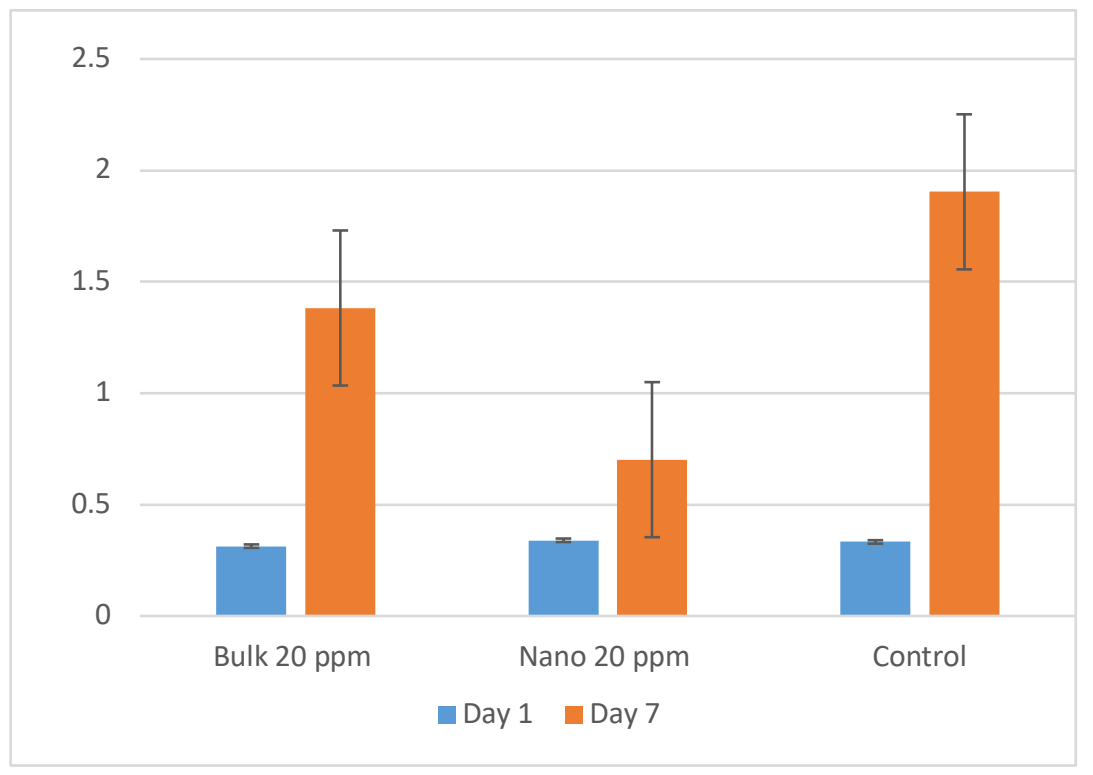

Figure 89: The effects of $\mathrm{ZnO}$ Nano, bulk particles and extra zinc on Chlorella sp. growth. 


\subsection{Enrichment and Isolation of Microalgae Tolerant to High Nano-ZnO Concentration}

\subsubsection{Optical microscope}

After three months, samples from the four enrichment flasks showing turbidity were observed under microscope. Initial enrichment flasks contained a variety of organisms from purple filaments, to round brown microalgae, and green microalgae (Figure 90). Repeated enrichment transfers showed that only one flask consistently showed algal growth, based on initial observation the cells appeared to be Chlorella sp. (Figure 90 f).
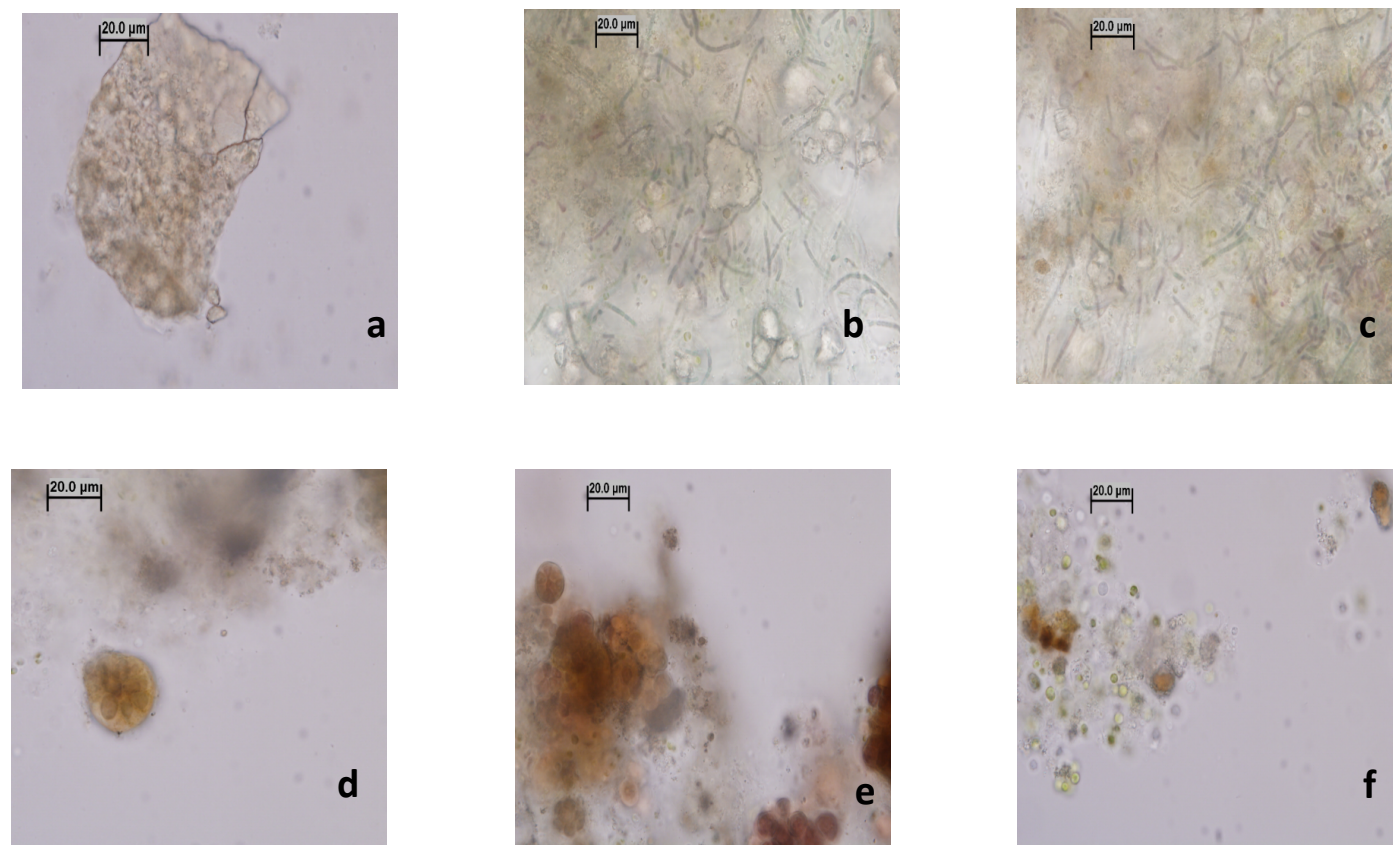

Figure 90: All of the images were taken from South Point Park Beach and exposed to $100 \mathrm{ppm}$. 


\section{Section 5: Discussion}

\subsection{Cyanobacteria}

Overall, the results showed that cyanobacterial species were more sensitive to nano $\mathrm{ZnO}$ than the green microalgae. Cyanobacteria differ from the green micro algae because they are prokaryotic gram-negative bacteria, while microalgae are eukaryotic. There have been multiple studies done with the E. coli bacteria, which is gram negative like the cyanobacteria, about their toxicity to bulk and ZnO NPs. Most of the studies showed that there is damage within the E. coli cells due to disorganization in the gramnegative triple membrane, which is highly unusual for these species (Brayner et al., 2006). Experiments have also been done with cyanobacteria showing similar results. For example, the cyanobacteria A. flosaquae and E. gracilis showed a decrease of photosynthetic activity for both when exposed to ZnO NPs (Brayner et al., 2010). Another study using Spirulina (Arthrospira) platensis discovered that ZnO NPs triggered substantial cytotoxicity within the $S$. platensis and caused cell death (Djearamane et al., 2018). Similar to all of these results, this research showed that most of the select group of cyanobacteria have some sensitivity to bulk and/or nano $\mathrm{ZnO}$.

Even though most of the cyanobacteria showed sensitivity to both bulk and nano $\mathrm{ZnO}$, Leptolyngbya sp. showed more sensitivity to nano $\mathrm{ZnO}$ than to bulk $\mathrm{ZnO}$. This corresponds with the microscope picture, as there is a noticeable morphological difference between nano and bulk $\mathrm{ZnO}$. These results are similar to research using $\mathrm{A}$. flosaquae, that showed (Figure 4) how nano $\mathrm{ZnO}$ has a lower growth than the bulk $\mathrm{ZnO}$ (Nandi et al., 2012). Surprisingly, the Porphoridium sp. showed no significant difference between all treatments. Although this microalga showed sensitivity with its color change 
from pink to green, the microplate reader may be faulty and not detect this change in color.

Another technical problem occurred when using a higher concentration of bulk and nano $\mathrm{ZnO}$ with the species: Limnothrix sp., Oscilatoria sp., Leptolyngbya sp., and Lyngbya sp., which could be attributed with the fact they were not new. Nevertheless, the majority of cyanobacteria in this experiment showed a clear sensitivity to both nano and bulk. Other than by absorbance measurements, this was proven visually with the pictures, which showed clear morphology change for both nano and bulk. These results raised a new hypothesis: If cyanobacteria are sensitive to both bulk and nano $\mathrm{ZnO}$, are they also sensitive to the zinc?

This hypothesis was researched by doing a new experiment with higher concentration of "normal" Zinc. The experiment of higher Zn concentration was done for Limnothrix sp., Leptolyngbya sp., Lyngbya 1 sp. and Lyngbya 2 sp. The results indicate that these cyanobacteria are not necessarily sensitive to the Nano "effect" but to the zinc concentration itself. Also, the optical microscope pictures confirmed that all of these cyanobacteria were sensitive to $\mathrm{Zn}$ and not only to nano and bulk. There was a study done by Djearamane et al. (2018), which showed that Cyanobacterium Synechococcus sp. was toxic when exposed to a high concentration of Zinc.

\subsection{Green Microalgae}

Green microalgae showed a tolerance to bulk and nano $\mathrm{ZnO}$ compared with these cyanobacteria. This could be due to the complexity of eukaryotic organisms (green microalgae) versus the simpler prokaryotic cell (cyanobacteria). To our knowledge, there has not been a comparative study of a mechanism of how the ZnO NPs' toxicity compares in the eukaryotic vs prokaryotic organisms. There has been research that shows 
NPs of metal oxides can induce cell death in eukaryotic cells (Nel 2006; Long et al., 2006) and growth inhibition in prokaryotic cells (Huang et al., 2008) due to cytotoxicity. At all levels of NPs ZnO tested ( $0.125 \mathrm{ppm}, 0.25 \mathrm{ppm}, 0.5 \mathrm{ppm}$, and $1 \mathrm{ppm})$ the three green microalgae showed marked tolerance (OD more than 0.8618 ). Due to the tolerance results of the low concentration experiment, all three green algal species were selected for assessing response to higher $\mathrm{ZnO}$ concentration levels. All the three green microalgae tested showed tolerance to higher concentration of nano $\mathrm{ZnO}$ based on growth response. These tolerances to $\mathrm{ZnO}$ NPs may be because the green microalgal cells are negatively charged, providing a set of binding sites for metal cations like $\mathrm{Zn}^{+2}$, which have the potential to lower toxicity in the microalgae (Monteiro, Fonseca, Castro, \& Malcata, 2010). However, for Chlamydomonas sp., there showed minor sensitivity when exposed to ZnO NPs. Also, abnormal cell morphology and clumping of cells were observed when exposed to nano $\mathrm{ZnO}$ NPs at concentrations of $7.5 \mathrm{ppm}$ and $10 \mathrm{ppm} \mathrm{Zn}$. After the 24 wells experiments, a flask experiment was conducted. The flask experiment was with the three green microalgae and $20 \mathrm{ppm} \mathrm{NPs} \mathrm{and} \mathrm{bulk} \mathrm{ZnO}$. The results on the flask versus the wells were different. Both Chlorococcum sp. and Chlorella sp. showed tolerance to $\mathrm{ZnO}$ Nano and bulk. The results for the morphology do not agree with these results. For Chloroccoum sp., there were transparent circle patches and for Chlorella sp. there was a transparent patch. Studies showed that the green microalgae S. obliquus can tolerate higher Zn concentrations than D. pleiomorphus (Monteiro, Fonseca, Castro, \& Malcata, 2010). Another study showed Raphidocelis subcapitata and Chlorella vulgaris are proven to have a tolerance to Zinc (Muyssen \& Janssen, 2001). For the species Tetraselmis sucica, there was no effect in a high 
concentration of 100 mg/L ZnO NPs (Castro-Bugallo, González-Fernández, Guisande, \& Barreiro, 2014)

For Chalydomonas sp., there were significant differences between the control with nano and bulk with nano, indicating that there is a clear sensitivity to NPs ZnO. This can also be seen by the microscope morphology results, where the cell has less pigmentation and a very small size. A study done with the Chalydomonas (D.tertiolecta) showed different results, with toxicity at a much higher concentration of $133 \mathrm{mg} / \mathrm{L} \mathrm{ZnO}$ NPs (Miglietta et al., 2011); but another study done with the same algae had toxicity at a lower concentration of $2.42 \mathrm{mg} / \mathrm{L}$ ZnO NPs (Manzo et al., 2013).

There have been other studies that showed some sensitivity to green microalgae. In one study done with S. obliquus and D. pleiomorphus, researchers discovered ZnO NPs are toxic to them (Monteiro, Fonseca, Castro, \& Malcata, 2010). Alexandrium minutum, Pseudokirchneriella subcapitata and T.pseudonana had a high inhibition of $80 \%$ with a very low concentration of $0.01 \mathrm{mg} / \mathrm{L} \mathrm{ZnO} \mathrm{NPs} \mathrm{(Lee} \mathrm{\&} \mathrm{An,} \mathrm{2013).}$

In the flask experiment, interesting results occurred for the first trial with Chloroccoum sp. The Chloroccoum sp. was contaminated with a filamentous structure, which could potentially be a cyanobacteria. For the Nano $\mathrm{ZnO} 20$ ppm flask results, the contamination was no longer there. Potentially the NPs ZnO eliminated the contamination of the cyanobacteria because the cyanobacteria from the previous experiment are sensitive to zinc.

For SEM and EDS results, we wanted to see the morphology change as well as the $\mathrm{Zn}$ concentration on the cell. There was not much change in the morphology for Chlorococcum sp. and Chlorella sp., but as expected in the nano, some patches on the cells can be observed, which can potentially be the NPs. For the EDS, these both 
microalgae had different zinc concentrations for each treatment, but it was not significant. For Chlamydomonas sp., there was a considerable morphology change where the flagella disappeared for bulk and for nano at $20 \mathrm{ppm}$. Also, in the EDS results, nano had more than a $50 \%$ difference than the control, indicating that there is a lot of $\mathrm{Zn}$ concentration in the cell.

\subsection{Zn NPs tolerant algae}

Long term incubation of enrichment cultures of sea water samples on high concentration of $\mathrm{Zn}$ NP showed no algal growth in all but one flask. Visible green algal growth in enrichment flask took close to one month. Light microscopic observation of microalgal cells growing in enrichment flask containing 100 ppm Zn NP most likely belong to Chlorella sp. In a study on Chlorella sp. (Chen, Powell, Mortimer, \& Ke, 2012), it was observed that Chlorella sp. is able naturally adapt to discharged nanomaterials because these algal cells have the capability of self-protection by minimizing their surface area through aggregation mediated. The mechanism is able to be achieved by the oppositely charged metal ions and suppressing zinc ion release from the NPs. Due to Chlorella sp. proven to have a natural resistance to ZnO NPs, the possibility of Chlorella sp. being the species able to survive the 100ppm ZnO NPs, is high. But additional purification of culture and subsequent DNA sequence analysis is needed to confirm the identification of the species.

\section{Section 6: Conclusions}

These findings provide a strong impetus for screening a larger collection of diverse indigenous microalgae for tolerance to NPs, potentially yielding viable candidates for bioremediation of NPs and also sensitive indicator species for Eco toxicological testing. Due to the results, cyanobacteria are more sensitive to ZnO NPs and bulk than the 
green microalgae, especially the one with a filamentous shape. The filamentous shape makes them more vulnerable to high concentration of zinc; meaning that filamentous cyanobacteria can be seen as an indicator species for ecotoxicology testing. While most of green microalgae show tolerance to ZnO NPs and bulk especially the ones with circular shape, Chlorella sp. was confirming to be tolerant not only in the lab setting but also nature even when tested at $100 \mathrm{ppm}$ experiment. Chlorella sp. can potentially be used for bioremediation since it is tolerant to such high concentrations of $\mathrm{ZnO}$ NPs.

\section{Section 7: Recommendations}

The $\mathrm{Zn}$ concentration of the Miami Beach, FL area has never been historically measured because it is not one of the elements required to be tested by the city's and state's regulations. Due to it being a high tourist region, it would be ideal to analyze the potential concentrations in popular beach areas in South Florida. For future studies, it would be desirable to try to create a regular and historical testing routine in order to be able to look for patterns over time. This will enable researchers and health and safety monitoring entities to check for any potential impacts for both the aquatic environment and for humans who come into contact with it. It would also be appropriate to learn more about the mechanisms of how Chlorella sp. is able to tolerate such high concentrations and why cyanobacteria are not. 
List of References

1- Adeel Irfan, M. (2014). This is nanotechnology - one of the fastest growing markets in the world. Retrieved from http://www.gaeu.com/item/this-is-nanotechnology-oneof-the-fastest-growing-markets-in-the-world.

2- Ahmed Abdal, D., Mohammed Kawser, H., Soo Bin, L., Kyeongseok, K., Subbroto Kumar, S., Gwang-Mo, Y., \& ... Ssang-Goo, C. (2017). The Role of Reactive Oxygen Species (ROS) in the Biological Activities of Metallic Nanoparticles. International Journal of Molecular Sciences, Vol 18, Iss 1, P 120 (2017), (1), 120. doi:10.3390/ijms18010120.

3- Akhil, K., \& S., S. K. (2016). Effect of short term exposure of $\mathrm{ZnO}$ and TiO2 nanoparticles on algae: Chlorella pyrenoidosa \& crustacean: Daphnia sp. 2016 IEEE 16th International Conference on Nanotechnology (IEEE-NANO). doi:10.1109/nano.2016.7751429.

4- Anastopoulos, I., \& Kyzas, G. Z. (2015). Progress in batch biosorption of heavy metals onto algae. Journal of Molecular Liquids, 209, 77-86. doi:10.1016/j.molliq.2015.05.023.

5- Aravantinou, A. F., Tsarpali, V., Dailianis, S., \& Manariotis, I. D. (2015). Effect of cultivation media on the toxicity of $\mathrm{ZnO}$ nanoparticles to freshwater and marine microalgae. Ecotoxicology and Environmental Safety, 114, 109-116. doi:10.1016/j.ecoenv.2015.01.016.

6- Auffan, M., Rose, J., Bottero, J., Lowry, G. V., Jolivet, J., \& Wiesner, M. R. (2009). Towards a definition of inorganic nanoparticles from an environmental, health and safety perspective. Nature Nanotechnology, 4(10), 634-641. doi:10.1038/nnano.2009.242.

7- Baker, T. J., Tyler, C. R., \& Galloway, T. S. (2014). Impacts of metal and metal oxide nanoparticles on marine organisms. Environmental Pollution, 186, 257-271. doi:10.1016/j.envpol.2013.11.014.

8- Binns, C. (2010). Introduction to nanoscience and nanotechnology. Hoboken, N.J: Wiley.

9- Binns, C. (2010). Introduction to nanoscience and nanotechnology. Hoboken, N.J: Wiley.

10-Blaise, C., Gagné, F., Férard, J., \& Eullaffroy, P. (2008). Ecotoxicity of selected nano-materials to aquatic organisms. Environmental Toxicology, 23(5), 591-598. doi:10.1002/tox.20402.

11-Blinova, I., Niskanen, J., Kajankari, P., Kanarbik, L., Käkinen, A., Tenhu, H., Kahru, A. (2012). Toxicity of two types of silver nanoparticles to aquatic crustaceans 
Daphnia magna and Thamnocephalus platyurus. Environmental Science and Pollution Research, 20(5), 3456-3463. doi:10.1007/s11356-012-1290-5.

12-Bondarenko, O., Juganson, K., Ivask, A., Kasemets, K., Mortimer, M., \& Kahru, A. (2013). Toxicity of $\mathrm{Ag}, \mathrm{CuO}$ and $\mathrm{ZnO}$ nanoparticles to selected environmentally relevant test organisms and mammalian cells in vitro: A critical review. Archives of Toxicology, 87(7), 1181-1200. doi:10.1007/s00204-013-1079-4.

13-Bradbury, J. (2004). Natures Nanotechnologists: Unveiling the Secrets of Diatoms. PLoS Biology, 2(10). doi:10.1371/journal.pbio.0020306.

14- Brauer M, Freedman G, Frostad J, van Donkelaar A, Martin RV, Dentener F, et al. 2016. Ambient air pollution exposure estimation for the Global Burden of Disease 2013. Environ Sci Technol 50(1):79-88, PMID: 26595236, https://doi.org/ 10.1021/acs.est.5b03709.

15- Brayner, R. (2010). ZnO Nanoparticles: Synthesis, Characterization, and Ecotoxicological Studies. ACS Publications, 26(9), 6522-6528. doi:10.1021/la100293s Monteiro, C. M., Fonseca, S. C., Castro, P. M., \& Malcata, F. X. (2010). Toxicity of cadmium and zinc on two microalgae, Scenedesmus obliquus and Desmodesmus pleiomorphus, from Northern Portugal. Journal of Applied Phycology, 23(1), 97-103. doi:10.1007/s10811-010-9542-

16- Brayner, R., Ferrari-Iliou, R., Brivois, N., Djediat, S., Benedetti, M. F., \& Fiévet, F. (2006). Toxicological Impact Studies Based onEscherichiacoliBacteria in Ultrafine ZnO Nanoparticles Colloidal Medium. Nano Letters, 6(4), 866-870. doi:10.1021/n1052326h.

17-Castro-Bugallo, A., González-Fernández, Á, Guisande, C., \& Barreiro, A. (2014). Comparative Responses to Metal Oxide Nanoparticles in Marine Phytoplankton. Archives of Environmental Contamination and Toxicology, 67(4), 483-493. doi:10.1007/s00244-014-0044-4.

18-Cavet, J. S., Borrelly, G. P., \& Robinson, N. J. (2003). Zn, Cu and Co in cyanobacteria: Selective control of metal availability. FEMS Microbiology Reviews, 27(2-3), 165-181. doi:10.1016/s0168-6445(03)00050-0.

19-Chapman, V. J. (2013). An introduction to the study of algae. Cambridge University. 20- Danovaro, R., Bongiorni, L., Corinaldesi, C., Giovannelli, D., Damiani, E., (2008). Sunscreens Cause Coral Bleaching by Promoting Viral Infections. Environmental Health Perspectives. doi:10.1289/ehp.10966.

21-Demey, H., Vincent, T., \& Guibal, E. (2018). A novel algal - based sorbent for heavy metal removal. Chemical Engineering Journal, 332, 582-595. doi:10.1016/j.cej.2017.09.083. 
22-Djearamane, S., Lim, Y. M., Wong, L. S., \& Lee, P. F. (2018). Cytotoxic effects of zinc oxide nanoparticles on cyanobacterium Spirulina (Arthrospira)

platensis. PeerJ, 6. doi:10.7717/peerj.4682.

23-Djurišić, A. B., Leung, Y. H., Ng, A. M., Xu, X. Y., Lee, P. K., Degger, N., \& Wu, R. S. (2014). Toxicity of Metal Oxide Nanoparticles: Mechanisms, Characterization, and Avoiding Experimental Artefacts. Small, 11(1), 26-44. doi:10.1002/smll.201303947.

24-Faraway, J. J. (2015). Linear models with R (2nd ed.). Boca Raton, FL: CRC Press.

25-Fernandes, S. C., Alonso-Varona, A., Palomares, T., Zubillaga, V., Labidi, J., \& Bulone, V. (2015). Exploiting Mycosporines as Natural Molecular Sunscreens for the Fabrication of UV-Absorbing Green Materials. ACS Applied Materials \& Interfaces, 7(30), 16558-16564. doi:10.1021/acsami.5b04064.

26- Feynman, R. (1959). There's Plenty of Room at the Bottom. Retrieved from http://www.zyvex.com/nanotech/feynman.html.

27-Fox, J. (2008). Applied regression analysis and generalized linear models (2nd ed.). Thousand Oaks, CA: Sage Publications, Inc.

28- Franklin, N. M., Rogers, N. J., Apte, S. C., Batley, G. E., Gadd, G. E., \& Casey, P. S. (2007). Comparative Toxicity of Nanoparticulate $\mathrm{ZnO}$, Bulk ZnO, and ZnCl2to a Freshwater Microalga (Pseudokirchneriella subcapitata): The Importance of Particle Solubility. Environmental Science \& Technology, 41(24), 8484-8490. doi:10.1021/es071445r.

29- G. Applerot, A. Lipovsky , R. Dror , N. Perkas , Y. Nitzan , R. Lubart ,A. Gedanken , Adv. Funct. Mater. 2009, 19, $842-852$.

30-Girden, E. R. (1992). ANOVA: Repeated measures. Newbury Park, CA: Sage.

31-Gong, R., Ding, Y., Liu, H. \& Chen, Q. (2005) Lead biosorption and desorption by intact and pretreated Spirulina maxima biomass. Chemosphere 58: 125-130

32-Greenhouse, S. W., \& Geisser, S. (1959). On the methods in the analysis of profile data. Psychometrika, 24, 95-112.

33- Grethe R. Hasle; Erik E. Syvertsen; Karen A. Steidinger; Karl Tangen (1996-01-25). "Marine Diatoms". In Carmelo R. Tomas. Identifying Marine Diatoms and Dinoflagellates. Academic Press. pp. 5-385. ISBN 978-0-08-053441-1. Retrieved 2013-11-13.

34- Guarnieri, D., Sabella, S., Muscetti, O., Belli, V., Malvindi, M. A., Fusco, S., Netti, P. A. (2014). Transport across the cell-membrane dictates nanoparticle fate and toxicity: A new paradigm in nanotoxicology. Nanoscale, 6(17), 10264. doi:10.1039/c4nr02008a. 
35-Gupta, S., Kushwah, T., Vishwakarma, A., \& Yadav, S. (2016). Optimization of ZnO-NPs to Investigate Their Safe Application by Assessing Their Effect on Soil Nematode Caenorhabditis elegans. Nano Online. doi:10.1515/nano.11671_2015.11.

36-Handy, R. D., Owen, R., \& Valsami-Jones, E. (2008). The ecotoxicology of nanoparticles and nanomaterials: Current status, knowledge gaps, challenges, and future needs. Ecotoxicology, 17(5), 315-325. doi:10.1007/s10646-008-0206-0.

37-Harper, T. (n.d.). Nanotechnology Funding a Global. Retrieved from http://www.nano.gov/sites/default/files/pub_resource/global_funding_rsl_harper.pdf.

38-Hazeem, L. J., Bououdina, M., Rashdan, S., Brunet, L., Slomianny, C., \& Boukherroub, R. (2015). Cumulative effect of zinc oxide and titanium oxide nanoparticles on growth and chlorophyll a content of Picochlorum sp. Environmental Science and Pollution Research, 23(3), 2821-2830. doi:10.1007/s11356-015-5493-4.

39-Heinlaan, M., Ivask, A., Blinova, I., Dubourguier, H., \& Kahru, A. (2008). Toxicity of nanosized and bulk $\mathrm{ZnO}, \mathrm{CuO}$ and $\mathrm{TiO} 2$ to bacteria Vibrio fischeri and crustaceans Daphnia magna and Thamnocephalus platyurus. Chemosphere, 71(7), 1308-1316. doi:10.1016/j.chemosphere.2007.11.047

40- Huang, Z., Zheng, X., Yan, D., Yin, G., Liao, X., Kang, Y., . . Hao, B. (2008). Toxicological Effect of ZnO Nanoparticles Based on Bacteria. Langmuir, 24(8), 4140-4144. doi:10.1021/la7035949.

41-Imber, B., Robinson, M., Ortega, A., \& Burton, J. (1985). Complexation of zinc by exudates from Skeletonema costatum grown in culture. Marine Chemistry, 16(2), 131-139. doi:10.1016/0304-4203(85)90018-0.

42- Jasim, N. (2015). Antifungal Activity of Zinc Oxide Nanoparticles on Aspergillus Fumigatus Fungus \&Candida Albicans Yeast. Journal of Natural Sciences Research,5(4), 26-28.

43- Ji, J., Long, Z. \& Lin, D. Toxicity of oxide nanoparticles to the green algae Chlorella sp. Chem. Engineer. J. 170, 525-530 (2011).

44- Johnson, R.C. (9 April 2009). "Diatoms could triple solar cell efficiency".

45-Kesselman, H. J., Rogan, J. C., Medoza, J. L., \& Breen, L. L. (1980). Testing the validity conditions of repeated measures F tests. Psychological Bulletin, 87, 479-481.

46- Kirk, R. E. (2013). Experimental design: Procedures for the behavioural sciences (4th ed.). Thousand Oaks, CA: Sage.

47- Klingshirn, C. F., Waag, A., Hoffmann, A., \& Geurts, J. (2013). Zinc Oxide from Fundamental Properties Towards Novel Applications. Berlin: Springer Berlin. 
48-Lee, W., \& An, Y. (2013). Effects of zinc oxide and titanium dioxide nanoparticles on green algae under visible, UVA, and UVB irradiations: No evidence of enhanced algal toxicity under UV reirradiation. Chemosphere, 91(4), 536-544.

doi:10.1016/j.chemosphere.2012.12.033.

49- Lee, W., \& An, Y. (2013). Effects of zinc oxide and titanium dioxide nanoparticles on green algae under visible, UVA, and UVB irradiations: No evidence of enhanced algal toxicity under UV preirradiation. Chemosphere, 91(4), 536-544.

doi:10.1016/j.chemosphere.2012.12.033.

50-Linkous, C. A., Carter, G. J., Locuson, D. B., Ouellette, A. J., Slattery, D. K., \& Smitha, L. A. (2000). Photocatalytic Inhibition of Algae Growth Using TiO2, WO3, and Cocatalyst Modifications. Environmental Science \& Technology, 34(22), 47544758. doi:10.1021/es001080.

51-Majedi, S. M., Kelly, B. C., \& Lee, H. K. (2014). Combined effects of water temperature and chemistry on the environmental fate and behavior of nanosized zinc oxide. Science of The Total Environment, 496, 585-593.

doi:10.1016/j.scitotenv.2014.07.082.

52-Manzo, S., Miglietta, M. L., Rametta, G., Buono, S., \& Francia, G. D. (2013). Toxic effects of $\mathrm{ZnO}$ nanoparticles towards marine algae Dunaliella tertiolecta. Science of The Total Environment, 445-446, 371-376. doi:10.1016/j.scitotenv.2012.12.051.

53-Matranga, V., \& Corsi, I. (2012). Toxic effects of engineered nanoparticles in the marine environment: Model organisms and molecular approaches. Marine Environmental Research, 76, 32-40. doi:10.1016/j.marenvres.2012.01.006.

54- Maxwell, S. (1980). Pairwise multiple comparison procedures in repeated measures designs. Journal of Educational Statistics, 5, 269-287.

55- Maxwell, S. E., \& Delaney, H. D. (2004). Designing experiments and analyzing data: A model comparison perspective (2nd ed.). New York, NY: Psychology Press.

56-Merdzan, V., Domingos, R. F., Monteiro, C. E., Hadioui, M., \& Wilkinson, K. J. (2014). The effects of different coatings on zinc oxide nanoparticles and their influence on dissolution and bioaccumulation by the green alga, C. reinhardtii. Science of The Total Environment, 488-489, 316-324. doi:10.1016/j.scitotenv.2014.04.094.

57-Miazek, K., Iwanek, W., Remacle, C., Richel, A., \& Goffin, D. (2015). Effect of Metals, Metalloids and Metallic Nanoparticles on Microalgae Growth and Industrial Product Biosynthesis: A Review. International Journal of Molecular Sciences, 16(10), 23929-23969. doi:10.3390/ijms16102392. 
58- Miglietta, ML, Rametta, G, Di Francia, G, Manzo, S, Rocco, A, Carotenuto, R, etal. Characterization of nanoparticles in seawater for toxicity assessment towards aquatic organisms. Lect Notes Electr Eng 2011;91:425-9.

59- Miller, R. J. (2010). Impacts of Metal Oxide Nanoparticles on Marine Phytoplankton. ACS Publications, 44(10), 7329-7334. doi:10.1021/es100247x.

60-Miller, R. J., Lenihan, H. S., Muller, E. B., Tseng, N., Hanna, S. K., \& Keller, A. A. (2010). Impacts of Metal Oxide Nanoparticles on Marine Phytoplankton. Environmental Science \& Technology, 44(19), 7329-7334. doi:10.1021/es100247.

61-Moezzi, A., McDonagh A.M., Cortie M.B., 2012, Zinc oxide particles: Synthesis, properties and applications, Chem. Eng. J. 185-186, 1-22.

62-Monteiro, C. M., Marques, A. P., Castro, P. M., \& Malcata, F. X. (2009). Characterization of Desmodesmus pleiomorphus isolated from a heavy metalcontaminated site: Biosorption of zinc. Biodegradation, 20(5), 629-641. doi:10.1007/s10532-009-9250-6.

63-Mortimer, M., Kasemets, K., \& Kahru, A. (2010). Toxicity of $\mathrm{ZnO}$ and $\mathrm{CuO}$ nanoparticles to ciliated protozoa Tetrahymena thermophila. Toxicology, 269(2-3), 182-189. doi:10.1016/j.tox.2009.07.007.

64- Muyssen, B., \& Janssen, C. (2001). Zinc acclimation and its effect on the zinc tolerance of Raphidocelis subcapitata and Chlorella vulgaris in laboratory experiments. Chemosphere, 45(4-5), 507-514. doi:10.1016/s0045-6535(01)00047-9.

65-Nagarajan, R. (2008). Nanoparticles: synthesis, stabilization, passivation, and functionalization. Washington, DC: American Chemical Society. Draper, N. R., \& Smith, H. (1998). Applied regression analysis (3rd ed.). Hoboken, NJ: John Wiley \& Sons, Inc.

66- Nandi, I., Mitra, P., Banerjee, P., Chakrabarti, A., Ghosh, M., \& Chakrabarti, S. (2012). Ecotoxicological impact of sunlight assisted photoreduction of hexavalent chromium present in wastewater with zinc oxide nanoparticles on common Anabaena flos-aquae. Ecotoxicology and Environmental Safety, 86, 7-12. doi:10.1016/j.ecoenv.2012.08.020.

67-Newby, R., Lee, L. H., Perez, J. L., Tao, X., \& Chu, T. (2017). Characterization of zinc stress response in Cyanobacterium Synechococcus sp. IU 625. Aquatic Toxicology,186, 159-170. doi:10.1016/j.aquatox.2017.03.005.

68- Nguyen-Deroche, T. L., Caruso, A., Le, T. T., Bui, T. V., Schoefs, B., Tremblin, G., \& Morant-Manceau, A. (2012). Zinc Affects Differently Growth, Photosynthesis, Antioxidant Enzyme Activities and Phytochelatin Synthase Expression of Four 
Marine Diatoms. The Scientific World Journal, 2012, 1-15.

doi:10.1100/2012/982957.

69- Nishikawa, K., \& Tominaga, N. (2001). Isolation, Growth, Ultrastructure, and Metal Tolerance of the Green Alga, Chlamydomonas acidophila (Chlorophyta). Bioscience, Biotechnology, and Biochemistry, 65(12), 2650-2656. doi:10.1271/bbb.65.2650.

70-Omar, H. (2002). Bioremoval of zinc ions by Scenedesmus obliquus and Scenedesmus quadricauda and its effect on growth and metabolism. International Biodeterioration \& Biodegradation, 50(2), 95-100. doi:10.1016/s09648305(02)00048-3.

71-Peng, X., Palma, S., Fisher, N. S., \& Wong, S. S. (2011). Effect of morphology of $\mathrm{ZnO}$ nanostructures on their toxicity to marine algae. Aquatic Toxicology, 102(3-4), 186-196. doi:10.1016/j.aquatox.2011.01.014.

72- Peng, X., Palma, S., Fisher, N. S., \& Wong, S. S. (2011). Effect of morphology of $\mathrm{ZnO}$ nanostructures on their toxicity to marine algae. Aquatic Toxicology, 102(3-4), 186-196. doi:10.1016/j.aquatox.2011.01.014.

73-Piccinno, F., Gottschalk, F., Seeger, S., \& Nowack, B. (2012). Industrial production quantities and uses of ten engineered nanomaterials in Europe and the world. Journal of Nanoparticle Research,14(9). doi:10.1007/s11051-012-1109-9

74-Pitcher, M. W. (2006, July 21). There's Still Plenty of Room at the Bottom. Retrieved from $h$ ttp://science.sciencemag.org/content/313/5785/300.1

75- Prasad, M. V. (2016). Bioremediation and bioeconomy. Amsterdam; Boston: Elsevier, [2016].

76- Ray, P. C., Yu, H., \& Fu, P. P. (2009). Toxicity and Environmental Risks of Nanomaterials: Challenges and Future Needs. Journal of Environmental Science and Health, Part C, 27(1), 1-35. doi:10.1080/10590500802708267.

77- Rutherford, A. (2011). ANOVA and ANCOVA: a GLM approach (2nd ed.). Hoboken, NJ: John Wiley \& Sons, Inc.

78-Sahu, D., Kannan, G. M., Tailang, M., \& Vijayaraghavan, R. (2016). In Vitro Cytotoxicity of Nanoparticles: A Comparison between Particle Size and Cell Type. Journal of Nanoscience, 2016, 1-9. doi:10.1155/2016/4023852.

79- Sanderson, H. (2003). Probabilistic hazard assessment of environmentally occurring pharmaceuticals toxicity to fish, daphnids and algae by ECOSAR screening. Toxicology Letters, 144(3), 383-395. doi:10.1016/s0378-4274(03)00257-1. 
80- Sawilowsky, S. S., \& Blair, R. C. (1992). A more realistic Seethe robustness and Type II error properties of the $t$ test to departures from population normality. Psychological Bulletin, 111, 352-360.

81-Sbihi, K.; Cherifi, O.; El Gharmali, A.; Oudra, B.; Aziz, F. Accumulation and toxicological effects of cadmium, copper and zinc on the growth and photosynthesis of the freshwater diatom Planothidium lanceolatum (Brébisson) Lange-Bertalot: A laboratory study. J. Mater. Environ. Sci. 2012, 3, 497-506.

82-Schmidt, M., Krasselt, A., \& Reuter, W. (2006). Local protein flexibility as a prerequisite for reversible chromophore isomerization in $\alpha$-phycoerythrocyanin. Biochimica Et Biophysica Acta (BBA) - Proteins and Proteomics, 1764(1), 55-62. doi:10.1016/j.bbapap.2005.10.022.

83-Schmidt, R. A., Wiebe, M. G., \& Eriksen, N. T. (2005). Heterotrophic high celldensity fed-batch cultures of the phycocyanin-producing red alga Galdieria sulphuraria. Biotechnology and Bioengineering, 90(1), 77-84. doi:10.1002/bit.20417.

84-Schopf, JW (2000) The fossil record: tracing the roots of the cyanobacterial lineage. In: Whitton BA, Potts M (eds) The ecology of cyanobacteria. Kluwer, Dordrecht, pp $13-35$.

85- Shadish, W. R., Cook, T. D., \& Campbell, D. T. (2002). Experimental and quasiexperimental designs for generalized causal inference. Belmont, CA: Wadsworth, Cengage Learning.

86- Sharma, N. K., Rai, A. K., \& Stal, L. J. (2014). Cyanobacteria: An economic perspective. Chichester, West Sussex, UK: Wiley Blackwell.

87- Singh, G., Babele, P. K., Kumar, A., Srivastava, A., Sinha, R. P., \& Tyagi, M. B. (2014). Synthesis of $\mathrm{ZnO}$ nanoparticles using the cell extract of the cyanobacterium, Anabaena strain L31 and its conjugation with UV-B absorbing compound shinorine. Journal of Photochemistry and Photobiology B: Biology, 138, 55-62. doi:10.1016/j.jphotobiol.2014.04.030.

88-Smijs, T., \& P. (2011). Titanium dioxide and zinc oxide nanoparticles in sunscreens: focus on their safety and effectiveness. Nanotechnology, Science and Applications, 95. doi:10.2147/nsa.s19419.

89-Suman, T., Rajasree, S. R., \& Kirubagaran, R. (2015). Evaluation of zinc oxide nanoparticles toxicity on marine algae chlorella vulgaris through flow cytometric, cytotoxicity and oxidative stress analysis. Ecotoxicology and Environmental Safety, 113, 23-30. doi:10.1016/j.ecoenv.2014.11.015. 
90-Tam, N.F.Y., Wong, J.P.K. \& Wong, Y.S. (2001) Repeated use of two Chlorella species, C. vulgaris and WW1 for cyclic nickel biosorption. Environ. Pollut. 114: 8592.

91-This is nanotechnology - one of the fastest growing markets in the world. (n.d.). Retrieved from http://www.gaeu.com/item/this-is-nanotechnology-one-of-the-fastestgrowing-markets-in-the-world.

92-Tien C-J (2002) Biosorption of metal ions by freshwater algae with different surface characteristics. Process Biochem 38:605-613. doi:10.1016/S0032-9592(02)00183-8.

93-Tomas, C. R., \& Hasle, G. R. (1997). Identifying marine phytoplankton. San Diego: Academic Press.

94- Tyupa, D. V., Kalenov, S. V., Baurina, M. M., Yakubovich, L. M., Morozov, A. N., Zakalyukin, R. M., \& ... Skladnev, D. A. (2016). Efficient continuous biosynthesis of silver nanoparticles by activated sludge micromycetes with enhanced tolerance to metal ion toxicity. Enzyme And Microbial Technology, 95137-145.

doi:10.1016/j.enzmictec.2016.10.008.

95-Wang, D., Gao, Y., Lin, Z., Yao, Z., \& Zhang, W. (2014). The joint effects on Photobacterium phosphoreum of metal oxide nanoparticles and their most likely coexisting chemicals in the environment. Aquatic Toxicology, 154, 200-206. doi:10.1016/j.aquatox.2014.05.023.

96- Wang, J., \& Chen, C. (2009). Biosorbents for heavy metals removal and their future. Biotechnology Advances, 27(2), 195-226. doi:10.1016/j.biotechadv.2008.11.002.

97-Wang, J., \& Chen, C. (2009). Biosorbents for heavy metals removal and their future. Biotechnology Advances, 27(2), 195-226. doi:10.1016/j.biotechadv.2008.11.002

98- We make statistics easy. The ultimate IBM ${ }^{\circledR}$ SPSS $®$ Statistics guides. (n.d.). Retrieved from https://statistics.laerd.com/.

99- Weinfurt, K. P. (2000). Repeated measures analyses: ANOVA, MANOVA, and HLM. In L. G. Grimm \& P. R. Yarnold (Eds.), Reading and understanding more multivariate statistics (pp. 317-361). Washington, DC: American Psychological Association.

100- Weisburg, S. (2014). Applied linear regression (4th ed.). Hoboken, NJ: John Wiley \& Sons, Inc.

101- Wilcox, R. (2012). Introduction to robust estimation and hypothesis testing (3rd ed.). Waltham, MA: Elsevier.

102- Wong, P. T., \& Chau, Y. K. (1990). Zinc toxicity to freshwater algae. Toxicity Assessment, 5(2), 167-177. doi:10.1002/tox.2540050205. 
103- Woomer, A. H., Farnsworth, T. W., Hu, J., Wells, R. A., Donley, C. L., \& Warren, S. C. (2015). Phosphorene: Synthesis, Scale-Up, and Quantitative Optical Spectroscopy. ACS Nano, 9(9), 8869-8884. doi:10.1021/acsnano.5b02599.

104- Xiong, D., Fang, T., Yu, L., Sima, X., \& Zhu, W. (2011). Effects of nano-scale TiO2, $\mathrm{ZnO}$ and their bulk counterparts on zebrafish: Acute toxicity, oxidative stress and oxidative damage. Science of The Total Environment, 409(8), 1444-1452. doi:10.1016/j.scitotenv.2011.01.015.

105- Yung, M. M., Kwok, K. W., Djurišić, A. B., Giesy, J. P., \& Leung, K. M. (2017). Influences of temperature and salinity on physicochemical properties and toxicity of zinc oxide nanoparticles to the marine diatom Thalassiosira pseudonana. Scientific Reports, 7(1). doi:10.1038/s41598-017-03889-1

106- Zeraatkar, A. K., Ahmadzadeh, H., Talebi, A. F., Moheimani, N. R., \& Mchenry, M. P. (2016). Potential use of algae for heavy metal bioremediation, a critical review. Journal of Environmental Management, 181, 817-831. doi:10.1016/j.jenvman.2016.06.059.

107- Zhang, R., Carlsson, F., Edman, M., Hummelgård, M., Jonsson, B., Bylund, D., \& Olin, H. (2018). Escherichia coli Bacteria Develop Adaptive Resistance to Antibacterial ZnO Nanoparticles. Advanced Biosystems, 2(5), 1800019. doi:10.1002/adbi.201800019.

108- Zhu, X., Zhu, L., Lang, Y., \& Chen, Y. (2008). Oxidative Stress And Growth Inhibition In The Freshwater Fish Carassius Auratus Induced By Chronic Exposure To Sublethal Fullerene Aggregates. Environmental Toxicology and Chemistry, 27(9), 1979. doi:10.1897/07-573.1

109- Fowler, S., Roush, R., \& Wise, J. (2016). Concepts of biology. Houston, TX: Openstax, Rice University.

110-Leadbetter, E. R., \& Poindexter, J. S. (1985). Bacteria in nature. New York, NY: Plenum Press. Nel, A. (2006).

111- Toxic Potential of Materials at the Nanolevel. Science, 311(5761), 622-627. doi:10.1126/science. 1114397

112-Long, T. C., Saleh, N., Tilton, R. D., Lowry, G. V., \& Veronesi, B. (2006). Titanium Dioxide (P25) Produces Reactive Oxygen Species in Immortalized Brain Microglia (BV2): Implications for Nanoparticle Neurotoxicity $\dagger$. Environmental Science \& Technology, 40(14), 4346-4352. doi:10.1021/es060589n 
113- Huang, Z., Zheng, X., Yan, D., Yin, G., Liao, X., Kang, Y., Hao, B. (2008). Toxicological Effect of ZnO Nanoparticles Based on Bacteria. Langmuir, 24(8), 4140-4144. doi:10.1021/la7035949

114-Monteiro, C. M., Fonseca, S. C., Castro, P. M., \& Malcata, F. X. (2010). Toxicity of cadmium and zinc on two microalgae, Scenedesmus obliquus and Desmodesmus pleiomorphus, from Northern Portugal. Journal of Applied Phycology, 23(1), 97-103. doi:10.1007/s10811-010-9542-6

115- Chen, P., Powell, B. A., Mortimer, M., \& Ke, P. C. (2012). Adaptive Interactions between Zinc Oxide Nanoparticles and Chlorella sp. Environmental Science \& Technology, 46(21), 12178-12185. doi:10.1021/es303303g 